\title{
Simulated Wake Characteristics Data for Closely Spaced Parallel Runway Operations Analysis
}

\author{
Nelson M. Guerreiro ${ }^{1}$ \\ Analytical Mechanics Associates, Inc., Hampton, VA, 23681-2199 \\ and \\ Kurt W. Neitzke ${ }^{2}$ \\ NASA Langley Research Center, Hampton, VA, 23681-2199
}

\begin{abstract}
A simulation experiment was performed to generate and compile wake characteristics data relevant to the evaluation and feasibility analysis of closely spaced parallel runway (CSPR) operational concepts. While the experiment in this work is not tailored to any particular operational concept, the generated data applies to the broader class of CSPR concepts, where a trailing aircraft on a CSPR approach is required to stay ahead of the wake vortices generated by a lead aircraft on an adjacent CSPR. Data for wake age, circulation strength, and wake altitude change, at various lateral offset distances from the wakegenerating lead aircraft approach path were compiled for a set of nine aircraft spanning the full range of FAA and ICAO wake classifications. A total of 54 scenarios were simulated to generate data related to key parameters that determine wake behavior. Of particular interest are wake age characteristics that can be used to evaluate both time- and distancebased in-trail separation concepts for all aircraft wake-class combinations. A simple firstorder difference model was developed to enable the computation of wake parameter estimates for aircraft models having weight, wingspan and speed characteristics similar to those of the nine aircraft modeled in this work.
\end{abstract}

\section{Introduction}

$\mathrm{T}$ The nation's airspace is becoming increasingly crowded as demand for passenger and cargo/freight air travel increases. The corresponding increase in commercial air traffic has many of the nation's airports forecasted to experience unprecedented arrival and departure delays in the future ${ }^{1,2}$. Some delays may be attributable to available operational throughput at particular airports resulting from runway use configurations, specific approach and departure procedures, nearby airport interactions, and other factors. As changes to operational procedures are considered, with the goal of increasing throughput capacity of the terminal airspace surrounding busy airports in the National Airspace System (NAS), the risk of un-safe wake vortex encounters by aircraft becomes an increasing concern. To reduce the likelihood of such encounters to extremely low levels, today's in-trail wake separation standards - both for en-route and terminal airspace environments - are conservative. For example, current Federal Aviation Administration (FAA) regulations require that parallel approaches to runways with centerlines less than 2500 feet apart be treated the same as in-trail aircraft approaching the same runway (i.e. same separation standards are used.). $)^{3}$ Efforts are underway to improve NAS performance, which include the FAA's Next Generation Air Transportation System (NextGen) initiative. Pursuant to NextGen, different concepts of operation (con-ops) have emerged for pairing aircraft on CSPR approaches, with the goal of increasing airport throughput ${ }^{4}$. Data for analyzing separation relative to wake vortex encounters during CSPR operations, however, is currently limited.

\footnotetext{
${ }^{1}$ Research Engineer, Aeronautics Systems Analysis Branch, Mail Stop 442, member AIAA.

${ }^{2}$ Senior Research Engineer, Aeronautics Systems Analysis Branch, Mail Stop 442, member AIAA.
} 
One new con-ops proposed by the FAA's Closely Spaced Parallel Operations (CSPO) working group is called the Simplified Aircraft-based Paired Approach (SAPA) Concept. The SAPA Concept is a procedure-based technique that allows simultaneous dependent instrument approaches to CSPRs with centerline spacing less than 2500 feet. Current air traffic control (ATC) rules allow independent approaches to parallel runways with centerline spacing of 4300 feet or greater (3000 feet or greater with the use of a precision runway monitor, offset localizer, and monitor controllers) $)^{3,5}$. Dependent approaches to parallel runways with centerline spacing between 2500 feet and 4300 feet are allowed, with a diagonal (direct aircraft-to-aircraft) separation requirement of $1.5 \mathrm{~nm}$ or greater to protect against wake encounters and aircraft collisions due to blunders. With the SAPA concept, the FAA is exploring the potential to safely modify current CSPR separation limits between aircraft pairs - and to potentially allow over-taking of the initial lead aircraft by the initial trailing aircraft as well. The SAPA Concept proposes the use of autopilot coupling between aircraft, precision Ground-Based Augmentation System (GBAS) or Space-Based Augmentation System (SBAS) surveillance, and pairing of aircraft which remain approximately abreast to ensure that each remains ahead of the other's wake vortices, ${ }^{6,7}$. Others have proposed similar CSPR approach concepts including the Paired Approach (PA) Concept ${ }^{8,9,10}$ and the Terminal Area Capacity Enhancing Concept (TACEC) ${ }^{11,12}$, and all such concepts require considerable wake data to analyze operational separation relative to potential wake encounters.

In this paper, a study has been conducted to generate and compile wake model data for the full range of wake class aircraft, which could be used in the development and analysis of CSPR con-ops. It is important to note that these data are not actual wake measurements but, rather, data generated using a fast-time, analytical model representation of wake dynamics. Also, these data apply to concepts where the trailing aircraft in a CSPR approach pairing remains approximately abreast of the lead aircraft and ahead of its trailing wake vortices. Data is presented for several lead aircraft wake classes in an attempt to fully span the current operational fleet. Additionally, sensitivity data are compiled such that wake characteristics estimates can be made for aircraft whose properties closely resemble those of the nine aircraft models simulated here.

\section{Motivation and Experiment Goals}

In a prior collaborative research study, the FAA's CSPO working group and NASA Langley Research Center (LaRC) explored an initial feasibility assessment and wake-safe region analysis related to the SAPA Concept for CSPR arrivals ${ }^{13,14}$. The study was performed to support near-term FAA investment decisions related to future parallel runway construction and CSPR approach procedure development. The study focused on assessing operational feasibility of the SAPA concept, specifically related to avoidance of un-safe wake vortex encounters. This was done via simulation and analysis by the characterization of a wake-free safe zone (WSZ) - or wake avoidance zone (WAZ), since safety is inherent in the assumptions of an analysis - in terms of a safe initial in-trail distance between a leader-follower pair on ILS final approaches to CSPRs. Analysis of the SAPA procedure was achieved by placing a lead aircraft at a final approach fix, aligned with the runway centerline and located five nautical miles from the runway threshold and simulating an ILS approach profile through runway touch-down. The SAPA analysis also simulated a trailing aircraft, flying an ILS approach profile to an adjacent CSPR, on its final approach course and at a safe initial in-trail distance behind the leader. Per the SAPA procedure, the trailing aircraft was to remain safely ahead of the lead aircraft's wake over the entire approach profile.

Characterizing the WAZ in terms of a safe initial in-trail distance enabled a reasonable feasibility assessment of the SAPA concept for the single aircraft pairing analyzed (lead \& trailing aircraft each were modeled as B747-8F) with varying landing weights and corresponding approach speed profiles. It did not, however, allow the WAZ to be defined more generally for approach pairing combinations spanning the full NAS operational fleet. Additionally, because the WAZ was characterized by an initial pairing in-trail distance, wake position relative to aircraft position (i.e., either lead or trailing aircraft) could not be readily determined at all points along each aircraft's final approach trajectory, limiting its usefulness. For these reasons, a more dynamic approach at characterizing the WAZ in terms of in-trail time between lead and trailing aircraft at all points along the final approach profiles was explored. It was expected that generating a series of simulated WAZ data plots for various CSPR spacings, cross-wind conditions and other relevant parameters, would provide a useful resource for approach procedure developers to quickly assess preliminary feasibility of various CSPR con-ops. This time-based WAZ characterization approach is also consistent with other recently studied time-based spacing applications whose goal is that of increasing the capacity and efficiency of the NAS, such as the PA or the TACEC concepts.

Current ATC rules governing wake vortex encounter avoidance require in-trail aircraft to remain sufficiently behind or above a lead aircraft's wake vortices ${ }^{3}$. Sufficiently behind corresponds to where the lead aircraft's wake has either safely descended below the path of the trailing aircraft, or its circulation strength has decreased below the 
level required to create an un-safe encounter for the trailing aircraft. In the SAPA and certain other CSPR operational concepts, aircraft relative spacing is substantially reduced such that the trailing aircraft remains ahead, rather than behind the lead aircraft's wake (i.e., within the WAZ). In the presence of a variable crosswind as shown in Figure 1, a dynamic triangular wake region can be visualized as translating with the generating aircraft. A WAZ can thereby be characterized in terms of either:

1. The instantaneous distance interval - measured along a line parallel to the runway center-line, between a wake-generating lead aircraft and the point where a trailing aircraft on final approach to an adjacent CSPR would encounter that wake (see Figure 1)

2. The instantaneous time interval - the time it would take the trailing aircraft to be ahead of the lead aircraft's most recently generated wake vortices (see Figure 2).

Characterizing the WAZ in either of the above two ways has distinct advantages over the initial in-trail distance characterization employed in the SAPA study. The SAPA WAZ preliminary characterization is highly dependent on the lead and trailing aircraft speed profiles, and provides little insight into effective techniques at achieving wake spacing along the entirety of each aircraft's final approach trajectory. The importance of this was discovered during the SAPA study, where data indicated that the WAZ size decreased rapidly and substantially as the lead aircraft transitioned from the out-of ground effect (OGE) region to the in ground effect (IGE) region of its final approach trajectory. The IGE region spans the altitude from approximately one-half of the wake generating aircraft's

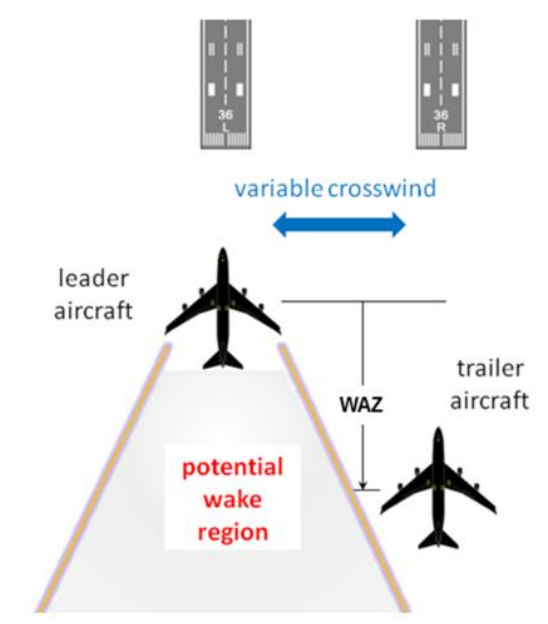

Figure 1. Wake avoidance zone reference. wingspan to the runway surface, while the OGE region extends from approximately one wingspan upward. The WAZ size in the OGE region is substantially larger than the IGE region and, consequently, a trailing aircraft safely within the OGE WAZ could find itself suddenly outside the WAZ once it transitioned to the IGE region. It was primarily for this reason that this follow-on study was completed. Characterizing the WAZ in either of the two ways above, enables CSPR approach procedure developers, to sufficiently understand relevant wake dynamics along the entire final approach course to allow design of safe and effective preliminary procedures.

Method 2 above - the instantaneous time interval - is used to characterize the time required for a lead aircraft's wake to move laterally into the path of a trailing aircraft because it decouples the WAZ from either aircraft's speed profile. Figure 2 illustrates how a lead aircraft's discrete wake element (i.e., a wake vortex element generated over a short time interval - e.g. one second) transports laterally towards the path of a trailing aircraft's CSPR approach to an adjacent runway. This lateral wake movement is due to crosswind and other mechanisms including interaction with the ground in the IGE region, and may be characterized independently of the generating aircraft's speed. Assuming no longitudinal wake transport, the trailing aircraft will remain ahead of each discrete wake element if it transits the longitudinal distance between the two aircraft (the distance at the instant wake element generation) in less time than it takes the wake element to transport laterally into the trailer's path. Referring again to Figure 2, a wake element transits a distance $d$ from the point of generation to an imaginary detection plane (shown edgewise) along a parallel approach path where there is the potential for a wake encounter with a trailing aircraft. This discrete wake element transits this distance over time interval $\Delta t_{w}$. This time interval can be identified by the age of the wake - wake age - at any lateral distance. Therefore, for a trailing aircraft to avoid a wake encounter, the time it takes to pass the point where the wake element penetrates the imaginary plane must be less than $\Delta t_{w}$ (i.e. the condition $\Delta t_{A C}<\Delta t_{w}$ must be met). It follows that, the only criteria required to

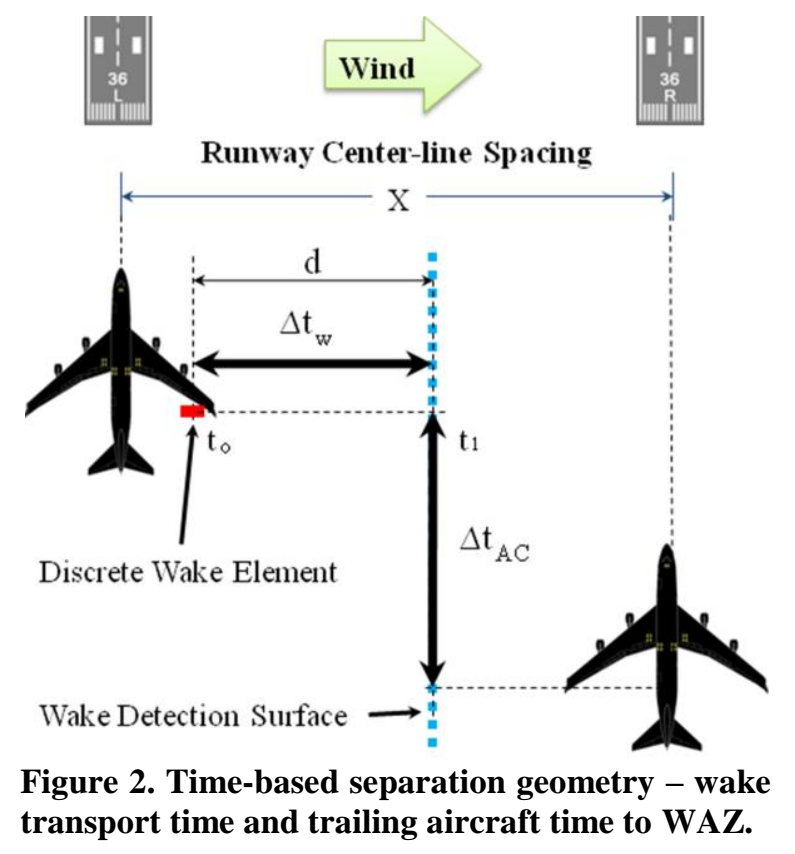


determine the WAZ in terms of in-trail time, are the lateral transport characteristics of the wake generated by a specific lead aircraft. To avoid hazardous wake encounters during a proposed CSPR concept of this type, the trailing aircraft must remain inside the WAZ over the entire final approach course.

The wake age characteristics are of particular importance in this simulation data collection exercise. Another characteristic of potential interest is the wake vortex circulation strength. Wake circulation strength can be used to determine whether a wake encounter by a specific following aircraft (wake class) is acceptable due to its impact on the trailing aircraft's trajectory. Similarly, the descent characteristic of wakes may be of use in determining whether a given wake will descend below a trailing aircraft's flight path, such that it is no longer a factor for that aircraft.

\section{Experiment Design}

The data for the lateral transport characteristics of wakes is collected using a fast-time wake trajectory prediction model. The Aircraft VOrtex Spacing System (AVOSS) Prediction Algorithm, or APA ${ }^{15,16}$, is a fast-time simulation that models the movement and circulation decay of a pair of wake vortices in a plane perpendicular to the generating aircraft's flight path. The APA has been extensively compared to other wake models and validated using observed wake vortex measurements. Because the APA is a deterministic model of wake behavior, and because the experiment conducted here is performed at specific fixed aircraft operating conditions and atmospheric conditions, it should be understood that the data presented here are simply estimates of wake behavior and may not reflect the variability seen in real conditions. The inclusion of variability in the input parameters to the wake model that reflect observed distributions creates a significant increase in the size of the experiment and the data that needs to be collected - relative to what will be presented here - and is reserved for future studies.

\section{A. Analysis Tools}

The data collection experiment is segmented into several scenarios assembled using the Wake Vortex Simulation and Analysis Tools (WVSAT ${ }^{\mathrm{TM}}$ ), developed exclusively for NASA LaRC by Air Traffic Simulation, Inc. (ATSI) ${ }^{17}$. WVSAT $^{\mathrm{TM}}$ is an aircraft simulation and visualization interface that allows for fast prototyping of various flight profiles, with wake generation and detection capabilities driven by the APA model. Some of the capabilities of WVSAT $^{\mathrm{TM}}$ include: fast prototyping of experiments through a drag-and-drop modular design, Monte Carlo simulations, 3-dimensional visualization of aircraft kinematic and wake trajectories for interactive evaluation of scenarios, and the ability to evaluate wake behavior for a broad fleet of aircraft. The current version of WVSAT ${ }^{\mathrm{TM}}$ has been modified to use version 3.4 of the APA algorithm, which has some minor improvements to the out-of ground effect model relative to APA version $3.2^{16}$. Specifically for this experiment, each WVSAT ${ }^{\mathrm{TM}}$ experimental scenario is comprised of a simulated aircraft approach and landing with fixed aircraft configuration and atmospheric conditions and with several wake detection surfaces that capture wake characteristics at specified lateral positions.

The APA model can be characterized by three primary stages: out of ground effect (OGE), near ground effect (NGE), and in ground effect (IGE). The OGE stage models the wake behavior and decay primarily as a function of the initial strength and initial vertical velocity of the wake vortices, and atmospheric conditions such as wind, temperature, and turbulence levels, resulting in a pair of vortices that descend and translate laterally at a constant separation distance. In the NGE stage, the wake is considered to be sufficiently close to the ground and the modeling includes simulated image vortices that serve to introduce a zero velocity condition at the ground, causing the distance between the vortices to increase. In the final stage, IGE, additional secondary vorticity is introduced due to the primary vortices' interaction with the ground, which tends to further increase the separation between the primary vortices. The boundaries for the OGE to NGE and NGE to IGE regions in the APA algorithm occur at approximately 1.5 and 0.6 times the initial wake vortex separation (assumed to be $\pi / 4$ times the aircraft wingspan), respectively.

\section{B. Setup}

The prior work in the SAPA study clearly indicated that the OGE and IGE regions were the limiting cases in lateral wake transport, where, in OGE, the lateral wake movement is primarily driven by the crosswind and produced large values for WAZs and, in IGE, the wake interaction with the ground increased lateral wake velocities and resulted in the smallest WAZs. From this observation it is clear that knowledge of the wake transport characteristics at every point along the approach path is not necessary and allowed the data collection for this experiment to be greatly simplified by concentrating on these two primary regions of the approach path of a wake generating aircraft. Later, an example is shown depicting the wake transport properties for the full approach path of one scenario clearly illustrating the two dominant regions. 
The experiment is segmented into simulation scenarios; a graphic representation of a scenario is shown in Figure 3. A scenario is comprised of a wake generating aircraft with an assigned approach and landing procedure to a runway, and several stationary wake detection surfaces, IGE and OGE, which capture the wake properties at various lateral offset distances from the wake generating aircraft's approach centerline. In all of the scenarios tested, the approach and landing procedure is defined as a constant final approach speed along the runway centerline and on a three degree glideslope from three nautical miles out to a runway threshold crossing height of 50 feet, followed by a flare and slow-down to landing speed, and landing. The stationary wake detection planes are placed at lateral offset distances of 500, 700, 900, 1100, 1500, 2000, 2500 and 3000 feet in both the IGE and OGE regions, for a total of 16 stationary wake detection planes. The wake generated by the approach aircraft is compiled by $\mathrm{WVSAT}^{\mathrm{TM}}$ using multiple 2-dimensional tiles of wake vortex trajectories and circulation strengths obtained from evaluations of the APA algorithm at a frequency of $1 \mathrm{~Hz}$ along the approach path; the appropriate stitching together of these wake tiles is what provides the visualization of the in-trail wake, as seen in Figure 3, producing a wake that is discretized into wake elements. The width of the stationary wake detection planes is selected to capture a minimum of one wake element as it penetrates the surface, with a sampling frequency limit of $20 \mathrm{~Hz}$ for a wake age resolution of +/- 0.05 seconds. The WVSAT ${ }^{\mathrm{TM}}$ tool simulates each deterministic scenario and logs the aircraft trajectory and the wake element properties captured by the stationary wake detection planes.

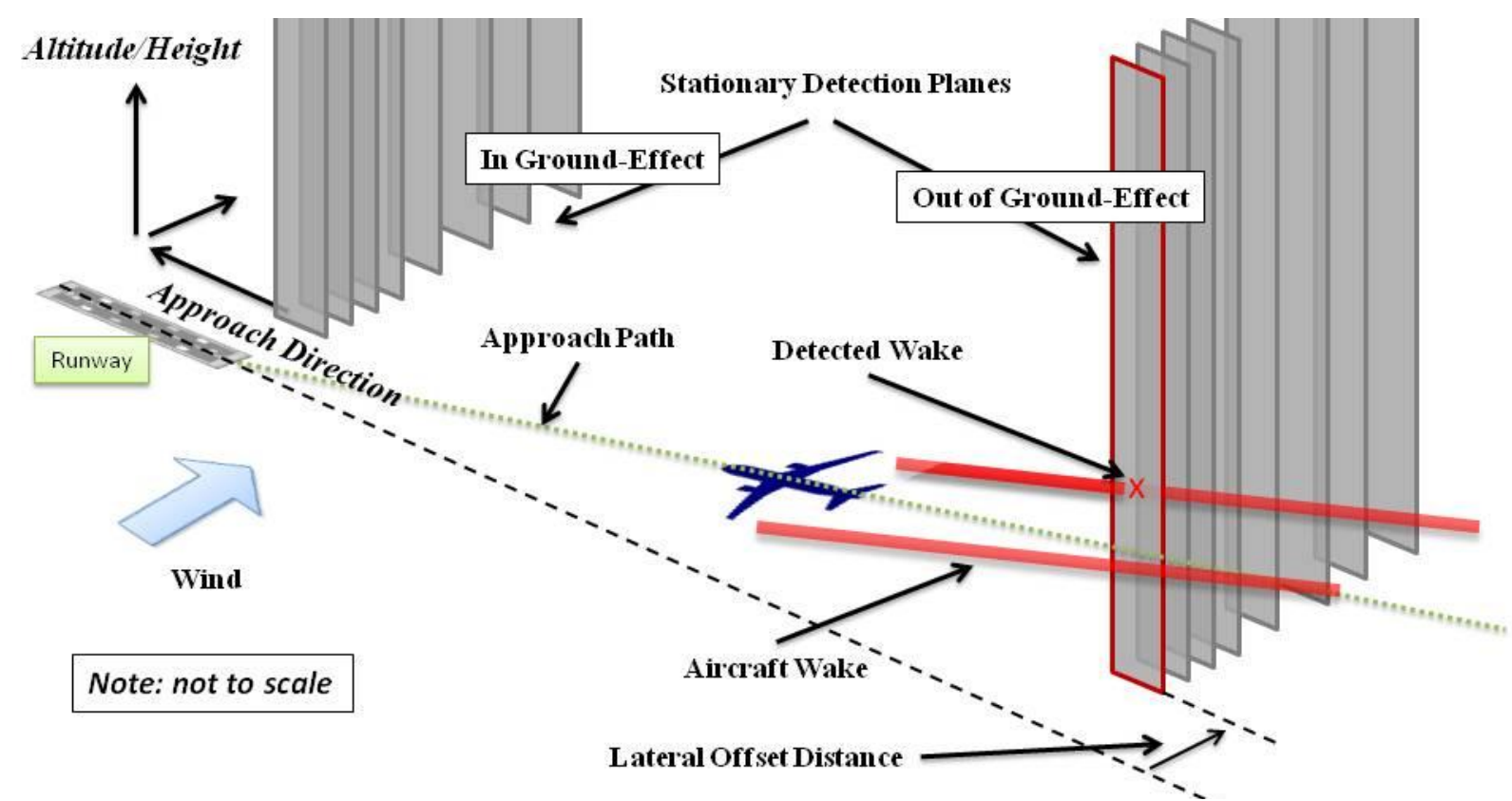

Figure 3. Experiment layout with simulated aircraft approach and landing and stationary wake detection planes in and out of ground-effect.

Nine aircraft were selected for analysis for this study, based primarily on their weight. These aircraft, listed in Table 1, were initially selected from a NASA Airspace System Program seed day of observed traffic targeting the historical day of September 26, 2006 to represent the aircraft with the most observed operations within one of the FAA's weight classifications of Small, Large and Heavy. Because a large percentage of operations falling under the Small weight class can be attributed to private or charter jets, two aircraft were selected to represent this category (C560 and C750) and one aircraft was selected to represent the Small weight class commercial operations (B190). The historical seed day indicated that the Large and Heavy weight classes were well represented by the operations of Boeing 737 (B737) and Boeing 767 (B763) model aircraft. The Boeing 757 aircraft model was included because special wake turbulence separation procedures are typically used for that aircraft, even though the aircraft falls in the FAA's Large weight class based on its maximum certificated takeoff weight. Additionally, the International Civil Aviation Organization (ICAO) has made recommendations that the Airbus A380 model of aircraft should be assigned special wake separation criteria (assigning it the classification of Super) based on a study of the aircraft's wake characteristics ${ }^{18}$, making it a candidate aircraft for inclusion in this study. Two additional aircraft models, specifically the Bombardier CRJ-200 and the Boeing 747-400, were included in the test set in order to populate more of the weight range for each of the Large and Heavy weight classes, respectively. It is important to note that, 
although these specific aircraft models are used for the experiment based on observed frequencies, the APA model is only dependent on the weight, wingspan and speed characteristics to define an aircraft; any aircraft with the same value for these 3 characteristics would produce the exact same wake solution for the same atmospheric conditions.

The aircraft characteristics (weight, wingspan, speed) and the atmospheric conditions (crosswind and eddy dissipation rate) are the primary variable parameters affecting the behavior of the wake model. As such, sensitivity scenarios were created to understand the impact of a step variation in each of these parameters for each test aircraft. Note that temperature also comes into play in the wake model but a standard atmosphere has been assumed for the temperature profile of this experiment. The nominal weight for each aircraft is an estimated value larger than the empty weight of the aircraft and the sensitivity weight is selected to be approximately equal to the maximum landing weight of the aircraft, based on publicly available performance data. The nominal approach speed is selected to be the published approach speed for the specific aircraft, where available, with an assumed 10 knot slower speed for landing, and the sensitivity speeds are simply selected to be 10 knots slower than the nominal speeds. Sensitivities to different wingspans are selected as a 5\% larger wingspan, compared to the baseline test aircraft. A pure constant crosswind of 15 knots is assumed in the direction shown in Figure 3 with a 5 knot increase used for the sensitivity case. The eddy dissipation rate - a measure of the turbulence level of the atmosphere - is assigned a low value for the nominal case with a two order-of-magnitude change for the sensitivity scenario. Table 1 lists the nominal and sensitivity parameters used for each aircraft. Six scenarios are simulated for each aircraft model (1 baseline, 5 sensitivities) for a total of 54 scenarios in this experiment.

Table 1. Experimental parameter values for each weight aircraft tested, including the baseline runs and the change to each parameter for the corresponding sensitivity run.

\begin{tabular}{|c|c|c|c|c|c|c|c|c|}
\hline $\begin{array}{l}\text { Weight } \\
\text { Class }\end{array}$ & Aircraft & $\begin{array}{l}\text { Aircraft } \\
\text { ID }\end{array}$ & Condition & Weight (lb.) & $\begin{array}{c}\text { Approach/Landing } \\
\text { Speeds (KIAS) }\end{array}$ & $\begin{array}{c}\text { Wingspan } \\
\text { (ft) }\end{array}$ & $\begin{array}{c}\text { Crosswind } \\
\text { (Knots) }\end{array}$ & $\begin{array}{l}\text { Eddy Dissipation } \\
\text { Rate }\left(\mathrm{m}^{\wedge} 2 / \mathrm{s}^{\wedge} 2\right)\end{array}$ \\
\hline \multirow{6}{*}{ Small } & \multirow{2}{*}{ Beechcraft 1900} & \multirow{2}{*}{ B190 } & Nominal - baseline & 14,000 & $110 / 100$ & 57.9 & 15 & 0.0001 \\
\hline & & & Sensitivity & 16,765 & $100 / 90$ & 60.8 & 20 & 0.01 \\
\hline & \multirow{2}{*}{ Cessna Citation XLS+ } & \multirow{2}{*}{ C560 } & Nominal - baseline & 15,500 & $120 / 110$ & 56.33 & 15 & 0.0001 \\
\hline & & & Sensitivity & 18,700 & $110 / 100$ & 59.15 & 20 & 0.01 \\
\hline & \multirow{2}{*}{ Cessna Citation X } & \multirow{2}{*}{ C750 } & Nominal - baseline & 25,000 & $120 / 110$ & 63.92 & 15 & 0.0001 \\
\hline & & & Sensitivity & 31,800 & $110 / 100$ & 67.12 & 20 & 0.01 \\
\hline \multirow{4}{*}{ Large } & \multirow{2}{*}{ Bombardier CRJ-200 } & \multirow{2}{*}{ CRJ2 } & Nominal - baseline & 37,000 & $130 / 120$ & 69.6 & 15 & 0.0001 \\
\hline & & & Sensitivity & 51,000 & $120 / 110$ & 73.08 & 20 & 0.01 \\
\hline & \multirow{2}{*}{ Boeing 737-700 } & \multirow{2}{*}{ B737 } & Nominal - baseline & 120,000 & $130 / 120$ & 112.6 & 15 & 0.0001 \\
\hline & & & Sensitivity & 129,200 & $120 / 110$ & 118.2 & 20 & 0.01 \\
\hline \multirow{2}{*}{757} & \multirow{2}{*}{ Boeing 757-200 } & \multirow{2}{*}{ B752 } & Nominal - baseline & 190,000 & $137 / 127$ & 124.8 & 15 & 0.0001 \\
\hline & & & Sensitivity & 210,000 & $127 / 117$ & 131 & 20 & 0.01 \\
\hline \multirow{4}{*}{ Heavy } & \multirow{2}{*}{ Boeing 767-300 } & \multirow{2}{*}{ B763 } & Nominal - baseline & 242,500 & $140 / 130$ & 156.1 & 15 & 0.0001 \\
\hline & & & Sensitivity & 300,000 & $130 / 120$ & 163.9 & 20 & 0.01 \\
\hline & \multirow{2}{*}{ Boeing 747-400 } & \multirow{2}{*}{ B744 } & Nominal - baseline & 500,000 & $157 / 147$ & 213 & 15 & 0.0001 \\
\hline & & & Sensitivity & 652,000 & $147 / 137$ & 224.6 & 20 & 0.01 \\
\hline \multirow{2}{*}{ Super } & \multirow{2}{*}{ Airbus A380-800 } & \multirow{2}{*}{ A380 } & Nominal - baseline & 825,000 & $142 / 132$ & 261.65 & 15 & 0.0001 \\
\hline & & & Sensitivity & 870,000 & $132 / 122$ & 274.73 & 20 & 0.01 \\
\hline
\end{tabular}

\section{Results}

Data related to wake age, circulation strength, and altitude change, were collected for each of the 54 simulation scenarios for both the IGE and OGE regions. Wake age - the primary variable of interest for WAZ determination is the age of the wake from its time of initial generation, to the time it transports laterally and intersects the stationary wake detection planes. Circulation strength is measured for each of the vortices as they intersect the stationary wake detection planes. Wake altitude change is the change in altitude of a wake, between the initial wake generation altitude and its altitude when it intersects the stationary wake detection planes. In all data presented here, only the first vortex to penetrate the stationary wake detection planes is used for data collection; consistent with the wind direction convention in Figure 2, only the right wake vortex is sampled.

As previously mentioned, there are two primary regions of interest when considering CSPR operations - IGE and OGE. Figure 4a) illustrates the variation in wake age as a function of the wake generation altitude (along the glideslope of the final approach) for the nominal B763 scenario with 1500 feet lateral offset distance. The wake age is constant in the OGE region and reduces sharply and substantially to a smaller value (with corresponding rapid reduction in the size of the WAZ) through the IGE region until the wake generating aircraft touches down on the runway. Consequently, a trailing aircraft would be in-capable of flying the required speed profile to remain within the WAZ, were it only minimally within it at the end of the OGE region. The WAZ speed profile of the trailing 
aircraft must be determined by moving backward along the approach trajectory from when the trailing aircraft touches down on the runway after the lead aircraft, as this corresponds to the smallest WAZ size. From there backward, the size of the WAZ increases through the IGE - OGE transition region until it steadies to a nearly constant value in the OGE region. With this understanding, a reasonable speed profile can then be defined that keeps the trailing aircraft within the WAZ through the OGE region, the transition between OGE \& IGE regions, and finally through the IGE region and touch-down. Figure 4b) and Figure $4 \mathrm{c}$ ), respectively, show how the wake circulation strength and wake altitude change vary with generation altitude. These two measures do not immediately affect the WAZ size but the figures show nearly constant values in the OGE region, with some variation in the IGE region.

The wake age data for the nominal scenarios for each aircraft are presented in Table 2 for each lateral offset distance and for both the IGE and OGE regions. Figure 5 is a graphical representation of the wake age data for these scenarios. The wake age trends are qualitatively in line with the expected. First, the wake age is monotonically increasing with lateral offset distance. Second, the OGE wake age is largely a function of the crosswind, indicated by the linear trends versus lateral offset distance; the variations in wake age between aircraft models is due to the different wingspans - large wingspan aircraft generate a wake closer to the stationary planes than small wingspan aircraft on the same runway centerline. Third, the IGE wake age is smaller than the OGE wake age for the same scenario because the wake experiences additional lateral velocity as a result of the interaction with the ground. Fourth, the IGE wake age is highly dependent on the weight class of the aircraft - heavier aircraft produce wakes with smaller wake ages as compared to lighter aircraft, for the same lateral offset distances. This is expected since the initial downward velocity of the wake vortices - per the APA algorithm formulation - is proportional to the aircraft weight and inversely proportional to the aircraft speed and the wake vortices' initial separation; which translates into higher lateral wake velocities for higher weights, close to the ground. Note that some aircraft and lateral offset distances do not have a wake age measurement, simply indicating that the wake had fully dissipated by the time it reached the corresponding detection plane. The full set of wake age data from this experiment, which includes the sensitivity scenarios data, can be found in Table 12 through Table 16 in the Appendix.

Circulation strength data for the nominal scenarios of each aircraft are presented in Table 3 for each of the lateral offset distances and for both the IGE and OGE regions. Figure 6 is a graphical representation of the circulation strength data for these scenarios. Circulation strength is a function of the initial velocity of the wake, which itself is initially inversely proportional to the aircraft speed generating the wake, therefore higher circulation strengths IGE are observed when compared to OGE for the same scenario. The circulation strength dependence on aircraft weight is also clearly visible in these data. The full set of circulation strength data from this experiment, which includes the sensitivity scenarios data, can be found in Table 17 through Table 21 in the Appendix.

Figure 6 shows significant wake circulation strengths at the lateral distance of 2500 feet. As previously mentioned, this lateral distance is the current day limit for dependent operations with a $1.5 \mathrm{~nm}$ diagonal spacing requirement between a leader-follower pair. After further analysis, it was shown that today's operations are not necessarily un-safe, according to these results. In all instances of a leader groundspeed above 100 knots (well below

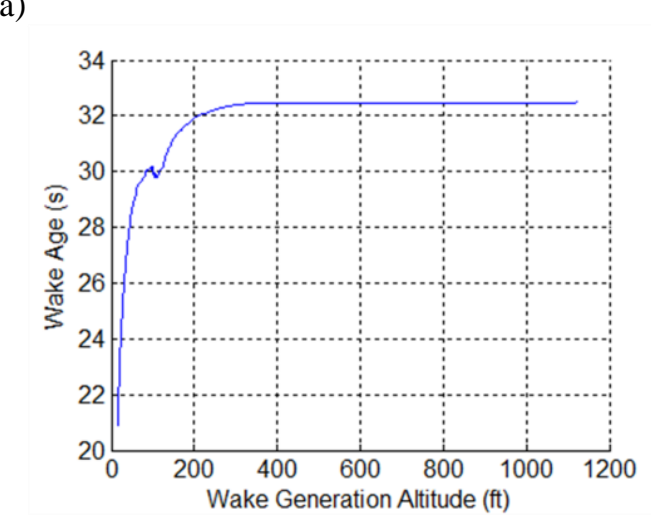

b)

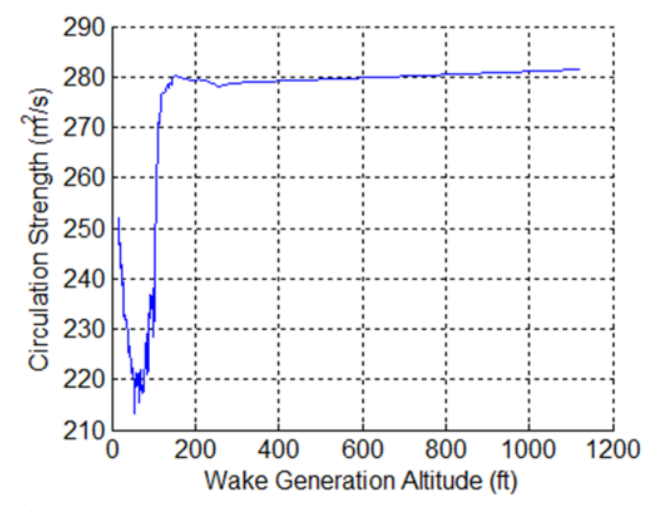

c)

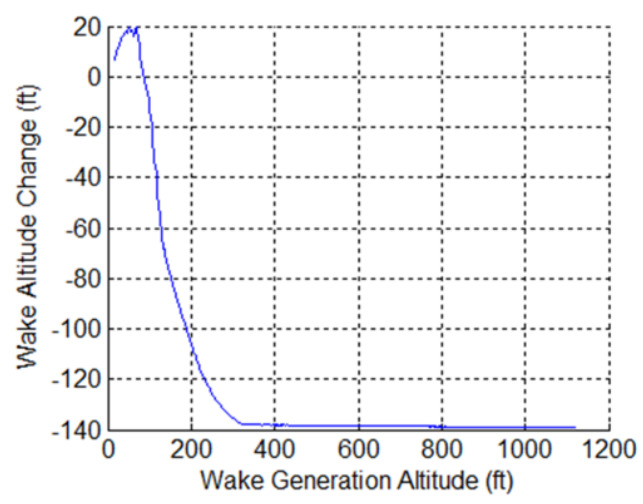

Figure 4. Sample wake characteristics versus wake generation altitude for the nominal B763 and $1500 \mathrm{ft}$ lateral offset distance; a) wake age, b) circulation strength, and c) wake altitude change. 
most commercial airliner approach speeds), and at the $1.5 \mathrm{~nm}$ diagonal spacing, aircraft are spaced at less than 56 seconds of instantaneous in-trail spacing. As can be seen in Figure 5, all simulated wakes take longer than 60 seconds to transport to the 2500 foot lateral distance in the presence of the moderate crosswind of 15 knots. This implies that the trailing aircraft is always ahead and above the wake generated by the leading aircraft.

Wake altitude change data for the nominal scenarios of each aircraft are presented in Table 4 for each of the lateral offset distances and for both the IGE and OGE regions. Figure 7 is a graphical representation of the wake altitude change data for these scenarios. The expected behavior is that wakes descend relative to the wake generation altitude; this is represented in the OGE scenario data. However, wakes that are generated very close to the ground - IGE at touchdown for example - experience what can be described as a "bounce." The interaction with the ground creates the qualitative behavior in wakes whereby wakes move outward and upward because the ground boundary condition does not allow the wakes to descend very far. Correspondingly, the IGE wake altitude change data here illustrates this positive change in altitude relative to the wake generation altitude at the different lateral offset distances. The full set of wake altitude change data from this experiment, which includes the sensitivity scenarios data, can be found in Table 22 through Table 26 in the Appendix.

Table 2. Wake age data IGE and OGE at various lateral offset distances for the nominal aircraft scenarios.

\begin{tabular}{|c|c|c|c|c|c|c|c|c|c|c|c|}
\hline \multirow{2}{*}{$\begin{array}{c}\text { Weight } \\
\text { Class }\end{array}$} & \multirow{2}{*}{ Aircraft ID } & \multirow{2}{*}{ Sensitivity } & \multirow{2}{*}{$\begin{array}{l}\text { Altitude } \\
\text { Region }\end{array}$} & \multicolumn{8}{|c|}{ Wake Age (s) at Offset Distances (ft) } \\
\hline & & & & 500 & 700 & 900 & 1100 & 1500 & 2000 & 2500 & 3000 \\
\hline \multirow{6}{*}{ Small } & \multirow{2}{*}{ B190 } & \multirow{2}{*}{ Nominal } & IGE & 14.65 & 21.6 & 28.7 & 35.95 & 50.8 & 69.95 & - & - \\
\hline & & & OGE & 18.35 & 26.3 & 34.2 & 42.1 & 57.95 & 77.75 & 97.45 & 117.2 \\
\hline & \multirow{2}{*}{ C560 } & \multirow{2}{*}{ Nominal } & IGE & 14.6 & 21.55 & 28.7 & 36 & 50.9 & - & - & - \\
\hline & & & OGE & 18.4 & 26.3 & 34.25 & 42.15 & 57.95 & 77.75 & 97.5 & 117.25 \\
\hline & \multirow{2}{*}{ C750 } & \multirow{2}{*}{ Nominal } & IGE & 13.3 & 19.95 & 26.8 & 33.9 & 48.6 & - & - & - \\
\hline & & & OGE & 18.25 & 26.2 & 34.15 & 42 & 57.85 & 77.65 & 97.35 & 117.1 \\
\hline \multirow{4}{*}{ Large } & \multirow{2}{*}{ CRJ2 } & \multirow{2}{*}{ Nominal } & IGE & 12.3 & 18.55 & 25.1 & 32 & 46.35 & - & - & - \\
\hline & & & OGE & 18.15 & 26.1 & 34.05 & 41.95 & 57.75 & 77.55 & 97.25 & 117.05 \\
\hline & \multirow[b]{2}{*}{ B737 } & \multirow{2}{*}{ Nominal } & IGE & 10.05 & 15.45 & 21.2 & 27.25 & 40.05 & 57.35 & 75.85 & - \\
\hline & & & OGE & 17.5 & 25.45 & 33.35 & 41.25 & 57.1 & 76.9 & 96.6 & 116.35 \\
\hline \multirow{2}{*}{757} & \multirow{2}{*}{ B752 } & \multirow{2}{*}{ Nominal } & IGE & 9.95 & 15.4 & 21.2 & 27.3 & 40.3 & 57.9 & - & - \\
\hline & & & OGE & 17.4 & 25.35 & 33.1 & 41 & $\begin{array}{l}4.5 \\
57\end{array}$ & 76.8 & 96.35 & 116.1 \\
\hline \multirow{4}{*}{ Heavy } & \multirow[b]{2}{*}{ B763 } & \multirow[b]{2}{*}{ Nominal } & IGE & 10.05 & 15.45 & 21.1 & 27.05 & 39.45 & 55.95 & 73.25 & 91.4 \\
\hline & & & OGE & 16.85 & 24.75 & 32.7 & 40.6 & 56.4 & 76.2 & 95.95 & 115.7 \\
\hline & \multirow{2}{*}{ B744 } & \multirow{2}{*}{ Nominal } & IGE & 9.3 & 14.4 & 19.75 & 25.35 & 37.1 & 52.6 & 68.85 & 85.75 \\
\hline & & & OGE & 15.95 & 23.9 & 31.8 & 39.7 & 55.55 & 75.35 & 95.05 & 114.8 \\
\hline \multirow{2}{*}{ Super } & \multirow{2}{*}{ A380 } & \multirow{2}{*}{ Nominal } & IGE & 7.55 & 11.9 & 16.5 & 21.4 & 31.75 & 45.6 & 60.4 & 76 \\
\hline & & & OGE & 15.2 & 23.15 & 31.05 & 38.95 & 54.8 & 74.6 & 94.3 & 114.05 \\
\hline
\end{tabular}

Table 3. Circulation strength data IGE and OGE at various lateral offset distances for the nominal aircraft scenarios.

\begin{tabular}{|c|c|c|c|c|c|c|c|c|c|c|c|}
\hline \multirow{2}{*}{$\begin{array}{c}\text { Weight } \\
\text { Class }\end{array}$} & \multirow{2}{*}{ Aircraft ID } & \multirow{2}{*}{ Sensitivity } & \multirow{2}{*}{$\begin{array}{c}\text { Altitude } \\
\text { Region }\end{array}$} & \multicolumn{8}{|c|}{ Circulation Strength $\left(\mathrm{m}^{\wedge} 2 / \mathrm{s}\right)$ at Offset Distances (ft) } \\
\hline & & & & 500 & 700 & 900 & 1100 & 1500 & 2000 & 2500 & 3000 \\
\hline \multirow{6}{*}{ Small } & \multirow[b]{2}{*}{ B190 } & \multirow{2}{*}{ Nominal } & IGE & 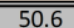 & $=44.6$ & 39.4 & 34.1 & 23.2 & $\bar{~} 9.2$ & 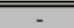 & $\overline{-}$ \\
\hline & & & OGE & 56.7 & 53.2 & 49.9 & 46.8 & 41.0 & 34.6 & 29.2 & 24.4 \\
\hline & \multirow[b]{2}{*}{ C560 } & \multirow[b]{2}{*}{ Nominal } & IGE & 51.5 & 45.0 & 38.9 & 32.7 & 20.1 & - & - & - \\
\hline & & & OGE & 58.7 & 54.9 & 51.3 & 47.9 & 41.7 & 35.0 & 29.1 & 24.1 \\
\hline & \multirow[b]{2}{*}{ C750 } & \multirow[b]{2}{*}{ Nominal } & IGE & 73.0 & 63.4 & 54.3 & 44.8 & 25.3 & - & - & - \\
\hline & & & OGE & 83.4 & 77.9 & 72.7 & 67.9 & 59.0 & 49.4 & 41.1 & 34.0 \\
\hline \multirow{4}{*}{ Large } & \multirow{2}{*}{ CRJ2 } & \multirow{2}{*}{ Nominal } & IGE & 90.9 & 79.1 & 68.1 & 56.5 & 32.3 & - & - & - \\
\hline & & & OGE & 104.7 & 97.7 & 91.2 & 85.1 & 73.9 & 61.8 & 51.4 & 42.4 \\
\hline & \multirow{2}{*}{ B737 } & \multirow{2}{*}{ Nominal } & IGE & 206.0 & 184.1 & 166.3 & 150.4 & 117.4 & 72.7 & 24.9 & - \\
\hline & & & OGE & 218.3 & 207.0 & 196.3 & 186.0 & 166.9 & 145.3 & 126.2 & 109.2 \\
\hline \multirow{2}{*}{757} & \multirow{2}{*}{ B752 } & \multirow{2}{*}{ Nominal } & IGE & 270.6 & 240.4 & 215.9 & 193.1 & 144.5 & 78.7 & - & - \\
\hline & & & OGE & 295.3 & 279.7 & 265.0 & 250.9 & 224.2 & 194.5 & 168.5 & 145.2 \\
\hline \multirow{4}{*}{ Heavy } & \multirow{2}{*}{ B763 } & \multirow{2}{*}{ Nominal } & IGE & 297.7 & 270.6 & 249.4 & 231.3 & 200.7 & 161.9 & 121.2 & 78.6 \\
\hline & & & OGE & 304.1 & 291.7 & 279.6 & 268.0 & 246.1 & 220.7 & 197.6 & 176.5 \\
\hline & \multirow{2}{*}{ B744 } & \multirow{2}{*}{ Nominal } & IGE & 441.6 & 400.2 & 373.2 & 350.8 & 313.9 & 276.1 & 238.6 & 199.6 \\
\hline & & & OGE & 418.0 & 403.9 & 390.1 & 376.8 & 351.2 & 321.2 & 293.4 & 267.5 \\
\hline \multirow{2}{*}{ Super } & \multirow{2}{*}{ A380 } & \multirow{2}{*}{ Nominal } & IGE & 682.2 & 621.9 & 580.6 & 547.2 & 492.6 & 437.3 & 386.9 & 333.8 \\
\hline & & & OGE & 625.1 & 605.1 & 585.7 & 566.8 & 530.3 & 487.4 & 447.5 & 410.2 \\
\hline
\end{tabular}


Table 4. Wake altitude change data IGE and OGE at various lateral offset distances for the nominal aircraft scenarios.

\begin{tabular}{|c|c|c|c|c|c|c|c|c|c|c|c|}
\hline \multirow{2}{*}{$\begin{array}{c}\text { Weight } \\
\text { Class }\end{array}$} & \multirow{2}{*}{ Aircraft ID } & \multirow{2}{*}{ Sensitivity } & \multirow{2}{*}{$\begin{array}{c}\text { Altitude } \\
\text { Region }\end{array}$} & \multicolumn{8}{|c|}{ Wake Altitude Change (ft) at Offset Distances (ft) } \\
\hline & & & & 500 & 700 & 900 & 1100 & 1500 & 2000 & 2500 & 3000 \\
\hline \multirow{6}{*}{ Small } & \multirow{2}{*}{ B190 } & \multirow{2}{*}{ Nominal } & IGE & 3.3 & 4.7 & 6.0 & 7.2 & 9.0 & 10.4 & - & - \\
\hline & & & OGE & -43.4 & -59.9 & -75.3 & -89.6 & -115.8 & -144.0 & -167.6 & -187.5 \\
\hline & \multirow{2}{*}{ C560 } & \multirow{2}{*}{ Nominal } & IGE & 3.5 & 5.0 & 6.4 & 7.6 & 9.4 & - & - & - \\
\hline & & & OGE & -46.5 & -63.9 & -80.3 & -95.4 & -122.8 & -152.1 & -176.6 & -196.9 \\
\hline & \multirow{2}{*}{ C750 } & \multirow{2}{*}{ Nominal } & IGE & 3.5 & 5.1 & 6.6 & 7.8 & 9.7 & - & - & - \\
\hline & & & OGE & -57.8 & -79.7 & -100.1 & -119.0 & -153.2 & -189.8 & -220.1 & -245.4 \\
\hline \multirow{4}{*}{ Large } & \multirow{2}{*}{ CRJ2 } & \multirow{2}{*}{ Nominal } & IGE & 3.4 & 4.9 & 6.3 & 7.5 & 9.4 & - & - & - \\
\hline & & & OGE & -66.2 & -91.4 & -114.9 & -136.8 & -176.1 & -218.1 & -252.9 & -281.9 \\
\hline & \multirow{2}{*}{ B737 } & \multirow{2}{*}{ Nominal } & IGE & 3.2 & 4.9 & 6.5 & 8.1 & 10.9 & 13.6 & 15.1 & - \\
\hline & & & OGE & -80.7 & -113.5 & -144.3 & -173.6 & -227.7 & -287.5 & -339.2 & -384.2 \\
\hline \multirow{2}{*}{757} & \multirow{2}{*}{ B752 } & \multirow{2}{*}{ Nominal } & IGE & 4.5 & 6.8 & 9.1 & 11.3 & 15.1 & 18.6 & - & - \\
\hline & & & OGE & -98.0 & -138.0 & -174.9 & -210.5 & -276.9 & -349.2 & -411.1 & -465.2 \\
\hline \multirow{4}{*}{ Heavy } & \multirow{2}{*}{ B763 } & \multirow{2}{*}{ Nominal } & IGE & 3.5 & 5.5 & 7.4 & 9.3 & 12.8 & 16.8 & 20.1 & 22.6 \\
\hline & & & OGE & -77.0 & -109.9 & -141.6 & -171.8 & -228.5 & -293.0 & -350.7 & -402.3 \\
\hline & \multirow{2}{*}{ B744 } & \multirow{2}{*}{ Nominal } & IGE & 3.1 & 5.0 & 6.9 & 8.8 & 12.6 & 16.9 & 21.0 & 24.6 \\
\hline & & & OGE & -72.8 & -106.3 & -138.4 & -169.4 & -228.5 & -296.6 & -358.6 & -415.2 \\
\hline \multirow{2}{*}{ Super } & \multirow{2}{*}{ A380 } & \multirow{2}{*}{ Nominal } & IGE & 2.6 & 4.4 & 6.3 & 8.1 & 11.8 & 16.2 & 20.4 & 24.3 \\
\hline & & & OGE & -84.3 & -125.1 & -164.3 & -202.2 & -274.7 & -358.6 & -435.4 & -506.0 \\
\hline
\end{tabular}

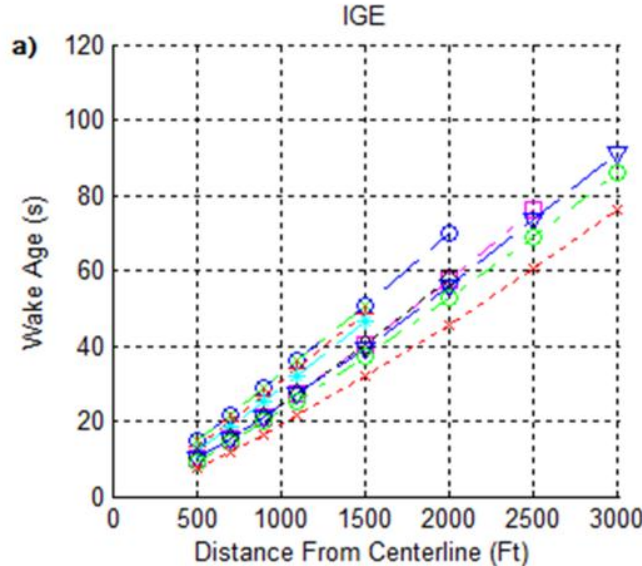

Figure 5. Wake age data IGE (a) and OGE (b)

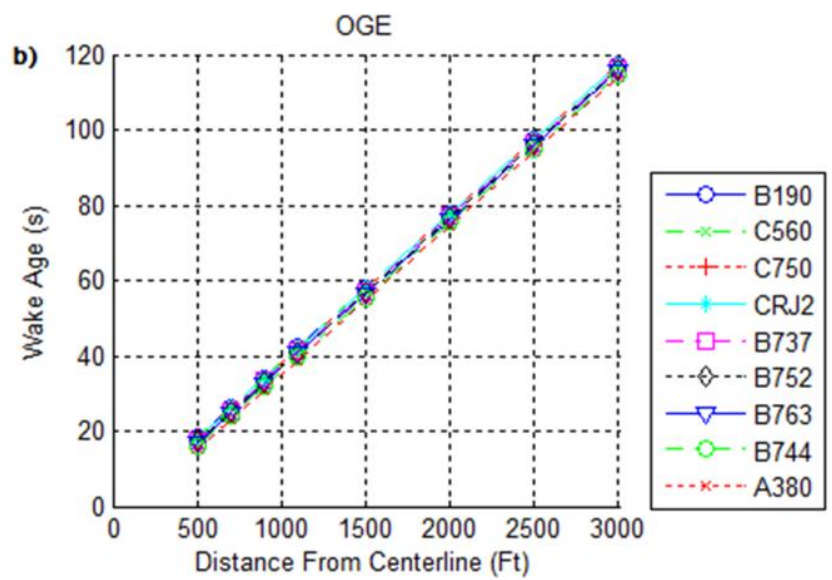

(b) at various lateral offset distances for the nominal aircraft scenarios.

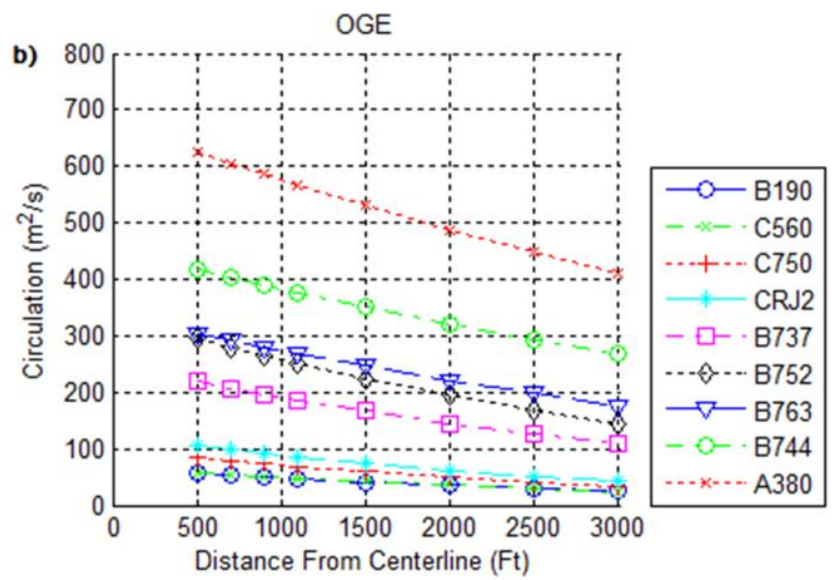

Figure 6. Circulation strength data IGE (a) and OGE (b) at various lateral offset distances for the nominal aircraft scenarios. 

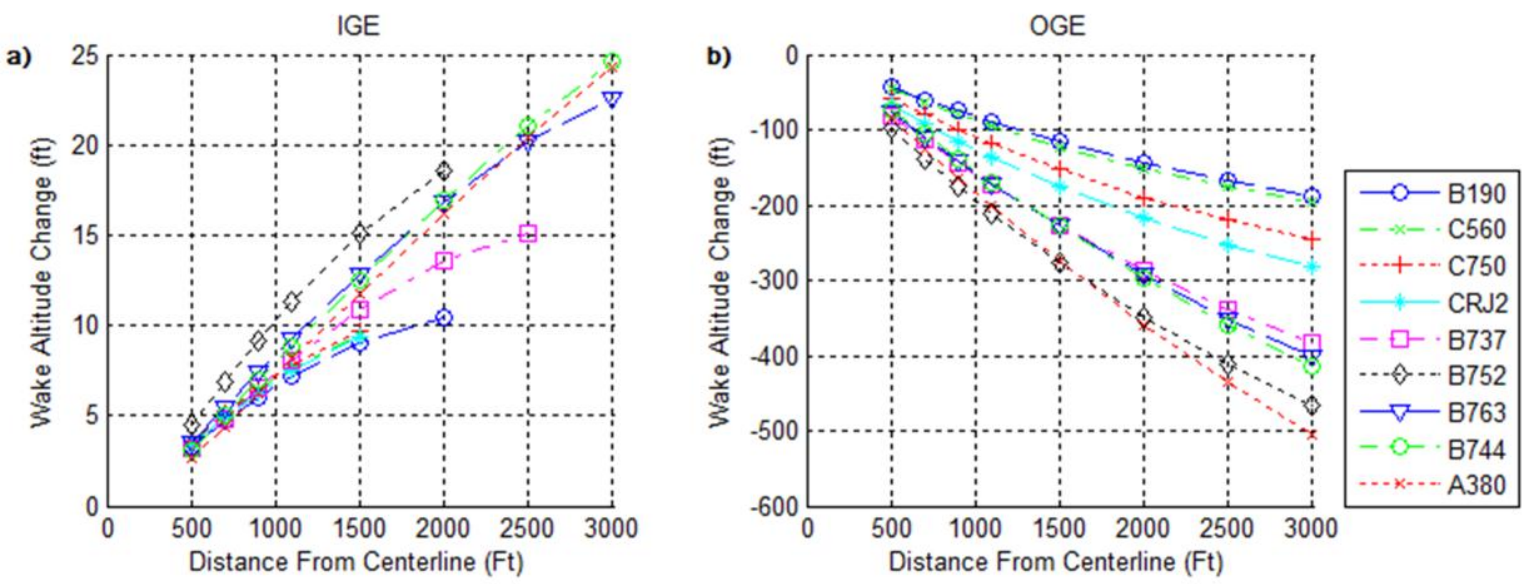

Figure 7. Wake altitude change data IGE (a) and OGE (b) at various lateral offset distances for the nominal aircraft scenarios.

\section{Discussion and Data Usage Examples}

There are several ways in which the data from this experiment can be used. The most direct way is to relate the data directly to in-trail time spacings. Suppose, for example, a scenario with a B763 aircraft at the nominal conditions tested in this experiment and a B737 aircraft that is in-trail but ahead of the wake of the B763. The approach is being performed to a pair of CSPRs with a lateral separation of 1400 feet. From the 1400 feet lateral runway spacing, one must subtract the appropriate separation buffer distances to account for assumed vortex diameter, navigational and other safety buffers, and the wingspan of the trailing aircraft. Using very rough assumptions that the wake vortex diameter is half the wingspan of the leading aircraft and the navigational errors and other buffers are zero, a very optimistic separation buffer (Figure 8) could be calculated to be: $1 / 4$ the wake generating aircraft's wingspan (the wake vortex assumed radius), plus $1 / 2$ the following aircraft's wingspan, plus zero additional safety buffer, for a total separation buffer of approximately 95 feet. Because the assumption was made that the same conditions exist as in the test scenario, i.e., wake generator aircraft configuration and atmospheric conditions are the same, the B763 data can be simply interpolated linearly at the lateral offset distance of 1400 feet minus the safety buffer; at $\sim 1305$ feet. This interpolation yields values of 33.39 s., $215.67 \mathrm{~m}^{\wedge} 2 / \mathrm{s}$ and $11.09 \mathrm{ft}$. for the IGE wake age, circulation strength and wake altitude change, respectively. Similarly, the values of $48.68 \mathrm{~s}$., $256.79 \mathrm{~m}^{\wedge} 2 / \mathrm{s}$ and -200.83 feet are obtained for the OGE

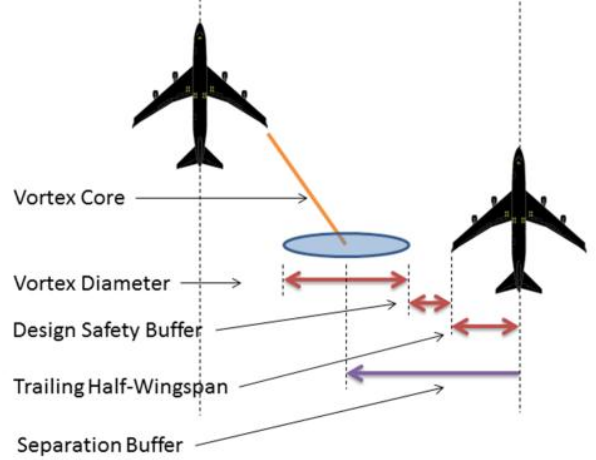

Figure 8. Separation buffer components.

region. In an operational sense, under the assumptions stated here, these values translate to (as an example):

1. The in-trail aircraft must be less than $33.39 \mathrm{~s}$ in-trail of the leader aircraft at the time the leader touches down

2. The in-trail aircraft must be less than 48.68 seconds in-trail of the leader aircraft everywhere along the parallel approach

3. And, the in-trail aircraft must have sufficient speed differential to satisfy both of these first two criteria. If these estimates were available to an on-board flight management system on an aircraft, this data could be used to inform the pilot as to whether the conditions are or are not being met in real time. Similarly, this data could be gathered for several assumed buffer zones, independent of the following aircraft, to create in-trail avoidance zones as a function of how much buffer zone is required.

Time-based in-trail spacings provide a more flexible means for evaluation of specific closely-spaced parallel runway operational concepts because these can be converted directly to in-trail distances for various leaderfollower speed profile assumptions. Conversely, if the only information available was a wake-avoidance in-trail distance for a specific pair of aircraft, it would be much more difficult to make an evaluation of wake-avoidance spacings for an alternative set of leader-follower speed profiles. As an example, consider the same leader-follower 
pair scenario - B763 followed by a B737 - given above. Note that, in this scenario, speed profile assumptions for the trailing aircraft are not required to obtain the in-trail time spacings for the IGE and OGE regions. For simplicity, an assumption can be made that the same IGE in-trail spacings can be applied at the runway threshold - a more convenient reference point than aircraft touchdown point since most speed differentials will only change the in-trail time by a very small margin between threshold crossing and touchdown. Assuming a constant final approach speed of 140 knots for the leader B763 aircraft, a distance versus time-to-threshold can be easily calculated (blue solid line in Figure 9). For a given trailing aircraft final approach speed - assume 150 knots for this example - an in-trail distance can be calculated for the time at which the leader aircraft crosses the runway threshold. This in-trail distance is $1.391 \mathrm{~nm}$. corresponding to an in-trail time of 33.39s. From the in-trail time/distance at the point the leader aircraft is crossing the threshold, and with the assumed follower approach speed, a distance versus time-tothreshold, relative to the leader's time-to-threshold, can also be quickly calculated (green dashed line in Figure 9). From these estimates, it is easy to identify that the follower aircraft needs to be $10.933 \mathrm{~nm}$ from the parallel runway threshold when the lead aircraft is $8.906 \mathrm{~nm}$ from the runway threshold, for a maximum in-trail time of $48.68 \mathrm{~s} \mathrm{OGE}$ (from above), which corresponds to an in-trail distance spacing of $2.027 \mathrm{~nm}$. These two in-trail times (and corresponding distances) represent the limit of where two aircraft, under the given scenario and assumptions, can operate to stay safe from wake encounters. The same technique can be used if the trailing aircraft is assumed to be slower than the leader. For an assumed final approach speed of 130 knots for the trailing aircraft, Figure 10 shows the follower aircraft at $1.206 \mathrm{~nm}$ (still $33.39 \mathrm{~s}$.) in-trail of the leader as the leader crosses the threshold and that, assuming constant approach speeds, the two aircraft would be abeam each other at $16.878 \mathrm{~nm}$ from the runway - the following aircraft is always well inside the OGE time window of $48.68 \mathrm{~s}$. due to the negative speed differential. Similar schemes can be used with more complicated scenarios, such as with different speed profiles, to evaluate the adherence to the wake avoidance regions as determined by wake age characteristics observed in this experiment and different safety buffer assumptions.

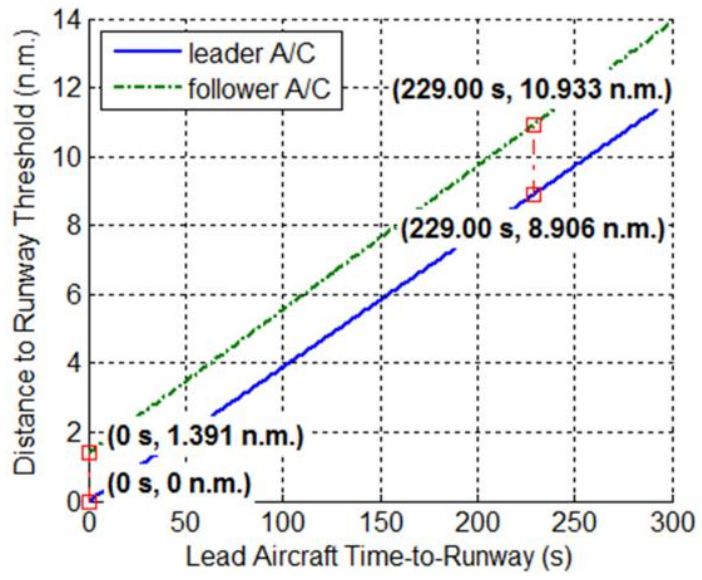

Figure 9. Example leader aircraft time to runway threshold versus leader and follower distance to the runway for a leader-follower configuration with +10 knot speed differential (faster aircraft in-trail).

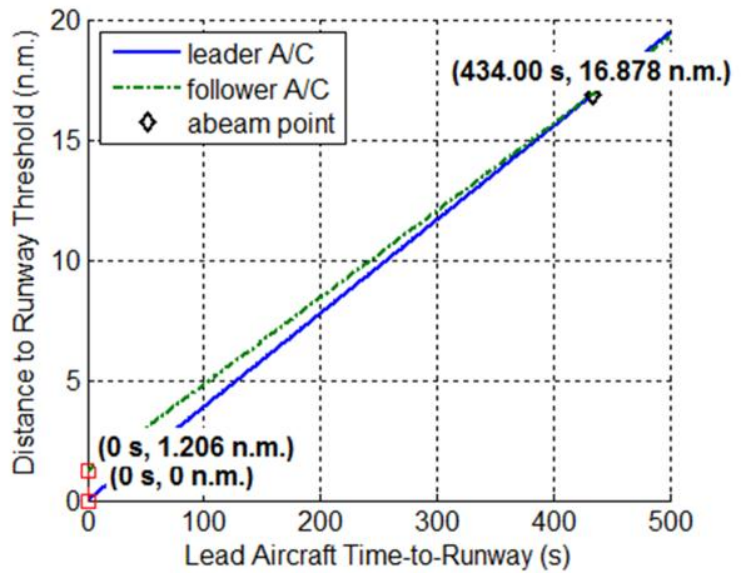

Figure 10. Example leader aircraft time to runway threshold versus leader and follower distance to the runway for a leader-follower configuration with -10 knot speed differential (slower aircraft intrail).

\section{A. Wake Characteristics Evaluation}

Because the data collected in this experiment does not fully cover all possibilities of aircraft models, aircraft speed and weight configuration, and atmospheric conditions, a model needs to be developed to estimate the wake characteristics of other scenarios in the absence of the APA algorithm. This was the motivation for generating the sensitivity scenarios for each of the aircraft models tested here, and for each of the primary parameters affecting wake behavior (weight, speed, wingspan, crosswind, and eddy dissipation rate). Using the data from these scenario runs and the nominal scenarios, a simple first-order finite-difference derivative model can be formulated as:

$$
p^{d, r} \approx p_{o}^{d, r}+\sum_{i=1}^{N} \frac{\Delta p_{o}^{d, r}}{\Delta Y_{i}} \Delta Y
$$


where $p^{d, r}$ is the value of the parameter $p$ (wake age, circulation strength, or wake altitude change) at offset distance $d$ and region $r$ (IGE, OGE), $p_{o}^{d, r}$ is the nominal value of the parameter $p$ at the same distance and region. The second term on the right hand side is the sum of the $N$ first derivative approximations of parameter $p$ to a change in the property $Y_{i}$ (weight, speed, wingspan, wind, EDR) multiplied by the change in the parameter for the new aircraft relative to the baseline aircraft. Examples of the calculated values of these first-order finite-difference derivatives $\left(\Delta p_{o}^{d, r} / \Delta Y_{i}\right)$ for the B737 aircraft are presented here in Table 5 through Table 10, while the full set of tables for all aircraft models tested are available in the appendix in Table 27 through Table 80.

Table 5. B737 wake age approximate derivatives, IGE.

\begin{tabular}{|c|c|c|c|c|c|c|c|c|}
\hline Distance (ft) & 500 & 700 & 900 & 1100 & 1500 & 2000 & 2500 & 3000 \\
\hline Nominal Wake Age (s) & 10.05 & 15.45 & 21.2 & 27.25 & 40.05 & 57.35 & 75.85 & 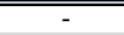 \\
\hline Weight Derivative (s/lb.) & $-3.261 \mathrm{E}-05$ & $-4.348 \mathrm{E}-05$ & $-4.891 \mathrm{E}-05$ & $-5.435 \mathrm{E}-05$ & $-5.978 \mathrm{E}-05$ & $-5.435 \mathrm{E}-05$ & $-2.717 \mathrm{E}-05$ & - \\
\hline Speed Derivative (s/knot) & 0.045 & 0.06 & 0.07 & 0.005 & 0 & 0.075 & - & - \\
\hline Wingspan Derivative (s/ft) & 0 & -0.0089286 & -0.0178571 & -0.0357143 & -0.0803571 & -0.1517857 & -0.2589286 & 195.05357 \\
\hline Wind Derivative (s/knot) & -0.35 & -0.57 & -0.82 & -1.09 & -1.69 & -2.57 & -3.57 & 214.2 \\
\hline EDR Derivative $\left(\mathrm{s} /\left(\mathrm{m}^{\wedge} 2 / \mathrm{s}^{\wedge} 2\right)\right)$ & 10.10101 & 15.151515 & 20.20202 & 35.353535 & 95.959596 & - & - & - \\
\hline
\end{tabular}

Table 6. B737 wake age approximate derivatives, OGE.

\begin{tabular}{|c|c|c|c|c|c|c|c|c|}
\hline Distance (ft) & 500 & 700 & 900 & 1100 & 1500 & 2000 & 2500 & 3000 \\
\hline Nominal Wake Age (s) & 17.5 & 25.45 & 33.35 & 41.25 & 57.1 & 76.9 & 96.6 & 116.35 \\
\hline Weight Derivative (s/lb.) & 0 & 0 & 0 & 0 & 0 & 0 & 0 & 0 \\
\hline Speed Derivative (s/knot) & 0 & 0 & 0 & 0 & 0 & 0 & 0 & 0 \\
\hline Wingspan Derivative $(\mathrm{s} / \mathrm{ft})$ & -0.0178571 & -0.0178571 & -0.0089286 & -0.0089286 & -0.0178571 & -0.0178571 & -0.0178571 & -0.0178571 \\
\hline Wind Derivative (s/knot) & -0.9 & -1.3 & -1.69 & -2.09 & -2.88 & -3.87 & -4.86 & -5.84 \\
\hline EDR Derivative $\left(\mathrm{s} /\left(\mathrm{m}^{\wedge} \mathbf{2} / \mathrm{s}^{\wedge} 2\right)\right)$ & 0 & 0 & 0 & 0 & 0 & 0 & 0 & 0 \\
\hline
\end{tabular}

Table 7. B737 circulation strength approximate derivatives, IGE.

\begin{tabular}{|c|c|c|c|c|c|c|c|c|}
\hline Distance (ft) & 500 & 700 & 900 & 1100 & 1500 & 2000 & 2500 & 3000 \\
\hline Nominal Wake Circulation ( $\left.\mathrm{m}^{\wedge} \mathbf{2} / \mathrm{s}\right)$ & 205.9765 & 184.05264 & 166.26885 & 150.4482 & 1117.37762 & 72.680655 & 24.883363 & 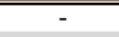 \\
\hline Weight Derivative $\left(\left(\mathrm{m}^{\wedge} 2 / \mathrm{s}\right) / \mathrm{lb}\right)$ & 0.0015417 & 0.0013098 & 0.0011022 & 0.0008633 & 0.0003073 & -0.0004825 & -0.001391 & - \\
\hline Speed Derivative ((m^2/s)/knot) & -1.9973207 & -1.6928975 & -1.4259186 & -0.644268 & -0.118179 & 0.6827416 & - & - \\
\hline Wingspan Derivative $\left(\left(\mathrm{m}^{\wedge} 2 / \mathrm{s}\right) / \mathrm{ft}\right)$ & -0.4295018 & -0.0948166 & 0.184578 & 0.5437354 & 1.6802936 & 3.2407323 & 4.9748407 & 180.63008 \\
\hline Wind Derivative $\left(\left(\mathrm{m}^{\wedge} 2 / \mathrm{s}\right) / \mathrm{knot}\right)$ & 1.2550026 & 1.6755646 & 2.0647646 & 2.5152232 & 4.220853 & 6.7437506 & 9.5882836 & 207.40134 \\
\hline EDR Derivative $\left(\left(\mathrm{m}^{\wedge} 2 / \mathrm{s}\right) /\left(\mathrm{m}^{\wedge} 2 / \mathrm{s}^{\wedge} 2\right)\right)$ & -658.15616 & -757.08566 & -1328.2838 & -2261.0451 & -4390.4013 & - & - & - \\
\hline
\end{tabular}

Table 8. B737 circulation strength approximate derivatives, OGE.

\begin{tabular}{|c|c|c|c|c|c|c|c|c|}
\hline Distance (ft) & 500 & 700 & 900 & 1100 & 1500 & 2000 & 2500 & 3000 \\
\hline Nominal Wake Circulation $\left(\mathrm{m}^{\wedge} 2 / \mathrm{s}\right)$ & 218.34664 & 207.02863 & 196.29338 & 186.04613 & 166.87179 & 145.30814 & 126.2205 & 109.19724 \\
\hline Weight Derivative ((m^2/s)/lb) & 0.0017079 & 0.0015721 & 0.0014456 & 0.0013273 & 0.0011123 & 0.0008813 & 0.0006876 & 0.0005243 \\
\hline Speed Derivative $\left(\left(\mathrm{m}^{\wedge} 2 / \mathrm{s}\right) /\right.$ knot $)$ & -1.7071483 & -1.5710638 & -1.4444486 & -1.32592 & -1.1106286 & -0.8794947 & -0.6856743 & -0.5223814 \\
\hline Wingspan Derivative $\left(\left(\mathrm{m}^{\wedge} 2 / \mathrm{s}\right) / \mathrm{ft}\right)$ & -1.4860491 & -1.2641161 & -1.0708734 & -0.8821987 & -0.5376607 & -0.1919584 & 0.0836513 & 0.3021641 \\
\hline Wind Derivative (( $\left.\left.\mathrm{m}^{\wedge} 2 / \mathrm{s}\right) / \mathrm{knot}\right)$ & 1.3209632 & 1.8430716 & 2.3005184 & 2.731891 & 3.4692846 & 4.2093704 & 4.7752256 & 5.180508 \\
\hline EDR Derivative $\left(\left(\mathrm{m}^{\wedge} 2 / \mathrm{s}\right) /\left(\mathrm{m}^{\wedge} 2 / \mathrm{s}^{\wedge} 2\right)\right)$ & -3409.813 & -4533.5126 & -5449.4418 & -6190.9578 & -7241.2626 & -7920.1612 & -8104.7673 & -7957.1183 \\
\hline
\end{tabular}

Table 9. B737 wake altitude change approximate derivatives, IGE.

\begin{tabular}{|c|c|c|c|c|c|c|c|c|}
\hline Distance (ft) & 500 & 700 & 900 & 1100 & 1500 & 2000 & 2500 & 3000 \\
\hline Nominal Wake Delta Altitude (ft) & 3.19447 & 4.866891 & 6.496909 & 8.051538 & 10.862557 & 13.597358 & 15.095361 & - \\
\hline Weight Derivative (ft/lb.) & 1.393E-05 & $2.184 \mathrm{E}-05$ & $3.141 \mathrm{E}-05$ & 4.052E-05 & $5.229 \mathrm{E}-05$ & $5.052 \mathrm{E}-05$ & $2.444 \mathrm{E}-05$ & - \\
\hline Speed Derivative (ft/knot) & -0.0055422 & -0.0169685 & -0.0270396 & -0.0909965 & -0.1140256 & -0.0471237 & - & - \\
\hline Wingspan Derivative (ft/ft) & -0.070925 & -0.1035204 & -0.136915 & -0.1601964 & -0.1963593 & -0.192577 & -0.1192846 & 181.14005 \\
\hline Wind Derivative (ft/knot) & -0.1035092 & -0.1567788 & -0.2122156 & -0.2583406 & -0.3324366 & -0.3472182 & -0.2359104 & 202.84278 \\
\hline EDR Derivative $\left(\mathrm{ft} /\left(\mathrm{m}^{\wedge} 2 / \mathrm{s}^{\wedge} 2\right)\right)$ & -5.939899 & -9.6405051 & -18.742525 & -32.421818 & -91.657071 & - & - & - \\
\hline
\end{tabular}

Table 10. B737 wake altitude change approximate derivatives, OGE.

\begin{tabular}{|c|c|c|c|c|c|c|c|c|}
\hline Distance (ft) & 500 & 700 & 900 & 1100 & 1500 & 2000 & 2500 & 3000 \\
\hline Nominal Wake Delta Altitude (ft) & -80.71339 & -113.46127 & -144.3163 & -173.56637 & -227.70126 & -287.48979 & -339.2277 & -384.19807 \\
\hline Weight Derivative (ft/lb.) & -0.0006523 & -0.0009047 & -0.0011355 & -0.0013476 & -0.0017214 & -0.0021025 & -0.0024008 & -0.0026317 \\
\hline Speed Derivative (ft/knot) & 0.6556552 & 0.9079668 & 1.1386049 & 1.3504964 & 1.7238269 & 2.1042389 & 2.4018263 & 2.6320094 \\
\hline Wingspan Derivative (ft/ft) & 1.3440714 & 1.8226289 & 2.2215418 & 2.6111789 & 3.3037361 & 3.9408495 & 4.3962518 & 4.7047555 \\
\hline Wind Derivative (ft/knot) & 3.8616546 & 5.3263932 & 6.610587 & 7.8039136 & 9.7849418 & 11.6654 & 12.977689 & 13.77377 \\
\hline EDR Derivative $\left(\mathrm{ft} /\left(\mathrm{m}^{\wedge} 2 / \mathrm{s}^{\wedge} \mathrm{2}\right)\right)$ & 634.05596 & 1248.4321 & 2014.6192 & 2907.3198 & 4982.8686 & 7909.4899 & 10979.845 & 14060.926 \\
\hline
\end{tabular}

Estimating the wake characteristics of the Airbus A320 aircraft based on the results of the closest weight class aircraft (the B737) would be an example use of the model above. Suppose the A320 aircraft configuration and atmospheric conditions were given to be the values in Table 11. Table 11 also lists the change in these parameters relative to the nominal scenario values of the B737. Using these values and the approximate derivative values of 
Table 5 through Table 10, the wake age, circulation strength, and wake altitude change characteristics of the A320 aircraft model can be estimated; Figure 11, Figure 12 and Figure 13 show the estimates for these three wake characteristics, respectively, for the IGE and OGE regions, along with the nominal B737 data used as the baseline for projection and the WVSAT ${ }^{\mathrm{TM}}$ simulation results for the A320 aircraft. Note that estimates are not calculated beyond 1500 feet lateral offset distance because some derivatives do not exist for the baseline aircraft due to wakes that had already dissipated in the sensitivity scenarios at those distances - extrapolation or other techniques could be used to estimate the data at these lateral offset distances. The estimates for wake age for the A320 aircraft are reasonable, given all of the assumptions associated with this simple model. Further investigation of these estimates and the simulation model revealed that the majority of the difference between the estimated wake age and the simulated values - particularly in the IGE region - can be attributed to wakes generated at different altitudes above the ground. More specifically, because of the B737 and A320 aircraft model differences, the last wake elements for the B737 at touchdown are generated at an altitude of 10 feet above the ground, while the A320 wakes are generated at 11 feet above the ground, producing slightly different ground-effects. Similar to this difference in wake altitude at touchdown, the circulation strength and wake altitude change models may benefit from further analysis into explanatory parameters that could enhance the estimates. Nonetheless, the sensitivity model can provide quick estimates of the wake characteristics of any aircraft when analyzing closely-spaced parallel runway operations, provided an appropriate baseline aircraft is used.

Table 11. A320 simulation scenario parameters.

\begin{tabular}{c|ccccc}
\hline & Weight (Ib.) & $\begin{array}{c}\text { Approach/Landing } \\
\text { Speeds (KIAS) }\end{array}$ & $\begin{array}{c}\text { Wingspan } \\
\text { (ft) }\end{array}$ & $\begin{array}{c}\text { Crosswind } \\
\text { (Knots) }\end{array}$ & $\begin{array}{c}\text { Eddy Dissipation } \\
\text { Rate (m^2/s^2) }\end{array}$ \\
\hline \hline A320 & 142,000 & $133 / 123$ & 111.25 & 22 & 0.001 \\
Delta Parameters & 22,000 & $3 / 3$ & -1.35 & 7 & -0.0009
\end{tabular}

a)

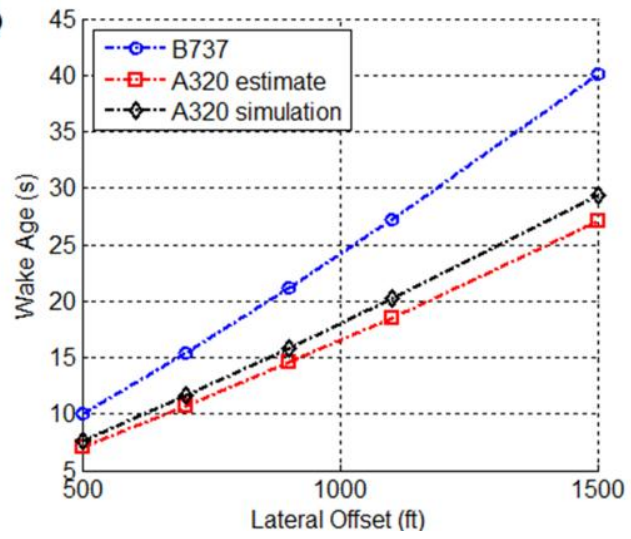

b)

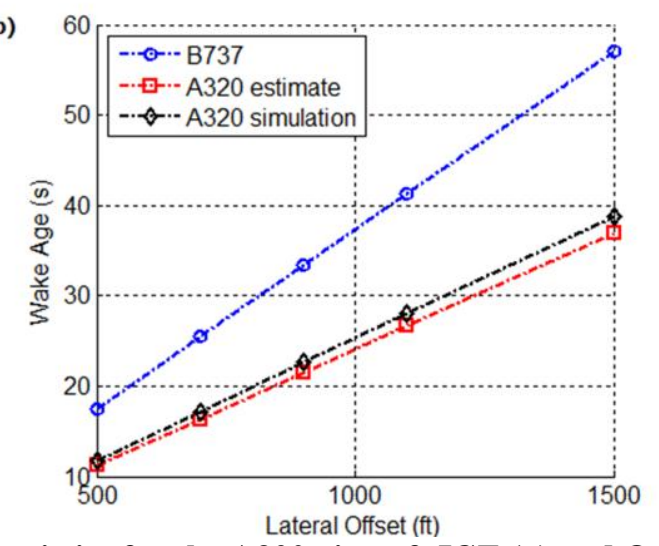

Figure 11. Estimated and simulated wake age characteristics for the A320 aircraft IGE (a) and OGE (b).
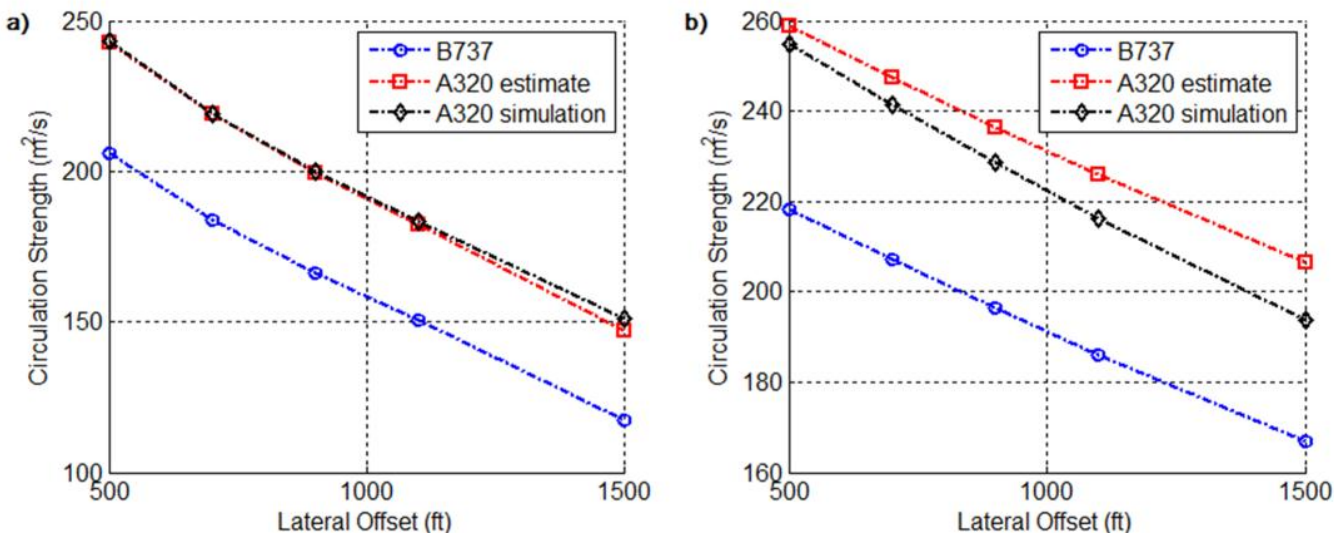

Figure 12. Estimated and simulated circulation strength characteristics for the A320 aircraft IGE (a) and OGE (b).

American Institute of Aeronautics and Astronautics 
a)

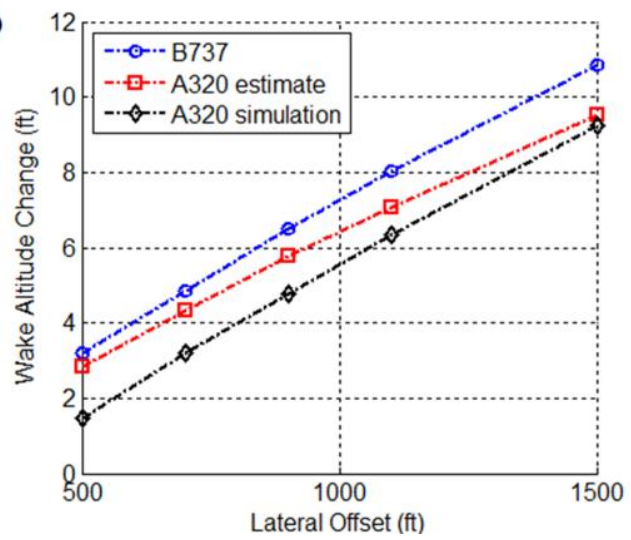

b)

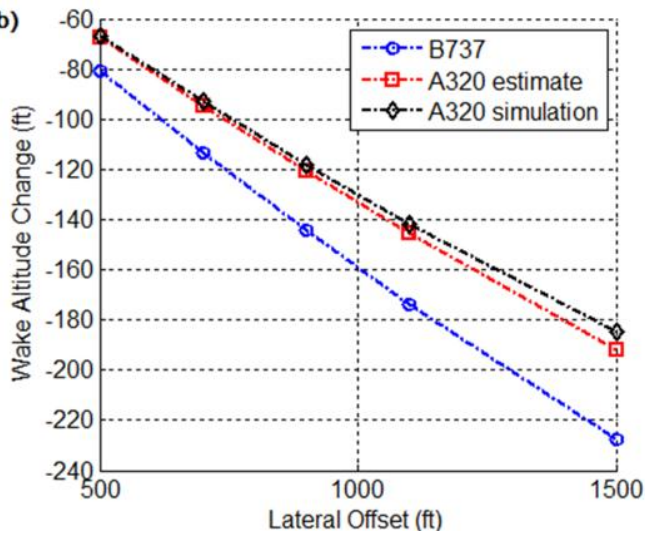

Figure 13. Estimated and simulated wake altitude change characteristics for the A320 aircraft IGE (a) and OGE (b).

\section{Conclusion}

An experiment was performed to collect simulation data on wake vortex characteristics, relevant to the evaluation (including feasibility analysis) of CSPR operational concepts. While the experiment was not tailored to any specific operational concept, the data generated and compiled applies to the class of concepts where an aircraft on a CSPR approach is required to stay ahead of the wake vortices of a lead aircraft on approach to an adjacent CSPR. Data related to the wake age, circulation strength, and wake altitude change, at various lateral offset distances from the wake generating lead aircraft, were collected for a set of nine aircraft. The aircraft selected span the full range of wake classes defined by the FAA and ICAO. A total of 54 simulation scenarios were performed to gather baseline and sensitivity data on dominant parameters that determine various wake characteristics. Of particular interest is the wake age, or lateral wake vortex transport time, to various distances normal to the generating aircraft's flight path. This data can be used to efficiently evaluate both time-based and distance-based intrail separation for all aircraft wake-class combinations. A simple first-order difference model was developed to enable the generation of wake characteristics estimates for aircraft models not included in this experiment. These estimates can be used to quickly assess the WAZ size for all possible aircraft pairings, for any CSPR operational scenario given specific, assumed separation buffers and speed profiles. Because of the simplicity of the model, further evaluation would need to be performed to enhance the model's predictive capabilities in regions outside the experimental matrix used here. For example, the effect on wake characteristics due to different IGE wake generation altitude at touchdown could be investigated using the $\mathrm{WVSAT}^{\mathrm{TM}}$ tool. Additionally, data for other aircraft models could also be generated.

The simulation data generated and compiled in this experiment illustrate the differences between wake characteristics of various aircraft and examples are provided showing potential uses of this data in the analysis of CSPR approach concepts. These examples illustrate how the time-based approach to this experiment enables use of the compiled data to analyze a wide range of scenarios with varying aircraft pairs and speed profiles. This capability was contrasted with a prior study that analyzed the SAPA operational concept, where a spacing characterization in terms of an initial in-trail distance at the start of the approach did not enable such flexibility.

Finally, it is important to note that this experiment is an exercise in the collection of simulation data from a wake model intended to provide informative estimates on wake characteristics for the purposes of preliminary feasibility analysis of various CSPR con-ops. The results presented here are only as good as the data from which these models have been calibrated and efforts are underway to collect additional field data to better enhance the predictive capabilities of models such as the APA.

Some of the possible follow-on studies to this work include: improving the predictive capabilities of the finitedifference estimation model, comparison of this simulated data with field data that is currently being collected, and the simulation and presentation of the wake characteristics data for same runway in-trail operational scenarios.

\section{Appendix}

The data collected in this experiment is extensive. As such, these data are presented in the tables in this appendix where only an example set of data is presented earlier in the manuscript. 
1. Wake Age Scenario Results

Table 12. Wake age data IGE and OGE at various lateral offset distances for the Small weight class aircraft (nominal and sensitivity scenarios).

\begin{tabular}{|c|c|c|c|c|c|c|c|c|c|c|c|}
\hline \multirow{2}{*}{$\begin{array}{c}\text { Weight } \\
\text { Class }\end{array}$} & \multirow{2}{*}{ Aircraft ID } & \multirow{2}{*}{ Sensitivity } & \multirow{2}{*}{$\begin{array}{c}\text { Altitude } \\
\text { Region } \\
\end{array}$} & \multicolumn{8}{|c|}{ Wake Age (s) at Offset Distances (ft) } \\
\hline & & & & 500 & 700 & 900 & 1100 & 1500 & 2000 & 2500 & 3000 \\
\hline \multirow{36}{*}{ Small } & \multirow{12}{*}{ B190 } & \multirow{2}{*}{ Nominal } & IGE & 14.65 & 21.6 & 28.7 & 35.95 & 50.8 & "69.95 & - & - \\
\hline & & & OGE & 18.35 & 26.3 & 34.2 & 42.1 & 57.95 & 77.75 & 97.45 & 117.2 \\
\hline & & \multirow{2}{*}{ Weight } & IGE & 14.2 & 21.1 & 28.15 & 35.45 & 50.35 & - & - & - \\
\hline & & & OGE & 18.35 & 26.3 & 34.2 & 42.1 & 57.95 & 77.75 & 97.45 & 117.2 \\
\hline & & \multirow{2}{*}{ Speed } & IGE & 14.45 & 21.35 & 28.45 & 35.7 & 50.6 & - & - & - \\
\hline & & & OGE & 18.35 & 26.3 & 34.2 & 42.1 & 57.95 & 77.75 & 97.45 & 117.2 \\
\hline & & \multirow{2}{*}{ Wingspan } & IGE & 14.6 & 21.55 & 28.55 & 35.8 & 50.45 & 69.4 & - & - \\
\hline & & & OGE & 18.3 & 26.25 & 34.2 & 42.05 & 57.9 & 77.7 & 97.4 & 117.15 \\
\hline & & \multirow{2}{*}{ Wind } & IGE & 11.25 & 16.75 & 21.9 & 27.35 & 38.45 & 52.65 & 67.45 & - \\
\hline & & & OGE & 13.65 & 19.6 & 25.55 & 31.45 & 43.35 & 58.15 & 72.95 & 87.8 \\
\hline & & \multirow{2}{*}{ EDR } & IGE & 14.8 & 21.9 & 29.2 & 36.8 & - & - & - & - \\
\hline & & & OGE & 18.35 & 26.3 & 34.2 & 42.1 & 57.95 & 77.75 & 97.45 & - \\
\hline & \multirow{12}{*}{ C560 } & \multirow{2}{*}{ Nominal } & IGE & 14.6 & 21.55 & 28.7 & 36 & 50.9 & - & - & - \\
\hline & & & OGE & 18.4 & 26.3 & 34.25 & 42.15 & 57.95 & 77.75 & 97.5 & 117.25 \\
\hline & & \multirow{2}{*}{ Weight } & IGE & 14.15 & 21.05 & 28.15 & 35.45 & 50.55 & - & - & - \\
\hline & & & OGE & 18.4 & 26.3 & 34.25 & 42.15 & 57.95 & 77.75 & 97.5 & 117.25 \\
\hline & & \multirow{2}{*}{ Speed } & IGE & 14.4 & 21.35 & 28.45 & 35.75 & 50.75 & - & - & - \\
\hline & & & OGE & 18.4 & 26.3 & 34.25 & 42.15 & 57.95 & 77.75 & 97.5 & 117.25 \\
\hline & & \multirow{2}{*}{ Wingspan } & IGE & 14.55 & 21.5 & 28.55 & 35.8 & 50.55 & 70.2 & - & - \\
\hline & & & OGE & 18.35 & 26.25 & 34.2 & 42.1 & 57.9 & 77.7 & 97.45 & 117.2 \\
\hline & & \multirow{2}{*}{ Wind } & IGE & 11.35 & 16.65 & 22.05 & 27.55 & 38.7 & 53 & 67.5 & - \\
\hline & & & OGE & 13.65 & 19.6 & 25.55 & 31.5 & 43.35 & 58.2 & 73 & 87.8 \\
\hline & & \multirow{2}{*}{ EDR } & IGE & 14.7 & 21.85 & 29.15 & 36.8 & - & - & - & - \\
\hline & & & OGE & 18.4 & 26.3 & 34.25 & 42.15 & 57.95 & 77.75 & - & - \\
\hline & \multirow{12}{*}{ C750 } & \multirow{2}{*}{ Nominal } & IGE & 13.3 & 19.95 & 26.8 & 33.9 & 48.6 & - & - & - \\
\hline & & & OGE & 18.25 & 26.2 & 34.15 & 42 & 57.85 & 77.65 & 97.35 & 117.1 \\
\hline & & \multirow{2}{*}{ Weight } & IGE & 12.6 & 19.15 & 25.95 & 33.1 & 48.65 & - & - & - \\
\hline & & & OGE & 18.25 & 26.2 & 34.15 & 42 & 57.85 & 77.65 & 97.35 & 117.1 \\
\hline & & \multirow{2}{*}{ Speed } & IGE & 13.1 & 19.7 & 26.55 & 33.65 & 48.4 & - & - & - \\
\hline & & & OGE & 18.25 & 26.2 & 34.15 & 42 & 57.85 & 77.65 & 97.35 & 117.1 \\
\hline & & Wingspan & IGE & 13.3 & 19.85 & 26.65 & 33.65 & 48.1 & 67 & - & - \\
\hline & & Wingspan & OGE & 18.2 & 26.15 & 34.1 & 41.95 & 57.8 & 77.6 & 97.3 & 117.05 \\
\hline & & Wind & IGE & 10.55 & 15.6 & 20.8 & 26.15 & 37.1 & 51.25 & - & - \\
\hline & & Wind & OGE & 13.55 & 19.5 & 25.45 & 31.4 & 43.25 & 58.1 & 72.9 & 87.75 \\
\hline & & $\mathbf{E}$ & IGE & 13.4 & 20.2 & 27.25 & 34.65 & - & - & - & - \\
\hline & & CDN & OGE & 18.25 & 26.2 & 34.15 & 42 & 57.85 & 77.65 & 97.35 & - \\
\hline
\end{tabular}

Table 13. Wake age data IGE and OGE at various lateral offset distances for the Large weight class aircraft (nominal and sensitivity scenarios).

\begin{tabular}{|c|c|c|c|c|c|c|c|c|c|c|c|}
\hline \multirow{2}{*}{$\begin{array}{c}\text { Weight } \\
\text { Class }\end{array}$} & \multirow{2}{*}{ Aircraft ID } & \multirow{2}{*}{ Sensitivity } & \multirow{2}{*}{$\begin{array}{l}\text { Altitude } \\
\text { Region }\end{array}$} & \multicolumn{8}{|c|}{ Wake Age (s) at Offset Distances (ft) } \\
\hline & & & & 500 & 700 & 900 & 1100 & 1500 & 2000 & 2500 & 3000 \\
\hline \multirow{24}{*}{ Large } & \multirow{12}{*}{ CRJ2 } & \multirow{2}{*}{ Nominal } & IGE & 12.3 & 18.55 & 25.1 & 32 & 46.35 & - & - & - \\
\hline & & & OGE & 18.15 & 26.1 & 34.05 & 41.95 & 57.75 & 77.55 & 97.25 & 117.05 \\
\hline & & \multirow{2}{*}{ Weight } & IGE & 11.25 & 17.3 & 23.8 & 30.75 & - & - & - & - \\
\hline & & & OGE & 18.15 & 26.1 & 34.05 & 41.95 & 57.75 & 77.55 & 97.25 & 117.05 \\
\hline & & \multirow{2}{*}{ Speed } & IGE & 11.9 & 18.1 & 24.6 & 32.15 & 46.65 & - & - & - \\
\hline & & & OGE & 18.15 & 26.1 & 34.05 & 41.95 & 57.75 & 77.55 & 97.25 & 117.05 \\
\hline & & \multirow{2}{*}{ Wingspan } & IGE & 12.25 & 18.5 & 24.95 & 31.75 & 45.8 & 64.5 & - & - \\
\hline & & & OGE & 18.1 & 26.05 & 34 & 41.9 & 57.7 & 77.5 & 97.2 & 116.95 \\
\hline & & \multirow{2}{*}{ Wind } & IGE & 9.85 & 14.7 & 19.7 & 24.9 & 35.65 & 49.6 & - & - \\
\hline & & & OGE & 13.5 & 19.45 & 25.4 & 31.3 & 43.2 & 58.05 & 72.8 & 87.65 \\
\hline & & \multirow{2}{*}{ EDR } & IGE & 12.4 & 18.75 & 25.5 & 32.7 & - & - & - & - \\
\hline & & & OGE & 18.15 & 26.1 & 34.05 & 41.95 & 57.75 & 77.55 & 97.25 & 117.05 \\
\hline & \multirow{12}{*}{ B737 } & \multirow{2}{*}{ Nominal } & IGE & 10.05 & 15.45 & 21.2 & 27.25 & 40.05 & 57.35 & 75.85 & - \\
\hline & & & OGE & 17.5 & 25.45 & 33.35 & 41.25 & 57.1 & 76.9 & 96.6 & 116.35 \\
\hline & & \multirow{2}{*}{ Weight } & IGE & 9.75 & 15.05 & 20.75 & 26.75 & 39.5 & 56.85 & 75.6 & - \\
\hline & & & OGE & 17.5 & 25.45 & 33.35 & 41.25 & 57.1 & 76.9 & 96.6 & 116.35 \\
\hline & & \multirow{2}{*}{ Speed } & IGE & 9.6 & 14.85 & 20.5 & 27.2 & 40.05 & 56.6 & - & - \\
\hline & & & OGE & 17.5 & 25.45 & 33.35 & 41.25 & 57.1 & 76.9 & 96.6 & 116.35 \\
\hline & & \multirow{2}{*}{ Wingspan } & IGE & 10.05 & 15.4 & 21.1 & 27.05 & 39.6 & 56.5 & 74.4 & 93.3 \\
\hline & & & OGE & 17.4 & 25.35 & 33.3 & 41.2 & 57 & 76.8 & 96.5 & 116.25 \\
\hline & & \multirow{2}{*}{ Wind } & IGE & 8.3 & 12.6 & 17.1 & 21.8 & 31.6 & 44.5 & 58 & 72 \\
\hline & & & OGE & 13 & 18.95 & 24.9 & 30.8 & 42.7 & 57.55 & 72.3 & 87.15 \\
\hline & & \multirow{2}{*}{ EDR } & IGE & 10.15 & 15.6 & 21.4 & 27.6 & 41 & - & - & - \\
\hline & & & OGE & 17.5 & 25.45 & 33.35 & 41.25 & 57.1 & 76.9 & 96.6 & 116.35 \\
\hline
\end{tabular}


Table 14. Wake age data IGE and OGE at various lateral offset distances for the 757 weight class aircraft (nominal and sensitivity scenarios).

\begin{tabular}{|c|c|c|c|c|c|c|c|c|c|c|c|}
\hline \multirow{2}{*}{$\begin{array}{c}\text { Weight } \\
\text { Class }\end{array}$} & \multirow{2}{*}{ Aircraft ID } & \multirow{2}{*}{ Sensitivity } & \multirow{2}{*}{$\begin{array}{c}\text { Altitude } \\
\text { Region }\end{array}$} & \multicolumn{8}{|c|}{ Wake Age (s) at Offset Distances (ft) } \\
\hline & & & & 500 & 700 & 900 & 1100 & 1500 & 2000 & 2500 & 3000 \\
\hline \multirow{12}{*}{757} & \multirow{12}{*}{ B752 } & \multirow{2}{*}{ Nominal } & IGE & 9.95 & 15.4 & 21.2 & 27.3 & 40.3 & 57.9 & 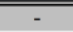 & - \\
\hline & & & OGE & 17.4 & 25.35 & 33.1 & 41 & 57 & 76.8 & 96.35 & 116.1 \\
\hline & & \multirow{2}{*}{ Weight } & IGE & 9.6 & 14.9 & 20.6 & 26.7 & 39.65 & 57.4 & - & - \\
\hline & & & OGE & 17.4 & 25.35 & 33.1 & 41 & 57 & 76.8 & 96.35 & 116.1 \\
\hline & & \multirow{2}{*}{ Speed } & IGE & 9.6 & 14.95 & 20.65 & 26.75 & 39.7 & 57.4 & - & - \\
\hline & & & OGE & 17.3 & 25.25 & 33.15 & 41.05 & 56.9 & 76.65 & 96.4 & 116.15 \\
\hline & & \multirow{2}{*}{ Wingspan } & IGE & 9.95 & 15.35 & 21.05 & 27.1 & 39.8 & 56.95 & 75.15 & - \\
\hline & & & OGE & 17.3 & 25.25 & 33 & 40.9 & 56.9 & 76.7 & 96.25 & 116 \\
\hline & & \multirow{2}{*}{ Wind } & IGE & 7.95 & 12.2 & 16.65 & 21.35 & 31.7 & 44.1 & 57.75 & 72.05 \\
\hline & & & OGE & 12.85 & 18.8 & 24.75 & 30.65 & 42.5 & 57.35 & 72.15 & 87 \\
\hline & & \multirow{2}{*}{ EDR } & IGE & 10 & 15.5 & 21.35 & 27.6 & 41 & - & - & - \\
\hline & & & OGE & 17.4 & 25.35 & 33.1 & 41 & 57 & 76.8 & 96.35 & 116.1 \\
\hline
\end{tabular}

Table 15. Wake age data IGE and OGE at various lateral offset distances for the Heavy weight class aircraft (nominal and sensitivity scenarios).

\begin{tabular}{|c|c|c|c|c|c|c|c|c|c|c|c|}
\hline \multirow{2}{*}{$\begin{array}{c}\text { Weight } \\
\text { Class }\end{array}$} & \multirow{2}{*}{ Aircraft ID } & \multirow{2}{*}{ Sensitivity } & \multirow{2}{*}{$\begin{array}{l}\text { Altitude } \\
\text { Region }\end{array}$} & \multicolumn{8}{|c|}{ Wake Age (s) at Offset Distances (ft) } \\
\hline & & & & 500 & 700 & 900 & 1100 & 1500 & 2000 & 2500 & 3000 \\
\hline \multirow{24}{*}{ Heavy } & \multirow{12}{*}{ B763 } & \multirow{2}{*}{ Nominal } & IGE & 10.05 & 15.45 & 21.1 & 27.05 & 39.45 & 55.95 & 73.25 & 91.4 \\
\hline & & & OGE & 16.85 & 24.75 & 32.7 & 40.6 & 56.4 & 76.2 & 95.95 & 115.7 \\
\hline & & \multirow{2}{*}{ Weight } & IGE & 9.25 & 14.4 & 19.85 & 25.6 & 37.8 & 54.2 & 71.7 & 90.35 \\
\hline & & & OGE & 16.85 & 24.75 & 32.7 & 40.6 & 56.4 & 76.2 & 95.95 & 115.7 \\
\hline & & \multirow{2}{*}{ Speed } & IGE & 9.65 & 14.9 & 20.4 & 26.25 & 38.5 & 54.9 & 72.25 & 90.5 \\
\hline & & & OGE & 16.85 & 24.75 & 32.7 & 40.6 & 56.4 & 76.2 & 95.95 & 115.7 \\
\hline & & \multirow{2}{*}{ Wingspan } & IGE & 10.1 & 15.45 & 21.05 & 26.95 & 39.2 & 55.45 & 72.4 & 90.1 \\
\hline & & & OGE & 16.7 & 24.65 & 32.6 & 40.45 & 56.3 & 76.1 & 95.8 & 115.55 \\
\hline & & \multirow{2}{*}{ Wind } & IGE & 8.05 & 12.3 & 16.7 & 21.25 & 30.8 & 43.2 & 56.15 & 69.5 \\
\hline & & & OGE & 12.5 & 18.45 & 24.4 & 30.3 & 42.2 & 57.05 & 71.8 & 86.65 \\
\hline & & \multirow{2}{*}{ EDR } & IGE & 10.15 & 15.65 & 21.4 & 27.4 & 40.25 & 57.65 & - & - \\
\hline & & & OGE & 16.85 & 24.75 & 32.7 & 40.6 & 56.4 & 76.2 & 95.95 & 115.7 \\
\hline & \multirow{12}{*}{ B744 } & \multirow{2}{*}{ Nominal } & IGE & 9.3 & 14.4 & 19.75 & 25.35 & 37.1 & 52.6 & 68.85 & 85.75 \\
\hline & & & OGE & 15.95 & 23.9 & 31.8 & 39.7 & 55.55 & 75.35 & 95.05 & 114.8 \\
\hline & & \multirow{2}{*}{ Weight } & IGE & 8.3 & 13.05 & 18.05 & 23.35 & 34.6 & 49.7 & 65.85 & 82.85 \\
\hline & & & OGE & 15.95 & 23.9 & 31.8 & 39.7 & 55.55 & 75.35 & 95.05 & 114.8 \\
\hline & & \multirow{2}{*}{ Speed } & IGE & 9.1 & 14.15 & 19.45 & 25 & 36.65 & 52.05 & 68.3 & 85.25 \\
\hline & & & OGE & 15.95 & 23.9 & 31.8 & 39.7 & 55.5 & 75.3 & 95.05 & 114.8 \\
\hline & & \multirow{2}{*}{ Wingspan } & IGE & 9.35 & 14.45 & 19.8 & 25.35 & 37 & 52.3 & 68.25 & 84.85 \\
\hline & & & OGE & 15.75 & 23.7 & 31.65 & 39.55 & 55.35 & 75.15 & 94.85 & 114.6 \\
\hline & & \multirow{2}{*}{ Wind } & IGE & 7.7 & 11.8 & 16.1 & 20.5 & 29.7 & 41.7 & 54.05 & 66.8 \\
\hline & & & OGE & 11.85 & 17.8 & 23.75 & 29.65 & 41.5 & 56.35 & 71.15 & 86 \\
\hline & & \multirow{2}{*}{ EDR } & IGE & 9.4 & 14.6 & 20.05 & 25.75 & 37.8 & 54 & 71.45 & 90.15 \\
\hline & & & OGE & 15.95 & 23.9 & 31.8 & 39.7 & 55.55 & 75.35 & 95.05 & 114.8 \\
\hline
\end{tabular}

Table 16. Wake age data IGE and OGE at various lateral offset distances for the Super weight class aircraft

\begin{tabular}{|c|c|c|c|c|c|c|c|c|c|c|c|}
\hline \multirow{2}{*}{$\begin{array}{c}\text { Weight } \\
\text { Class }\end{array}$} & \multirow{2}{*}{ Aircraft ID } & \multirow{2}{*}{ Sensitivity } & \multirow{2}{*}{$\begin{array}{c}\text { Altitude } \\
\text { Region }\end{array}$} & \multicolumn{8}{|c|}{ Wake Age (s) at Offset Distances (ft) } \\
\hline & & & & 500 & 700 & 900 & 1100 & 1500 & 2000 & 2500 & 3000 \\
\hline \multirow{12}{*}{ Super } & \multirow{12}{*}{ A380 } & \multirow{2}{*}{ Nominal } & IGE & 7.55 & 11.9 & 16.5 & 21.4 & 31.75 & 45.6 & 60.4 & $\overline{776}$ \\
\hline & & & OGE & 15.2 & 23.15 & 31.05 & 38.95 & 54.8 & 74.6 & 94.3 & 114.05 \\
\hline & & \multirow[b]{2}{*}{ Weight } & IGE & 7.35 & 11.6 & 16.15 & 20.95 & 31.2 & 45 & 59.7 & 75.25 \\
\hline & & & OGE & 15.2 & 23.15 & 31.05 & 38.95 & 54.8 & 74.6 & 94.3 & 114.05 \\
\hline & & \multirow{2}{*}{ Speed } & IGE & 7.1 & 11.25 & 15.7 & 20.4 & 31.15 & 44.05 & 59.65 & 75.2 \\
\hline & & & OGE & 15.2 & 23.15 & 31.05 & 38.95 & 54.8 & 74.6 & 94.3 & 114.05 \\
\hline & & \multirow{2}{*}{ Wingspan } & IGE & 7.6 & 11.95 & 16.55 & 21.4 & 31.65 & 45.35 & 59.9 & 75.15 \\
\hline & & & OGE & 15 & 22.9 & 30.85 & 38.75 & 54.6 & 74.4 & 94.1 & 113.85 \\
\hline & & \multirow{2}{*}{ Wind } & IGE & 6.4 & 10 & 13.8 & 17.75 & 26 & 36.95 & 48.4 & 60.3 \\
\hline & & & OGE & 11.25 & 17.2 & 23.15 & 29.1 & 40.95 & 55.8 & 70.6 & 85.45 \\
\hline & & \multirow{2}{*}{ EDR } & IGE & 7.6 & 12.05 & 16.75 & 21.75 & 32.3 & 46.65 & 62.35 & 79.3 \\
\hline & & & OGE & 15.2 & 23.15 & 31.05 & 38.95 & 54.8 & 74.6 & 94.3 & 114.05 \\
\hline
\end{tabular}


2. Circulation Strength Scenario Results

Table 17. Circulation strength data IGE and OGE at various lateral offset distances for the Small weight class aircraft (nominal and sensitivity scenarios).

\begin{tabular}{|c|c|c|c|c|c|c|c|c|c|c|c|}
\hline \multirow{2}{*}{$\begin{array}{l}\text { Weight } \\
\text { Class }\end{array}$} & \multirow{2}{*}{ Aircraft ID } & \multirow{2}{*}{ Sensitivity } & \multirow{2}{*}{$\begin{array}{l}\text { Altitude } \\
\text { Region }\end{array}$} & \multicolumn{8}{|c|}{ Circulation Strength $\left(\mathrm{m}^{\wedge} 2 / \mathrm{s}\right)$ at Offset Distances (ft) } \\
\hline & & & & 500 & 700 & 900 & 1100 & 1500 & 2000 & 2500 & 3000 \\
\hline \multirow{36}{*}{ Small } & \multirow{12}{*}{ B190 } & \multirow{2}{*}{ Nominal } & \multirow{2}{*}{$\begin{array}{l}\text { IGE } \\
\text { OGE }\end{array}$} & 50.6 & 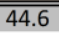 & 39.4 & 34.1 & 23.2 & 9.2 & $\overline{-1}$ & 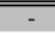 \\
\hline & & & & 56.7 & 53.2 & 49.9 & 46.8 & 41.0 & 34.6 & 29.2 & 24.4 \\
\hline & & \multirow{2}{*}{ Weight } & \multirow{2}{*}{$\begin{array}{l}\text { IGE } \\
\text { OGE }\end{array}$} & 58.0 & 50.3 & 42.9 & 35.2 & 19.6 & - & - & - \\
\hline & & & & 67.1 & 62.6 & 58.4 & 54.4 & 47.2 & 39.3 & 32.6 & 26.8 \\
\hline & & \multirow{2}{*}{ Speed } & \multirow{2}{*}{$\begin{array}{l}\text { IGE } \\
\text { OGE }\end{array}$} & 54.0 & 47.1 & 40.8 & 34.3 & 21.0 & - & - & - \\
\hline & & & & 62.0 & 58.0 & 54.3 & 50.7 & 44.2 & 37.1 & 31.0 & 25.7 \\
\hline & & \multirow{2}{*}{ Wingspan } & \multirow{2}{*}{$\begin{array}{l}\text { IGE } \\
\text { OGE }\end{array}$} & 50.5 & 44.9 & 40.5 & 36.2 & 27.3 & 15.9 & - & - \\
\hline & & & & 54.6 & 51.5 & 48.5 & 45.7 & 40.4 & 34.6 & 29.5 & 25.1 \\
\hline & & \multirow{2}{*}{ Wind } & \multirow{2}{*}{$\begin{array}{l}\text { IGE } \\
\text { OGE }\end{array}$} & 55.5 & 48.1 & 45.2 & 41.0 & 32.5 & 21.7 & 12.0 & - \\
\hline & & & & 58.9 & 56.2 & 53.5 & 51.0 & 46.3 & 40.9 & 36.1 & 31.8 \\
\hline & & \multirow{2}{*}{ EDR } & \multirow{2}{*}{$\begin{array}{l}\text { IGE } \\
\text { OGE }\end{array}$} & 44.7 & 33.7 & 22.3 & 10.5 & - & - & - & - \\
\hline & & & & 43.5 & 36.3 & 30.2 & 25.1 & 17.0 & 10.1 & 5.6 & - \\
\hline & & \multirow{2}{*}{ Nominal } & \multirow{2}{*}{$\begin{array}{l}\text { IGE } \\
\text { OGE }\end{array}$} & 51.5 & 45.0 & 38.9 & 32.7 & 20.1 & - & - & - \\
\hline & & & & 58.7 & 54.9 & 51.3 & 47.9 & 41.7 & 35.0 & 29.1 & 24.1 \\
\hline & & \multirow{2}{*}{ Weight } & \multirow{2}{*}{$\begin{array}{l}\text { IGE } \\
\text { OGE }\end{array}$} & 59.1 & 50.4 & 41.7 & 32.7 & 14.1 & - & - & - \\
\hline & & & & 69.8 & 64.9 & 60.2 & 55.9 & 48.1 & 39.6 & 32.4 & 26.4 \\
\hline & & \multirow{2}{*}{ Speed } & IGE & 55.1 & 47.7 & 40.6 & 33.3 & 18.2 & - & - & - \\
\hline & C560 & & OGE & 63.7 & 59.4 & 55.3 & 51.5 & 44.6 & 37.1 & 30.7 & 25.2 \\
\hline & & Wingspan & IGE & 51.5 & 45.5 & 40.5 & 35.5 & 25.2 & 12.5 & - & - \\
\hline & & wingspan & OGE & 56.6 & 53.2 & 50.0 & 46.9 & 41.3 & 35.1 & 29.7 & 24.9 \\
\hline & & Wind & IGE & 54.4 & 48.7 & 44.0 & 39.6 & 30.7 & 19.2 & 7.6 & - \\
\hline & & Wind & OGE & 61.1 & 58.1 & 55.3 & 52.5 & 47.4 & 41.6 & 36.5 & 31.9 \\
\hline & & & IGE & 45.8 & 33.8 & 21.5 & 8.6 & - & - & - & - \\
\hline & & EDR & OGE & 44.7 & 37.1 & 30.7 & 25.3 & 16.9 & 9.8 & - & - \\
\hline & & Nominal & IGE & 73.0 & 63.4 & 54.3 & 44.8 & 25.3 & - & - & - \\
\hline & & Nominal & OGE & 83.4 & 77.9 & 72.7 & 67.9 & 59.0 & 49.4 & 41.1 & 34.0 \\
\hline & & & IGE & 87.4 & 73.2 & 58.6 & 43.2 & 12.7 & - & - & - \\
\hline & & Weight & OGE & 104.0 & 96.2 & 89.0 & 82.4 & 70.3 & 57.4 & 46.5 & 37.4 \\
\hline & & Sneed & IGE & 77.8 & 66.8 & 56.1 & 44.9 & 21.8 & - & - & - \\
\hline & $C 750$ & speed & OGE & 90.4 & 84.2 & 78.3 & 72.9 & 63.0 & 52.2 & 43.1 & 35.3 \\
\hline & C/50 & Wingspan & IGE & 72.9 & 64.2 & 56.7 & 49.1 & 33.3 & 12.7 & - & - \\
\hline & & wingspan & OGE & 80.5 & 75.6 & 71.0 & 66.6 & 58.6 & 49.7 & 42.0 & 35.3 \\
\hline & & & IGE & 76.6 & 68.2 & 61.4 & 54.6 & 40.9 & 23.1 & - & - \\
\hline & & Wind & OGE & 86.8 & 82.6 & 78.4 & 74.5 & 67.2 & 58.9 & 51.6 & 45.0 \\
\hline & & $\mathbf{E}$ & IGE & 67.9 & 52.3 & 36.1 & 19.1 & - & - & - & - \\
\hline & & EUK & OGE & 64.8 & 54.2 & 45.2 & 37.6 & 25.6 & 15.3 & 8.5 & - \\
\hline
\end{tabular}

Table 18. Circulation strength data IGE and OGE at various lateral offset distances for the Large weight class aircraft (nominal and sensitivity scenarios).

\begin{tabular}{|c|c|c|c|c|c|c|c|c|c|c|c|}
\hline \multirow{2}{*}{$\begin{array}{c}\text { Weight } \\
\text { Class }\end{array}$} & \multirow{2}{*}{ Aircraft ID } & \multirow{2}{*}{ Sensitivity } & \multirow{2}{*}{$\begin{array}{c}\text { Altitude } \\
\text { Region }\end{array}$} & \multicolumn{8}{|c|}{ Circulation Strength $\left(\mathrm{m}^{\wedge} 2 / \mathrm{s}\right)$ at Offset Distances ( $\mathrm{ft}$ ) } \\
\hline & & & & 500 & 700 & 900 & 1100 & 1500 & 2000 & 2500 & 3000 \\
\hline \multirow{24}{*}{ Large } & \multirow{12}{*}{ CRJ2 } & \multirow{2}{*}{ Nominal } & IGE & 90.9 & 79.1 & 68.1 & 56.5 & 32.3 & 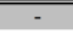 & 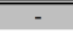 & 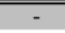 \\
\hline & & & OGE & 104.7 & 97.7 & 91.2 & 85.1 & 73.9 & 61.8 & 51.4 & 42.4 \\
\hline & & \multirow{2}{*}{ Weight } & IGE & 114.8 & 95.2 & 74.4 & 52.2 & - & - & - & - \\
\hline & & & OGE & 140.0 & 129.1 & 118.8 & 109.4 & 92.5 & 74.6 & 59.8 & 47.4 \\
\hline & & \multirow{2}{*}{ Speed } & IGE & 98.6 & 84.9 & 71.4 & 56.1 & 27.9 & - & - & - \\
\hline & & & OGE & 112.7 & 104.9 & 97.6 & 90.8 & 78.4 & 65.0 & 53.6 & 43.9 \\
\hline & & \multirow{2}{*}{ Wingspan } & IGE & 90.3 & 79.5 & 70.4 & 61.0 & 41.6 & 15.7 & - & - \\
\hline & & & OGE & 101.0 & 94.9 & 89.0 & 83.6 & 73.5 & 62.3 & 52.6 & 44.2 \\
\hline & & \multirow{2}{*}{ Wind } & IGE & 95.4 & 84.9 & 76.3 & 67.9 & 50.5 & 27.9 & - & - \\
\hline & & & OGE & 108.9 & 103.5 & 98.3 & 93.4 & 84.2 & 73.7 & 64.5 & 56.2 \\
\hline & & \multirow{2}{*}{ EDR } & IGE & 86.0 & 68.7 & 50.3 & 30.8 & - & - & - & - \\
\hline & & & OGE & 82.5 & 69.3 & 58.1 & 48.6 & 33.6 & 20.4 & 11.6 & 5.7 \\
\hline & \multirow{12}{*}{ B737 } & \multirow{2}{*}{ Nominal } & IGE & 206.0 & 184.1 & 166.3 & 150.4 & 117.4 & 72.7 & 24.9 & - \\
\hline & & & OGE & 218.3 & 207.0 & 196.3 & 186.0 & 166.9 & 145.3 & 126.2 & 109.2 \\
\hline & & \multirow{2}{*}{ Weight } & IGE & 220.2 & 196.1 & 176.4 & 158.4 & 120.2 & 68.2 & 12.1 & - \\
\hline & & & OGE & 234.1 & 221.5 & 209.6 & 198.3 & 177.1 & 153.4 & 132.5 & 114.0 \\
\hline & & \multirow{2}{*}{ Speed } & IGE & 225.9 & 201.0 & 180.5 & 156.9 & 118.6 & 65.9 & - & - \\
\hline & & & OGE & 235.4 & 222.7 & 210.7 & 199.3 & 178.0 & 154.1 & 133.1 & 114.4 \\
\hline & & \multirow{2}{*}{ Wingspan } & IGE & 203.6 & 183.5 & 167.3 & 153.5 & 126.8 & 90.8 & 52.7 & 12.5 \\
\hline & & & OGE & 210.0 & 199.9 & 190.3 & 181.1 & 163.9 & 144.2 & 126.7 & 110.9 \\
\hline & & \multirow{2}{*}{ Wind } & IGE & 212.3 & 192.4 & 176.6 & 163.0 & 138.5 & 106.4 & 72.8 & 38.0 \\
\hline & & & OGE & 225.0 & 216.2 & 207.8 & 199.7 & 184.2 & 166.4 & 150.1 & 135.1 \\
\hline & & \multirow{2}{*}{ EDR } & IGE & 199.5 & 176.6 & 153.1 & 128.1 & 73.9 & - & - & - \\
\hline & & & OGE & 184.6 & 162.1 & 142.3 & 124.8 & 95.2 & 66.9 & 46.0 & 30.4 \\
\hline
\end{tabular}


Table 19. Circulation strength data IGE and OGE at various lateral offset distances for the 757 weight class aircraft (nominal and sensitivity scenarios).

\begin{tabular}{|c|c|c|c|c|c|c|c|c|c|c|c|}
\hline \multirow{2}{*}{$\begin{array}{c}\text { Weight } \\
\text { Class }\end{array}$} & \multirow{2}{*}{ Aircraft ID } & \multirow{2}{*}{ Sensitivity } & \multirow{2}{*}{$\begin{array}{c}\text { Altitude } \\
\text { Region }\end{array}$} & \multicolumn{8}{|c|}{ Circulation Strength $\left(\mathrm{m}^{\wedge} 2 / \mathrm{s}\right)$ at Offset Distances $(\mathrm{ft})$} \\
\hline & & & & 500 & 700 & 900 & 1100 & 1500 & 2000 & 2500 & 3000 \\
\hline \multirow{12}{*}{757} & \multirow{12}{*}{ B752 } & \multirow{2}{*}{ Nominal } & IGE & 270.6 & 240.4 & 215.9 & 193.1 & 144.5 & 78.7 & $\overline{-1}$ & $\overline{-1}$ \\
\hline & & & OGE & 295.3 & 279.7 & 265.0 & 250.9 & 224.2 & 194.5 & 168.5 & 145.2 \\
\hline & & \multirow{2}{*}{ Weight } & IGE & 294.1 & 259.9 & 231.9 & 204.0 & 144.9 & 63.9 & - & - \\
\hline & & & OGE & 324.3 & 306.2 & 289.3 & 273.1 & 242.5 & 208.8 & 179.4 & 153.3 \\
\hline & & \multirow{2}{*}{ Speed } & IGE & 290.7 & 256.9 & 229.5 & 202.5 & 145.1 & 66.6 & - & - \\
\hline & & & OGE & 317.2 & 299.7 & 283.2 & 267.4 & 238.1 & 205.5 & 176.7 & 151.3 \\
\hline & & \multirow{2}{*}{ Wingspan } & IGE & 266.9 & 239.3 & 217.1 & 197.7 & 158.7 & 105.9 & 49.9 & - \\
\hline & & & OGE & 284.3 & 270.4 & 257.3 & 244.7 & 220.6 & 193.7 & 169.8 & 148.2 \\
\hline & & \multirow{2}{*}{ Wind } & IGE & 292.5 & 263.2 & 239.9 & 219.8 & 176.3 & 129.0 & 74.5 & 17.4 \\
\hline & & & OGE & 304.6 & 292.5 & 280.8 & 269.6 & 248.3 & 223.6 & 201.2 & 180.6 \\
\hline & & \multirow{2}{*}{ EDR } & IGE & 264.3 & 233.4 & 202.9 & 170.4 & 100.6 & - & - & - \\
\hline & & & OGE & 252.8 & 222.9 & 196.9 & 173.2 & 133.0 & 94.5 & 66.1 & 44.5 \\
\hline
\end{tabular}

Table 20. Circulation strength data IGE and OGE at various lateral offset distances for the Heavy weight class aircraft (nominal and sensitivity scenarios).

\begin{tabular}{|c|c|c|c|c|c|c|c|c|c|c|c|}
\hline \multirow{2}{*}{$\begin{array}{c}\text { Weight } \\
\text { Class } \\
\end{array}$} & \multirow{2}{*}{ Aircraft ID } & \multirow{2}{*}{ Sensitivity } & \multirow{2}{*}{$\begin{array}{c}\text { Altitude } \\
\text { Region }\end{array}$} & \multicolumn{8}{|c|}{ Circulation Strength $\left(\mathrm{m}^{\wedge} 2 / \mathrm{s}\right)$ at Offset Distances ( $\mathrm{ft}$ ) } \\
\hline & & & & 500 & 700 & 900 & 1100 & 1500 & 2000 & 2500 & 3000 \\
\hline \multirow{24}{*}{ Heavy } & \multirow{12}{*}{ B763 } & \multirow{2}{*}{ Nominal } & IGE & 297.7 & 270.6 & 249.4 & 231.3 & 200.7 & 161.9 & 121.2 & 78.6 \\
\hline & & & OGE & 304.1 & 291.7 & 279.6 & 268.0 & 246.1 & 220.7 & 197.6 & 176.5 \\
\hline & & \multirow{2}{*}{ Weight } & IGE & 357.0 & 321.9 & 294.0 & 270.2 & 226.1 & 167.0 & 104.0 & 36.9 \\
\hline & & & OGE & 372.9 & 356.2 & 340.0 & 324.6 & 295.5 & 262.2 & 232.2 & 205.0 \\
\hline & & \multirow{2}{*}{ Speed } & IGE & 323.4 & 293.1 & 269.2 & 248.6 & 212.8 & 166.0 & 116.4 & 64.3 \\
\hline & & & OGE & 326.6 & 312.8 & 299.4 & 286.7 & 262.5 & 234.6 & 209.3 & 186.3 \\
\hline & & \multirow{2}{*}{ Wingspan } & IGE & 292.2 & 266.8 & 247.5 & 231.0 & 203.8 & 172.3 & 139.5 & 105.3 \\
\hline & & & OGE & 291.6 & 280.3 & 269.5 & 259.1 & 239.2 & 216.1 & 195.0 & 175.5 \\
\hline & & \multirow{2}{*}{ Wind } & IGE & 319.0 & 291.6 & 271.1 & 254.0 & 225.3 & 194.1 & 161.6 & 128.2 \\
\hline & & & OGE & 311.1 & 301.6 & 292.2 & 283.2 & 265.7 & 245.2 & 226.2 & 208.2 \\
\hline & & \multirow{2}{*}{ EDR } & IGE & 284.2 & 256.9 & 232.6 & 207.2 & 152.9 & 79.4 & - & - \\
\hline & & & OGE & 266.5 & 240.4 & 216.4 & 194.8 & 157.2 & 119.1 & 89.2 & 65.5 \\
\hline & \multirow{12}{*}{ B744 } & \multirow{2}{*}{ Nominal } & IGE & 441.6 & 400.2 & 373.2 & 350.8 & 313.9 & 276.1 & 238.6 & 199.6 \\
\hline & & & OGE & 418.0 & 403.9 & 390.1 & 376.8 & 351.2 & 321.2 & 293.4 & 267.5 \\
\hline & & \multirow{2}{*}{ Weight } & IGE & 553.1 & 502.6 & 465.6 & 434.3 & 382.1 & 322.8 & 259.5 & 192.8 \\
\hline & & & OGE & 541.2 & 521.0 & 501.5 & 482.7 & 446.6 & 404.7 & 366.3 & 330.8 \\
\hline & & \multirow{2}{*}{ Speed } & IGE & 462.1 & 419.9 & 390.8 & 366.6 & 326.5 & 284.8 & 242.3 & 197.9 \\
\hline & & & OGE & 445.8 & 430.3 & 415.4 & 400.9 & 373.1 & 340.6 & 310.5 & 282.5 \\
\hline & & \multirow{2}{*}{ Wingspan } & IGE & 430.9 & 391.4 & 366.0 & 345.6 & 312.2 & 278.6 & 248.7 & 217.8 \\
\hline & & & OGE & 398.3 & 385.6 & 373.2 & 361.2 & 338.1 & 310.8 & 285.4 & 261.6 \\
\hline & & \multirow{2}{*}{ Wind } & IGE & 453.2 & 414.5 & 388.3 & 367.7 & 334.0 & 300.1 & 271.5 & 242.5 \\
\hline & & & OGE & 425.4 & 414.7 & 404.1 & 393.8 & 373.8 & 349.9 & 327.3 & 305.9 \\
\hline & & \multirow{2}{*}{ EDR } & IGE & 417.9 & 376.7 & 349.3 & 322.6 & 266.3 & 190.5 & 108.9 & 21.5 \\
\hline & & & OGE & 376.5 & 345.4 & 316.8 & 290.3 & 243.1 & 193.7 & 153.1 & 119.7 \\
\hline
\end{tabular}

Table 21. Circulation strength data IGE and OGE at various lateral offset distances for the Super weight class aircraft (nominal and sensitivity scenarios).

\begin{tabular}{|c|c|c|c|c|c|c|c|c|c|c|c|}
\hline \multirow{2}{*}{$\begin{array}{c}\text { Weight } \\
\text { Class } \\
\end{array}$} & \multirow{2}{*}{ Aircraft ID } & \multirow{2}{*}{ Sensitivity } & \multirow{2}{*}{$\begin{array}{c}\text { Altitude } \\
\text { Region } \\
\end{array}$} & \multicolumn{8}{|c|}{ Circulation Strength $\left(\mathrm{m}^{\wedge} 2 / \mathrm{s}\right)$ at Offset Distances $(\mathrm{ft})$} \\
\hline & & & & 500 & 700 & 900 & 1100 & 1500 & 2000 & 2500 & 3000 \\
\hline \multirow{12}{*}{ Super } & \multirow{12}{*}{ A380 } & \multirow{2}{*}{ Nominal } & IGE & 682.2 & 621.9 & 580.6 & 547.2 & 492.6 & 437.3 & 386.9 & 333.8 \\
\hline & & & OGE & 625.1 & 605.1 & 585.7 & 566.8 & 530.3 & 487.4 & 447.5 & 410.2 \\
\hline & & \multirow{2}{*}{ Weight } & IGE & 715.4 & 649.6 & 605.7 & 570.1 & 511.6 & 452.0 & 396.4 & 337.5 \\
\hline & & & OGE & 658.4 & 637.0 & 616.2 & 595.9 & 556.8 & 510.9 & 468.4 & 428.6 \\
\hline & & \multirow{2}{*}{ Speed } & IGE & 755.3 & 684.8 & 638.0 & 600.2 & 521.4 & 473.6 & 402.5 & 341.3 \\
\hline & & & OGE & 671.4 & 649.3 & 628.0 & 607.1 & 567.0 & 520.0 & 476.4 & 435.7 \\
\hline & & \multirow{2}{*}{ Wingspan } & IGE & 653.1 & 610.8 & 570.2 & 539.2 & 489.4 & 439.1 & 396.4 & 353.7 \\
\hline & & & OGE & 597.8 & 579.7 & 562.0 & 544.9 & 511.8 & 472.7 & 436.2 & 401.8 \\
\hline & & \multirow{2}{*}{ Wind } & IGE & 683.3 & 644.5 & 601.5 & 569.9 & 519.7 & 469.2 & 427.0 & 386.9 \\
\hline & & & OGE & 635.0 & 620.0 & 605.1 & 590.4 & 562.1 & 528.1 & 495.8 & 465.1 \\
\hline & & \multirow{2}{*}{ EDR } & IGE & 658.6 & 591.5 & 549.9 & 516.1 & 449.8 & 359.5 & 260.8 & 154.2 \\
\hline & & & OGE & 572.4 & 529.3 & 489.5 & 452.3 & 385.1 & 313.6 & 253.9 & 203.8 \\
\hline
\end{tabular}


3. Wake Altitude Change Scenario Results

Table 22. Wake altitude change data IGE and OGE at various lateral offset distances for Small weight class aircraft (nominal and sensitivity scenarios).

\begin{tabular}{|c|c|c|c|c|c|c|c|c|c|c|c|}
\hline \multirow{2}{*}{$\begin{array}{l}\text { Weight } \\
\text { Class }\end{array}$} & \multirow{2}{*}{ Aircraft ID } & \multirow{2}{*}{ Sensitivity } & \multirow{2}{*}{$\begin{array}{c}\text { Altitude } \\
\text { Region }\end{array}$} & \multicolumn{8}{|c|}{ Wake Altitude Change ( $\mathrm{ft}$ ) at Offset Distances ( $\mathrm{ft}$ ) } \\
\hline & & & & 500 & 700 & 900 & 1100 & 1500 & 2000 & 2500 & 3000 \\
\hline \multirow{36}{*}{ Small } & \multirow{12}{*}{ B190 } & \multirow{2}{*}{ Nominal } & IGE & 3.3 & 4.7 & 6.0 & 7.2 & 9.0 & 10.4 & - & - \\
\hline & & & OGE & -43.4 & -59.9 & -75.3 & -89.6 & -115.8 & -144.0 & -167.6 & -187.5 \\
\hline & & \multirow{2}{*}{ Weight } & IGE & 3.8 & 5.4 & 6.8 & 8.0 & 9.9 & - & - & - \\
\hline & & & OGE & -51.7 & -71.1 & -89.1 & -105.9 & -136.2 & -168.3 & -194.9 & -217.0 \\
\hline & & \multirow{2}{*}{ Speed } & IGE & 3.5 & 5.1 & 6.4 & 7.6 & 9.4 & - & - & - \\
\hline & & & OGE & -47.6 & -65.6 & -82.3 & -97.9 & -126.2 & -156.4 & -181.6 & -202.7 \\
\hline & & \multirow{2}{*}{ Wingspan } & IGE & 2.9 & 4.2 & 5.3 & 6.4 & 8.3 & 9.9 & - & - \\
\hline & & & OGE & -39.5 & -54.6 & -68.9 & -82.1 & -106.6 & -133.2 & -155.8 & -175.1 \\
\hline & & \multirow{2}{*}{ Wind } & IGE & 2.5 & 3.8 & 4.8 & 5.8 & 7.6 & 9.2 & 10.7 & - \\
\hline & & & OGE & -33.2 & -46.1 & -58.4 & -70.0 & -91.8 & -116.1 & -137.5 & -156.5 \\
\hline & & \multirow{2}{*}{ EDR } & IGE & 3.1 & 4.3 & 5.2 & 5.7 & - & - & - & - \\
\hline & & & OGE & -38.3 & -50.2 & -60.1 & -68.3 & -80.7 & -90.7 & -96.4 & - \\
\hline & \multirow{12}{*}{ C560 } & \multirow{2}{*}{ Nominal } & IGE & 3.5 & 5.0 & 6.4 & 7.6 & 9.4 & - & - & - \\
\hline & & & OGE & -46.5 & -63.9 & -80.3 & -95.4 & -122.8 & -152.1 & -176.6 & -196.9 \\
\hline & & \multirow{2}{*}{ Weight } & IGE & 4.1 & 5.8 & 7.3 & 8.5 & 10.2 & - & - & - \\
\hline & & & OGE & -55.7 & -76.3 & -95.6 & -113.3 & -145.1 & -178.6 & -206.1 & -228.5 \\
\hline & & \multirow{2}{*}{ Speed } & IGE & 3.8 & 5.4 & 6.9 & 8.2 & 10.0 & - & - & - \\
\hline & & & OGE & -50.6 & -69.4 & -87.0 & -103.4 & -132.7 & -164.0 & -189.8 & -211.1 \\
\hline & & \multirow{2}{*}{ Wingspan } & IGE & 3.1 & 4.5 & 5.7 & 6.8 & 8.7 & 10.9 & - & - \\
\hline & & & OGE & -42.3 & -58.3 & -73.4 & -87.6 & -113.2 & -141.0 & -164.6 & -184.4 \\
\hline & & \multirow{2}{*}{ Wind } & IGE & 2.9 & 4.1 & 5.3 & 6.3 & 8.2 & 9.9 & 10.8 & - \\
\hline & & & OGE & -35.5 & -49.2 & -62.3 & -74.7 & -97.6 & -123.2 & -145.5 & -165.1 \\
\hline & & \multirow{2}{*}{ EDR } & IGE & 3.3 & 4.6 & 5.5 & 6.1 & - & - & - & - \\
\hline & & & OGE & -40.9 & -53.4 & -63.8 & -72.3 & -85.1 & -95.1 & - & - \\
\hline & \multirow{12}{*}{ C750 } & \multirow{2}{*}{ Nominal } & IGE & 3.5 & 5.1 & 6.6 & 7.8 & 9.7 & - & - & - \\
\hline & & & OGE & -57.8 & -79.7 & -100.1 & -119.0 & -153.2 & -189.8 & -220.1 & -245.4 \\
\hline & & \multirow{2}{*}{ Weight } & IGE & 4.2 & 6.0 & 7.6 & 8.9 & 11.2 & - & - & - \\
\hline & & & OGE & -72.8 & -99.9 & -125.0 & -148.0 & -189.2 & -232.2 & -267.0 & -295.2 \\
\hline & & \multirow{2}{*}{ Speed } & IGE & 3.8 & 5.5 & 7.0 & 8.3 & 10.1 & - & - & - \\
\hline & & & OGE & -62.8 & -86.5 & -108.5 & -128.8 & -165.5 & -204.3 & -236.3 & -262.6 \\
\hline & & Wingsnan & IGE & 3.1 & 4.5 & 5.9 & 7.1 & 9.0 & 10.4 & - & - \\
\hline & & Wingspan & OGE & -52.6 & -72.8 & -91.7 & -109.2 & -141.5 & -176.2 & -205.5 & -230.3 \\
\hline & & Wind & IGE & 3.0 & 4.3 & 5.5 & 6.6 & 8.5 & 10.2 & - & - \\
\hline & & Wind & OGE & -44.1 & -61.3 & -77.7 & -93.2 & -121.8 & -153.7 & -181.6 & -206.0 \\
\hline & & E & IGE & 3.4 & 4.9 & 6.0 & 6.7 & - & - & - & - \\
\hline & & EDK & OGE & -51.3 & -67.4 & -80.8 & -91.9 & -108.8 & -122.4 & -130.2 & - \\
\hline
\end{tabular}

Table 23. Wake altitude change data IGE and OGE at various lateral offset distances for Large weight class aircraft (nominal and sensitivity scenarios).

\begin{tabular}{|c|c|c|c|c|c|c|c|c|c|c|c|}
\hline \multirow{2}{*}{$\begin{array}{c}\text { Weight } \\
\text { Class }\end{array}$} & \multirow{2}{*}{ Aircraft ID } & \multirow{2}{*}{ Sensitivity } & \multirow{2}{*}{$\begin{array}{l}\text { Altitude } \\
\text { Region }\end{array}$} & \multicolumn{8}{|c|}{ Wake Altitude Change (ft) at Offset Distances (ft) } \\
\hline & & & & 500 & 700 & 900 & 1100 & 1500 & 2000 & 2500 & 3000 \\
\hline \multirow{24}{*}{ Large } & \multirow{12}{*}{ CRJ2 } & \multirow{2}{*}{ Nominal } & "IGE & 3.4 & 40.9 & " & "7.5 & 9.4 & - & - & - \\
\hline & & & OGE & -66.2 & -91.4 & -114.9 & -136.8 & -176.1 & -218.1 & -252.9 & -281.9 \\
\hline & & \multirow{2}{*}{ Weight } & IGE & 4.0 & 5.9 & 7.5 & 8.7 & - & - & - & - \\
\hline & & & OGE & -89.9 & -123.4 & -154.3 & -182.6 & -232.5 & -284.1 & -325.5 & -358.6 \\
\hline & & \multirow{2}{*}{ Speed } & IGE & 3.4 & 5.1 & 6.5 & 8.5 & 10.3 & - & - & - \\
\hline & & & OGE & -71.5 & -98.6 & -123.8 & -147.1 & -188.9 & -233.3 & -269.8 & -300.0 \\
\hline & & \multirow{2}{*}{ Wingspan } & IGE & 3.0 & 4.3 & 5.6 & 6.7 & 8.6 & 10.1 & - & - \\
\hline & & & OGE & -60.3 & -83.5 & -105.3 & -125.7 & -162.6 & -202.7 & -236.4 & -264.9 \\
\hline & & \multirow{2}{*}{ Wind } & IGE & 2.8 & 4.1 & 5.3 & 6.4 & 8.3 & 9.9 & - & - \\
\hline & & & OGE & -50.6 & -70.5 & -89.3 & -107.0 & -140.1 & -176.8 & -208.7 & -236.7 \\
\hline & & \multirow{2}{*}{ EDR } & IGE & 3.3 & 4.7 & 5.8 & 6.7 & - & - & - & - \\
\hline & & & OGE & -59.1 & -78.0 & -93.8 & -107.0 & -127.1 & -143.6 & -153.3 & -158.6 \\
\hline & \multirow{12}{*}{ B737 } & \multirow{2}{*}{ Nominal } & IGE & 3.2 & 4.9 & 6.5 & 8.1 & 10.9 & 13.6 & 15.1 & - \\
\hline & & & OGE & -80.7 & -113.5 & -144.3 & -173.6 & -227.7 & -287.5 & -339.2 & -384.2 \\
\hline & & \multirow{2}{*}{ Weight } & IGE & 3.3 & 5.1 & 6.8 & 8.4 & 11.3 & 14.1 & 15.3 & - \\
\hline & & & OGE & -86.7 & -121.8 & -154.8 & -186.0 & -243.5 & -306.8 & -361.3 & -408.4 \\
\hline & & \multirow{2}{*}{ Speed } & IGE & 3.2 & 5.0 & 6.8 & 9.0 & 12.0 & 14.1 & - & - \\
\hline & & & OGE & -87.3 & -122.5 & -155.7 & -187.1 & -244.9 & -308.5 & -363.2 & -410.5 \\
\hline & & \multirow{2}{*}{ Wingspan } & IGE & 2.8 & 4.3 & 5.7 & 7.2 & 9.8 & 12.5 & 14.4 & 15.4 \\
\hline & & & OGE & -73.2 & -103.3 & -131.9 & -158.9 & -209.2 & -265.4 & -314.6 & -357.9 \\
\hline & & \multirow{2}{*}{ Wind } & IGE & 2.7 & 4.1 & 5.4 & 6.8 & 9.2 & 11.9 & 13.9 & 15.2 \\
\hline & & & OGE & -61.4 & -86.8 & -111.3 & -134.5 & -178.8 & -229.2 & -274.3 & -315.3 \\
\hline & & \multirow{2}{*}{ EDR } & IGE & 3.1 & 4.8 & 6.3 & 7.7 & 10.0 & - & - & - \\
\hline & & & OGE & -74.4 & -101.1 & -124.4 & -144.8 & -178.4 & -209.2 & -230.5 & -245.0 \\
\hline
\end{tabular}

19

American Institute of Aeronautics and Astronautics 
Table 24. Wake altitude change data IGE and OGE at various lateral offset distances for 757 weight class aircraft (nominal and sensitivity scenarios).

\begin{tabular}{|c|c|c|c|c|c|c|c|c|c|c|c|}
\hline \multirow{2}{*}{$\begin{array}{c}\text { Weight } \\
\text { Class }\end{array}$} & \multirow{2}{*}{ Aircraft ID } & \multirow{2}{*}{ Sensitivity } & \multirow{2}{*}{$\begin{array}{c}\text { Altitude } \\
\text { Region }\end{array}$} & \multicolumn{8}{|c|}{ Wake Altitude Change (ft) at Offset Distances (ft) } \\
\hline & & & & 500 & 700 & 900 & 1100 & 1500 & 2000 & 2500 & 3000 \\
\hline \multirow{12}{*}{757} & \multirow{12}{*}{ B752 } & \multirow{2}{*}{ Nominal } & IGE & 4.5 & 6.8 & 9.1 & 11.3 & 15.1 & 18.6 & - & - \\
\hline & & & OGE & -98.0 & -138.0 & -174.9 & -210.5 & -276.9 & -349.2 & -411.1 & -465.2 \\
\hline & & \multirow{2}{*}{ Weight } & IGE & 4.7 & 7.2 & 9.6 & 12.0 & 16.0 & 19.2 & - & - \\
\hline & & & OGE & -108.0 & -151.8 & -192.1 & -231.0 & -303.0 & -380.9 & -447.1 & -504.5 \\
\hline & & \multirow{2}{*}{ Speed } & IGE & 4.7 & 7.1 & 9.5 & 11.8 & 15.8 & 19.1 & - & - \\
\hline & & & OGE & -104.9 & -147.8 & -188.0 & -226.0 & -296.0 & -372.4 & -438.3 & -494.8 \\
\hline & & \multirow{2}{*}{ Wingspan } & IGE & 3.9 & 6.0 & 8.0 & 10.0 & 13.6 & 17.2 & 19.5 & - \\
\hline & & & OGE & -88.9 & -125.6 & -159.7 & -192.7 & -254.6 & -322.9 & -381.9 & -434.1 \\
\hline & & \multirow{2}{*}{ Wind } & IGE & 3.5 & 5.4 & 7.3 & 9.1 & 12.9 & 16.0 & 18.5 & 19.6 \\
\hline & & & OGE & -74.2 & -105.2 & -135.0 & -163.4 & -217.0 & -278.2 & -333.1 & -382.5 \\
\hline & & \multirow{2}{*}{ EDR } & IGE & 4.4 & 6.7 & 8.9 & 11.0 & 14.1 & - & - & - \\
\hline & & & OGE & -90.9 & -124.0 & -152.4 & -177.9 & -220.5 & -259.5 & -286.7 & -305.6 \\
\hline
\end{tabular}

Table 25. Wake altitude change data IGE and OGE at various lateral offset distances for Heavy weight class aircraft (nominal and sensitivity scenarios).

\begin{tabular}{|c|c|c|c|c|c|c|c|c|c|c|c|}
\hline \multirow{2}{*}{$\begin{array}{c}\text { Weight } \\
\text { Class } \\
\end{array}$} & \multirow{2}{*}{ Aircraft ID } & \multirow{2}{*}{ Sensitivity } & \multirow{2}{*}{$\begin{array}{c}\text { Altitude } \\
\text { Region } \\
\end{array}$} & \multicolumn{8}{|c|}{ Wake Altitude Change (ft) at Offset Distances (ft) } \\
\hline & & & & 500 & 700 & 900 & 1100 & 1500 & 2000 & 2500 & 3000 \\
\hline \multirow{24}{*}{ Heavy } & \multirow{12}{*}{ B763 } & \multirow{2}{*}{ Nominal } & IGE & 3.5 & 5.5 & 7.4 & 9.3 & 12.8 & 16.8 & 20.1 & 22.6 \\
\hline & & & OGE & -77.0 & -109.9 & -141.6 & -171.8 & -228.5 & -293.0 & -350.7 & -402.3 \\
\hline & & \multirow{2}{*}{ Weight } & IGE & 4.0 & 6.2 & 8.4 & 10.6 & 14.6 & 18.9 & 22.2 & 23.9 \\
\hline & & & OGE & -94.8 & -135.1 & -173.7 & -210.4 & -278.8 & -355.9 & -424.1 & -484.3 \\
\hline & & \multirow{2}{*}{ Speed } & IGE & 3.6 & 5.6 & 7.6 & 9.6 & 13.3 & 17.4 & 20.6 & 22.8 \\
\hline & & & OGE & -82.8 & -118.1 & -152.1 & -184.5 & -245.1 & -313.8 & -375.0 & -429.5 \\
\hline & & \multirow{2}{*}{ Wingspan } & IGE & 3.1 & 4.8 & 6.5 & 8.2 & 11.3 & 15.0 & 18.3 & 20.9 \\
\hline & & & OGE & -69.4 & -99.7 & -128.8 & -156.4 & -208.9 & -268.9 & -322.7 & -371.4 \\
\hline & & \multirow{2}{*}{ Wind } & IGE & 2.6 & 4.2 & 5.8 & 7.3 & 10.3 & 13.7 & 16.7 & 19.3 \\
\hline & & & OGE & -58.3 & -83.8 & -108.5 & -132.2 & -177.8 & -230.8 & -279.3 & -324.4 \\
\hline & & \multirow[b]{2}{*}{ EDR } & IGE & 3.5 & 5.4 & 7.2 & 8.9 & 12.0 & 14.7 & - & - \\
\hline & & & OGE & -72.2 & -100.1 & -125.5 & -148.2 & -186.9 & -224.9 & -253.5 & -274.7 \\
\hline & \multirow{12}{*}{ B744 } & \multirow{2}{*}{ Nominal } & IGE & 3.1 & 5.0 & 6.9 & 8.8 & 12.6 & 16.9 & 21.0 & 24.6 \\
\hline & & & OGE & -72.8 & -106.3 & -138.4 & -169.4 & -228.5 & -296.6 & -358.6 & -415.2 \\
\hline & & \multirow{2}{*}{ Weight } & IGE & 3.6 & 5.9 & 8.1 & 10.4 & 14.7 & 19.9 & 24.5 & 28.3 \\
\hline & & & OGE & -94.6 & -137.9 & -179.2 & -219.0 & -294.4 & -380.7 & -458.4 & -528.8 \\
\hline & & \multirow{2}{*}{ Speed } & IGE & 3.2 & 5.2 & 7.3 & 9.2 & 13.0 & 17.6 & 21.8 & 25.5 \\
\hline & & & OGE & -77.7 & -113.4 & -147.6 & -180.6 & -243.2 & -315.5 & -381.3 & -441.2 \\
\hline & & \multirow{2}{*}{ Wingspan } & IGE & 2.6 & 4.3 & 6.0 & 7.6 & 10.9 & 14.8 & 18.4 & 21.8 \\
\hline & & & OGE & -64.9 & -95.1 & -124.4 & -152.6 & -206.2 & -268.6 & -325.6 & -378.0 \\
\hline & & \multirow{2}{*}{ Wind } & IGE & 2.5 & 4.0 & 5.6 & 7.2 & 10.2 & 13.9 & 17.3 & 20.6 \\
\hline & & & OGE & -55.1 & -80.7 & -105.6 & -129.7 & -176.3 & -231.3 & -282.6 & -330.7 \\
\hline & & \multirow{2}{*}{ EDR } & IGE & 3.0 & 4.9 & 6.7 & 8.5 & 11.9 & 15.4 & 17.9 & 19.1 \\
\hline & & & OGE & -69.2 & -98.6 & -125.3 & -149.9 & -193.1 & -237.2 & -272.0 & -299.5 \\
\hline
\end{tabular}

Table 26. Wake altitude change data IGE and OGE at various lateral offset distances for Super weight class aircraft (nominal and sensitivity scenarios).

\begin{tabular}{|c|c|c|c|c|c|c|c|c|c|c|c|}
\hline \multirow{2}{*}{$\begin{array}{c}\text { Weight } \\
\text { Class } \\
\end{array}$} & \multirow{2}{*}{ Aircraft ID } & \multirow{2}{*}{ Sensitivity } & \multirow{2}{*}{$\begin{array}{c}\text { Altitude } \\
\text { Region } \\
\end{array}$} & \multicolumn{8}{|c|}{ Wake Altitude Change ( $\mathrm{ft}$ ) at Offset Distances ( $\mathrm{ft}$ ) } \\
\hline & & & & 500 & 700 & 900 & 1100 & 1500 & 2000 & 2500 & 3000 \\
\hline \multirow{12}{*}{ Super } & \multirow{12}{*}{ A380 } & \multirow{2}{*}{ Nominal } & IGE & 2.6 & 4.4 & 6.3 & 8.1 & 11.8 & 16.2 & 20.4 & 24.3 \\
\hline & & & OGE & -84.3 & -125.1 & -164.3 & -202.2 & -274.7 & -358.6 & -435.4 & -506.0 \\
\hline & & \multirow{2}{*}{ Weight } & IGE & 2.7 & 4.5 & 6.4 & 8.3 & 12.1 & 16.6 & 21.0 & 25.0 \\
\hline & & & OGE & -88.9 & -131.8 & -173.0 & -213.0 & -289.1 & -377.2 & -457.5 & -531.3 \\
\hline & & \multirow{2}{*}{ Speed } & IGE & 2.5 & 4.4 & 6.4 & 8.3 & 12.5 & 16.9 & 21.7 & 25.8 \\
\hline & & & OGE & -90.7 & -134.4 & -176.5 & -217.1 & -294.7 & -384.4 & -466.2 & -541.2 \\
\hline & & \multirow{2}{*}{ Wingspan } & IGE & 2.2 & 3.9 & 5.5 & 7.1 & 10.3 & 14.3 & 18.1 & 21.7 \\
\hline & & & OGE & -75.7 & -112.6 & -148.6 & -183.3 & -249.8 & -327.1 & -398.2 & -463.9 \\
\hline & & \multirow{2}{*}{ Wind } & IGE & 2.1 & 3.7 & 5.2 & 6.8 & 9.8 & 13.5 & 17.1 & 20.5 \\
\hline & & & OGE & -63.6 & -94.7 & -125.1 & -154.8 & -211.7 & -279.1 & -342.3 & -401.7 \\
\hline & & \multirow{2}{*}{ EDR } & IGE & 2.6 & 4.4 & 6.1 & 7.9 & 11.4 & 15.4 & 18.7 & 21.2 \\
\hline & & & OGE & -80.7 & -117.2 & -150.8 & -181.8 & -237.0 & -294.5 & -340.9 & -378.5 \\
\hline
\end{tabular}


Table 27. Wake age approximate derivatives, IGE.

\begin{tabular}{|c|c|c|c|c|c|c|c|c|}
\hline Distance (ft) & 500 & 700 & 900 & 1100 & 1500 & 2000 & 2500 & 3000 \\
\hline Nominal Wake Age (s) & 14.65 & 21.6 & 28.7 & 35.95 & 50.8 & 69.95 & - & - \\
\hline Weight Derivative (s/lb.) & -0.0001627 & -0.0001808 & -0.0001989 & -0.0001808 & -0.0001627 & - & - & - \\
\hline Speed Derivative (s/knot) & 0.02 & 0.025 & 0.025 & 0.025 & 0.02 & - & - & - \\
\hline Wingspan Derivative $(\mathrm{s} / \mathrm{ft})$ & -0.0172414 & -0.0172414 & -0.0517241 & -0.0517241 & -0.1206897 & -0.1896552 & - & - \\
\hline Wind Derivative (s/knot) & -0.68 & -0.97 & -1.36 & -1.72 & -2.47 & -3.46 & 213.29 & - \\
\hline EDR Derivative $\left(\mathrm{s} /\left(\mathrm{m}^{\wedge} \mathbf{2} / \mathrm{s}^{\wedge} \mathbf{2}\right)\right)$ & 15.151515 & 30.30303 & 50.505051 & 85.858586 & - & - & - & - \\
\hline
\end{tabular}

Table 28. Wake age approximate derivatives, OGE.

\begin{tabular}{|c|c|c|c|c|c|c|c|c|}
\hline Distance (ft) & 500 & 700 & 900 & 1100 & 1500 & 2000 & 2500 & 3000 \\
\hline Nominal Wake Age (s) & 18.35 & 26.3 & 34.2 & 42.1 & 57.95 & 77.75 & 97.45 & 117.2 \\
\hline Weight Derivative (s/lb.) & 0 & 0 & 0 & 0 & 0 & 0 & 0 & 0 \\
\hline Speed Derivative (s/knot) & 0 & 0 & 0 & 0 & 0 & 0 & 0 & 0 \\
\hline Wingspan Derivative (s/ft) & -0.0172414 & -0.0172414 & 0 & -0.0172414 & -0.0172414 & -0.0172414 & -0.0172414 & -0.0172414 \\
\hline Wind Derivative (s/knot) & -0.94 & -1.34 & -1.73 & -2.13 & -2.92 & -3.92 & -4.9 & -5.88 \\
\hline EDR Derivative $\left(\mathrm{s} /\left(\mathrm{m}^{\wedge} 2 / \mathrm{s}^{\wedge} 2\right)\right)$ & 0 & 0 & 0 & 0 & 0 & 0 & 0 & - \\
\hline
\end{tabular}

Table 29. Circulation strength approximate derivatives, IGE.

\begin{tabular}{|c|c|c|c|c|c|c|c|c|}
\hline Distance (ft) & 500 & 700 & 900 & 1100 & 1500 & 2000 & 2500 & 3000 \\
\hline Nominal Wake Circulation (m^2/s) & 50.612276 & "44.593184 & 39.388312 & 34.085256 & 23.223126 & 9.215727 & - & - \\
\hline Weight Derivative $\left(\left(\mathrm{m}^{\wedge} 2 / \mathrm{s}\right) / \mathrm{lb}\right)$ & 0.0026791 & 0.0020538 & 0.0012618 & 0.0004104 & -0.0013135 & - & - & - \\
\hline Speed Derivative $\left(\left(\mathrm{m}^{\wedge} 2 / \mathrm{s}\right) / \mathrm{knot}\right)$ & -0.334127 & -0.2518995 & -0.1396891 & -0.0239303 & 0.2176317 & - & - & - \\
\hline Wingspan Derivative $\left(\left(\mathrm{m}^{\wedge} 2 / \mathrm{s}\right) / \mathrm{ft}\right)$ & -0.0533583 & 0.1142983 & 0.3873276 & 0.7120359 & 1.41861 & 2.3177776 & - & - \\
\hline Wind Derivative $\left(\left(\mathrm{m}^{\wedge} 2 / \mathrm{s}\right) / \mathrm{knot}\right)$ & 0.970932 & 0.7019904 & 1.1594374 & 1.3862476 & 1.8616342 & 2.4921236 & 202.19009 & - \\
\hline EDR Derivative $\left(\left(\mathrm{m}^{\wedge} 2 / \mathrm{s}\right) /\left(\mathrm{m}^{\wedge} 2 / \mathrm{s}^{\wedge} 2\right)\right)$ & -596.27596 & -1102.0007 & -1721.3417 & -2377.8241 & - & - & - & - \\
\hline
\end{tabular}

Table 30. Circulation strength approximate derivatives, OGE.

\begin{tabular}{|c|c|c|c|c|c|c|c|c|}
\hline Distance (ft) & 500 & 700 & 900 & 1100 & 1500 & 2000 & 2500 & 3000 \\
\hline Nominal Wake Circulation ( $\left.\mathrm{m}^{\wedge} 2 / \mathrm{s}\right)$ & 56.748064 & 53.223218 & 49.912047 & 46.775442 & 40.996758 & 34.648589 & 29.174101 & 24.417885 \\
\hline Weight Derivative $\left(\left(\mathrm{m}^{\wedge} 2 / \mathrm{s}\right) / \mathrm{lb}\right)$ & 0.0037487 & 0.0033897 & 0.0030614 & 0.0027617 & 0.0022295 & 0.0016777 & 0.0012328 & 0.0008731 \\
\hline Speed Derivative $\left(\left(\mathrm{m}^{\wedge} 2 / \mathrm{s}\right) / \mathrm{knot}\right)$ & -0.5289255 & -0.4797162 & -0.4342034 & -0.3929826 & -0.3195374 & -0.2429655 & -0.1808621 & -0.1303025 \\
\hline Wingspan Derivative $\left(\left(\mathrm{m}^{\wedge} 2 / \mathrm{s}\right) / \mathrm{ft}\right)$ & -0.7299093 & -0.6049276 & -0.497519 & -0.3849969 & -0.2009514 & -0.0183434 & 0.1196379 & 0.218 \\
\hline Wind Derivative $\left(\left(\mathrm{m}^{\wedge} 2 / \mathrm{s}\right) / \mathrm{knot}\right)$ & 0.4349318 & 0.5915932 & 0.7271794 & 0.8540478 & 1.059857 & 1.2559856 & 1.3862432 & 1.4680946 \\
\hline EDR Derivative $\left(\left(\mathrm{m}^{\wedge} 2 / \mathrm{s}\right) /\left(\mathrm{m}^{\wedge} 2 / \mathrm{s}^{\wedge} 2\right)\right)$ & -1340.5044 & -1710.8913 & -1987.9029 & -2189.2009 & -2419.0659 & -2478.6535 & -2385.9747 & - \\
\hline
\end{tabular}

Table 31. Wake altitude change approximate derivatives, IGE.

\begin{tabular}{|c|c|c|c|c|c|c|c|c|}
\hline Distance (ft) & 500 & 700 & 900 & 1100 & 1500 & 2000 & 2500 & 3000 \\
\hline Nominal Wake Delta Altitude (ft) & 3.280296 & 4.698599 & 5.980121 & $\overline{\overline{7} .16546}$ & 9.027983 & 10.413899 & - & - \\
\hline Weight Derivative (ft/lb.) & 0.0001738 & 0.0002419 & 0.0003017 & 0.0003173 & 0.0003006 & - & - & - \\
\hline Speed Derivative (ft/knot) & -0.0262043 & -0.0358314 & -0.0456234 & -0.0434655 & -0.0411003 & - & - & - \\
\hline Wingspan Derivative $(\mathrm{ft} / \mathrm{ft}$ ) & -0.1317355 & -0.1875362 & -0.2214503 & -0.2495438 & -0.2589631 & -0.1695393 & - & - \\
\hline Wind Derivative (ft/knot) & -0.1521468 & -0.1701132 & -0.2452216 & -0.2767328 & -0.2945122 & -0.2383526 & 201.93216 & - \\
\hline EDR Derivative $\left(\mathrm{ft} /\left(\mathrm{m}^{\wedge} 2 / \mathrm{s}^{\wedge} 2\right)\right)$ & -18.703434 & -42.534343 & -81.811919 & -145.70343 & - & - & - & - \\
\hline
\end{tabular}

Table 32. Wake altitude change approximate derivatives, OGE.

\begin{tabular}{|c|c|c|c|c|c|c|c|c|}
\hline Distance (ft) & 500 & 700 & 900 & 1100 & 1500 & 2000 & 2500 & 3000 \\
\hline Nominal Wake Delta Altitude (ft) & -43.444531 & -59.907632 & -75.250777 & -89.634531 & -115.80667 & -143.96176 & -167.59594 & -187.49103 \\
\hline Weight Derivative (ft/lb.) & -0.002987 & -0.0040553 & -0.0050145 & -0.0058805 & -0.0073664 & -0.0088163 & -0.0098905 & -0.0106691 \\
\hline Speed Derivative (ft/knot) & 0.4165619 & 0.5675565 & 0.7034479 & 0.8264676 & 1.0386154 & 1.2474316 & 1.4039212 & 0247 \\
\hline Wingspan Derivative (ft/ft) & 1.3578407 & 1.8186934 & 2.1962717 & 2.5866841 & 3.1821824 & 3.7202352 & 4.070639 & 4.2763886 \\
\hline Wind Derivative (ft/knot) & 2.0575288 & 2.7704458 & 3.3799218 & 3.93229 & 4.8058206 & 5.5788012 & 6.0152958 & 6.20225 \\
\hline EDR Derivative $\left(\mathrm{ft} /\left(\mathrm{m}^{\wedge} 2 / \mathrm{s}^{\wedge} \mathrm{2}\right)\right)$ & 520.74273 & 980.13444 & 1532.5366 & 2155.7335 & 3541.5296 & 5380.5338 & 7192.5391 & - \\
\hline
\end{tabular}


Table 33. Wake age approximate derivatives, IGE.

\begin{tabular}{|c|c|c|c|c|c|c|c|c|}
\hline Distance (ft) & 500 & 700 & 900 & 1100 & 1500 & 2000 & 2500 & 3000 \\
\hline Nominal Wake Age (s) & 14.6 & 21.55 & 28.7 & 36 & 50.9 & 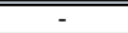 & 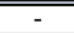 & - \\
\hline Weight Derivative (s/lb.) & -0.0001406 & -0.0001563 & -0.0001719 & -0.0001719 & -0.0001094 & - & - & - \\
\hline Speed Derivative (s/knot) & 0.02 & 0.02 & 0.025 & 0.025 & 0.015 & - & - & - \\
\hline Wingspan Derivative (s/ft) & -0.0177305 & -0.0177305 & -0.0531915 & -0.070922 & -0.1241135 & 379.14894 & - & - \\
\hline Wind Derivative (s/knot) & -0.65 & -0.98 & -1.33 & -1.69 & -2.44 & 210.4 & 213.3 & - \\
\hline EDR Derivative $\left(s /\left(m^{\wedge} 2 / s^{\wedge} 2\right)\right)$ & 10.10101 & 30.30303 & 45.454545 & 80.808081 & - & - & - & - \\
\hline
\end{tabular}

Table 34. Wake age approximate derivatives, OGE.

\begin{tabular}{|c|c|c|c|c|c|c|c|c|}
\hline Distance (ft) & 500 & 700 & 900 & 1100 & 1500 & 2000 & 2500 & 3000 \\
\hline Nominal Wake Age (s) & 18.4 & 26.3 & 34.25 & 42.15 & 57.95 & 77.75 & 97.5 & 117.25 \\
\hline Weight Derivative (s/lb.) & 0 & 0 & 0 & 0 & 0 & 0 & 0 & 0 \\
\hline Speed Derivative (s/knot) & 0 & 0 & 0 & 0 & 0 & 0 & 0 & 0 \\
\hline Wingspan Derivative (s/ft) & -0.0177305 & -0.0177305 & -0.0177305 & -0.0177305 & -0.0177305 & -0.0177305 & -0.0177305 & -0.0177305 \\
\hline Wind Derivative (s/knot) & -0.95 & -1.34 & -1.74 & -2.13 & -2.92 & -3.91 & -4.9 & -5.89 \\
\hline EDR Derivative $\left(\mathrm{s} /\left(\mathrm{m}^{\wedge} 2 / \mathrm{s}^{\wedge} 2\right)\right)$ & 0 & 0 & 0 & 0 & 0 & 0 & - & - \\
\hline
\end{tabular}

Table 35. Circulation strength approximate derivatives, IGE.

\begin{tabular}{|c|c|c|c|c|c|c|c|c|}
\hline Distance (ft) & 500 & 700 & 900 & 1100 & 1500 & 2000 & 2500 & 3000 \\
\hline Nominal Wake Circulation (m^2/s) & 51.450445 & 44.957113 & 38.908876 & 32.733775 & 20.129801 & 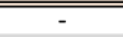 & - & - \\
\hline Weight Derivative $\left(\left(\mathrm{m}^{\wedge} 2 / \mathrm{s}\right) / \mathrm{lb}\right)$ & 0.0024011 & 0.0017064 & 0.0008647 & $-1.437 \mathrm{E}-05$ & -0.0018855 & - & - & - \\
\hline Speed Derivative $\left(\left(\mathrm{m}^{\wedge} 2 / \mathrm{s}\right) / \mathrm{knot}\right)$ & -0.3603311 & -0.2714744 & -0.1657248 & -0.0526455 & 0.1881714 & - & - & - \\
\hline Wingspan Derivative $\left(\left(\mathrm{m}^{\wedge} 2 / \mathrm{s}\right) / \mathrm{ft}\right)$ & 0.0015465 & 0.1940986 & 0.5804784 & 0.9814791 & 1.8117908 & 358.68018 & - & - \\
\hline Wind Derivative $\left(\left(\mathrm{m}^{\wedge} 2 / \mathrm{s}\right) / \mathrm{knot}\right)$ & 0.5947846 & 0.7413192 & 1.0259724 & 1.379818 & 2.1142248 & 203.64913 & 201.32603 & - \\
\hline EDR Derivative $\left(\left(\mathrm{m}^{\wedge} 2 / \mathrm{s}\right) /\left(\mathrm{m}^{\wedge} 2 / \mathrm{s}^{\wedge} 2\right)\right)$ & -569.79394 & -1129.3772 & -1759.4205 & -2436.1481 & - & - & - & - \\
\hline
\end{tabular}

Table 36. Circulation strength approximate derivatives, OGE.

\begin{tabular}{|c|c|c|c|c|c|c|c|c|}
\hline Distance (ft) & 500 & 700 & 900 & 1100 & 1500 & 2000 & 2500 & 3000 \\
\hline Nominal Wake Circulation ( $\left.\mathrm{m}^{\wedge} 2 / \mathrm{s}\right)$ & 58.728527 & 54.914764 & 51.297298 & 47.912709 & 41.724555 & 34.951636 & 29.142893 & 24.149456 \\
\hline Weight Derivative $\left(\left(\mathrm{m}^{\wedge} 2 / \mathrm{s}\right) / \mathrm{lb}\right)$ & 0.0034696 & 0.0031178 & 0.0027941 & 0.0024993 & 0.001982 & 0.001451 & 0.0010291 & 0.0006948 \\
\hline Speed Derivative $\left(\left(\mathrm{m}^{\wedge} 2 / \mathrm{s}\right) /\right.$ knot $)$ & -0.4922908 & -0.4438638 & -0.3993887 & -0.3587636 & -0.2871521 & -0.213155 & -0.1538717 & -0.1064811 \\
\hline Wingspan Derivative $\left(\left(\mathrm{m}^{\wedge} 2 / \mathrm{s}\right) / \mathrm{ft}\right)$ & -0.7539766 & -0.6092564 & -0.4763344 & -0.3571365 & -0.1532894 & 0.0387738 & 0.1807401 & 0.2830252 \\
\hline Wind Derivative $\left(\left(\mathrm{m}^{\wedge} 2 / \mathrm{s}\right) / \mathrm{knot}\right)$ & 0.4786886 & 0.6443342 & 0.7941508 & 0.9223736 & 1.1384394 & 1.3362744 & 1.4683178 & 1.5473876 \\
\hline EDR Derivative $\left(\left(\mathrm{m}^{\wedge} 2 / \mathrm{s}\right) /\left(\mathrm{m}^{\wedge} 2 / \mathrm{s}^{\wedge} 2\right)\right)$ & -1420.0994 & -1800.1995 & -2083.5591 & -2285.3182 & -2503.8182 & -2539.6382 & - & - \\
\hline
\end{tabular}

Table 37. Wake altitude change approximate derivatives, IGE.

\begin{tabular}{|c|c|c|c|c|c|c|c|c|}
\hline Distance (ft) & 500 & 700 & 900 & 1100 & 1500 & 2000 & 2500 & 3000 \\
\hline Nominal Wake Delta Altitude (ft) & 3.505669 & 5.030626 & 6.412215 & 7.62324 & 9.436369 & 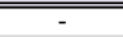 & - & - \\
\hline Weight Derivative (ft/lb.) & 0.000176 & 0.0002339 & 0.0002751 & 0.0002877 & 0.0002311 & - & - & - \\
\hline Speed Derivative (ft/knot) & -0.032125 & -0.0417116 & -0.0494621 & -0.0550249 & -0.0517323 & - & - & - \\
\hline Wingspan Derivative (ft/ft) & -0.1414468 & -0.1958411 & -0.2460475 & -0.2760082 & -0.2474167 & 358.12203 & - & - \\
\hline Wind Derivative (ft/knot) & -0.1260616 & -0.1822436 & -0.2244232 & -0.2583806 & -0.2514318 & 201.77709 & 201.9633 & - \\
\hline EDR Derivative (ft/(m^^2/s^2)) & -17.929798 & -43.09 & -88.965859 & -157.32242 & - & - & - & - \\
\hline
\end{tabular}

Table 38. Wake altitude change approximate derivatives, OGE.

\begin{tabular}{|c|c|c|c|c|c|c|c|c|}
\hline Distance (ft) & 500 & 700 & 900 & 1100 & 1500 & 2000 & 2500 & 3000 \\
\hline Nominal Wake Delta Altitude (ft) & -46.532971 & -63.909986 & -80.25292 & -95.422744 & -122.80605 & -152.13379 & -176.58627 & -196.91649 \\
\hline Weight Derivative (ft/lb.) & -0.0028763 & -0.0038829 & -0.0047922 & -0.0056013 & -0.0069675 & -0.0082759 & -0.0092181 & -0.0098723 \\
\hline Speed Derivative (ft/knot) & 0.405725 & 0.5487754 & 0.6784771 & 0.7943575 & 0.9913422 & 1.1820947 & 1.3216015 & 1.4204845 \\
\hline Wingspan Derivative (ft/ft) & 1.4866936 & 1.9788181 & 2.4139092 & 2.7914521 & 3.4011993 & 3.9353996 & 4.2661291 & 4.4387798 \\
\hline Wind Derivative (ft/knot) & 2.208656 & 2.9367924 & 3.5930344 & 4.1439506 & 5.0381728 & 5.7892792 & 6.2082738 & 6.3612036 \\
\hline EDR Derivative $\left(\mathrm{ft} /\left(\mathrm{m}^{\wedge} 2 / \mathrm{s}^{\wedge} 2\right)\right)$ & 570.7396 & 1066.0123 & 1666.0395 & 2336.0673 & 3811.9322 & 5758.4 & - & - \\
\hline
\end{tabular}


Table 39. Wake age approximate derivatives, IGE.

\begin{tabular}{|c|c|c|c|c|c|c|c|c|}
\hline Distance (ft) & 500 & 700 & 900 & 1100 & 1500 & 2000 & 2500 & 3000 \\
\hline Nominal Wake Age (s) & 13.3 & 19.95 & 26.8 & 33.9 & 48.6 & 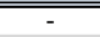 & $\overline{-}$ & $\overline{-1}$ \\
\hline Weight Derivative (s/lb.) & -0.0001029 & -0.0001176 & -0.000125 & -0.0001176 & 7.353E-06 & - & - & - \\
\hline Speed Derivative (s/knot) & 0.02 & 0.025 & 0.025 & 0.025 & 0.02 & - & - & - \\
\hline Wingspan Derivative $(\mathrm{s} / \mathrm{ft})$ & 0 & -0.03125 & -0.046875 & -0.078125 & -0.15625 & 333.125 & - & - \\
\hline Wind Derivative (s/knot) & -0.55 & -0.87 & -1.2 & -1.55 & -2.3 & 210.05 & - & - \\
\hline EDR Derivative $\left(\mathrm{s} /\left(\mathrm{m}^{\wedge} 2 / \mathrm{s}^{\wedge} 2\right)\right)$ & 10.10101 & 25.252525 & 45.454545 & 75.757576 & - & - & - & - \\
\hline
\end{tabular}

Table 40. Wake age approximate derivatives, OGE.

\begin{tabular}{|c|c|c|c|c|c|c|c|c|}
\hline Distance (ft) & 500 & 700 & 900 & 1100 & 1500 & 2000 & 2500 & 3000 \\
\hline Nominal Wake Age (s) & 18.25 & 26.2 & 34.15 & 42 & 57.85 & 77.65 & 97.35 & 1117.1 \\
\hline Weight Derivative (s/lb.) & 0 & 0 & 0 & 0 & 0 & 0 & 0 & 0 \\
\hline Speed Derivative (s/knot) & 0 & 0 & 0 & 0 & 0 & 0 & 0 & 0 \\
\hline Wingspan Derivative $(\mathrm{s} / \mathrm{ft}$ ) & -0.015625 & -0.015625 & -0.015625 & -0.015625 & -0.015625 & -0.015625 & -0.015625 & -0.015625 \\
\hline Wind Derivative (s/knot) & -0.94 & -1.34 & -1.74 & -2.12 & -2.92 & -3.91 & -4.89 & -5.87 \\
\hline EDR Derivative $\left(\mathrm{s} /\left(\mathrm{m}^{\wedge} 2 / \mathrm{s}^{\wedge} 2\right)\right)$ & 0 & 0 & 0 & 0 & 0 & 0 & 0 & - \\
\hline
\end{tabular}

Table 41. Circulation strength approximate derivatives, IGE.

\begin{tabular}{|c|c|c|c|c|c|c|c|c|}
\hline Distance (ft) & 500 & 700 & 900 & 1100 & 1500 & 2000 & 2500 & 3000 \\
\hline Nominal Wake Circulation (m^2/s) & 73.006084 & 63.352987 & 54.261376 & 44.837961 & 25.327521 & 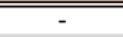 & - & - \\
\hline Weight Derivative $\left(\left(\mathrm{m}^{\wedge} 2 / \mathrm{s}\right) / \mathrm{lb}\right)$ & 0.0021214 & 0.0014438 & 0.0006333 & -0.0002389 & -0.0018564 & - & - & - \\
\hline Speed Derivative $\left(\left(\mathrm{m}^{\wedge} 2 / \mathrm{s}\right) / \mathrm{knot}\right)$ & -0.4754838 & -0.3471567 & -0.1806678 & -0.0081032 & 0.3570296 & - & - & - \\
\hline Wingspan Derivative $\left(\left(\mathrm{m}^{\wedge} 2 / \mathrm{s}\right) / \mathrm{ft}\right)$ & -0.0484291 & 0.2557609 & 0.7622272 & 1.3190238 & 2.4864869 & 316.14119 & - & - \\
\hline Wind Derivative $\left(\left(\mathrm{m}^{\wedge} 2 / \mathrm{s}\right) / \mathrm{knot}\right)$ & 0.716024 & 0.9715074 & 1.4221196 & 1.961925 & 3.11141 & 204.41991 & - & - \\
\hline EDR Derivative $\left(\left(\mathrm{m}^{\wedge} 2 / \mathrm{s}\right) /\left(\mathrm{m}^{\wedge} 2 / \mathrm{s}^{\wedge} 2\right)\right)$ & -513.12687 & -1114.7929 & -1831.1449 & -2595.1358 & - & - & - & - \\
\hline
\end{tabular}

Table 42. Circulation strength approximate derivatives, OGE.

\begin{tabular}{|c|c|c|c|c|c|c|c|c|}
\hline Distance (ft) & 500 & 700 & 900 & 1100 & 1500 & 2000 & 2500 & 3000 \\
\hline Nominal Wake Circulation ( $\left.\mathrm{m}^{\wedge} 2 / \mathrm{s}\right)$ & 83.444729 & 77.934305 & 72.748809 & 67.93005 & 59.045204 & 499.367402 & 41.100762 & 33.987002 \\
\hline Weight Derivative $\left(\left(\mathrm{m}^{\wedge} 2 / \mathrm{s}\right) / \mathrm{lb}\right)$ & 0.003017 & 0.0026904 & 0.0023926 & 0.0021241 & 0.0016518 & 0.0011742 & 0.0008005 & 0.000508 \\
\hline Speed Derivative $\left(\left(\mathrm{m}^{\wedge} 2 / \mathrm{s}\right) / \mathrm{knot}\right)$ & -0.6942135 & -0.6230022 & -0.5578027 & -0.4987617 & -0.3941224 & -0.2870621 & -0.2021603 & -0.1347018 \\
\hline Wingspan Derivative $\left(\left(\mathrm{m}^{\wedge} 2 / \mathrm{s}\right) / \mathrm{ft}\right)$ & -0.9238019 & -0.7318194 & -0.5582862 & -0.4039019 & -0.1413238 & 0.106445 & 0.2875059 & 0.4166469 \\
\hline Wind Derivative $\left(\left(\mathrm{m}^{\wedge} 2 / \mathrm{s}\right) / \mathrm{knot}\right)$ & 0.6798316 & 0.924722 & 1.1384508 & 1.3155506 & 1.629025 & 1.9093152 & 2.0911082 & 2.1970486 \\
\hline EDR Derivative $\left(\left(\mathrm{m}^{\wedge} 2 / \mathrm{s}\right) /\left(\mathrm{m}^{\wedge} 2 / \mathrm{s}^{\wedge} 2\right)\right)$ & -1881.1784 & -2399.8394 & -2787.5689 & -3064.5095 & -3376.1552 & -3443.5645 & -3297.0307 & - \\
\hline
\end{tabular}

Table 43. Wake altitude change approximate derivatives, IGE.

\begin{tabular}{|c|c|c|c|c|c|c|c|c|}
\hline Distance (ft) & 500 & 700 & 900 & 1100 & 1500 & 2000 & 2500 & 3000 \\
\hline Nominal Wake Delta Altitude (ft) & 3.540065 & 5.139624 & 6.577019 & 7.832792 & 9.69256 & - & - & - \\
\hline Weight Derivative (ft/lb.) & $9.198 \mathrm{E}-05$ & 0.0001307 & 0.0001554 & 0.000163 & 0.0002268 & - & - & - \\
\hline Speed Derivative (ft/knot) & -0.0290095 & -0.0383864 & -0.0451306 & -0.049442 & -0.0422209 & - & - & - \\
\hline Wingspan Derivative (ft/ft) & -0.1290119 & -0.1886278 & -0.2189047 & -0.2413675 & -0.2219625 & 315.43861 & - & - \\
\hline Wind Derivative (ft/knot) & -0.1159284 & -0.1764458 & -0.2220254 & -0.2490042 & -0.2368744 & 201.83142 & - & - \\
\hline EDR Derivative (ft/(m^^2/s^2)) & -11.859495 & -27.802525 & -62.445859 & -114.77768 & - & - & - & - \\
\hline
\end{tabular}

Table 44. Wake altitude change approximate derivatives, OGE.

\begin{tabular}{|c|c|c|c|c|c|c|c|c|}
\hline Distance (ft) & 500 & 700 & 900 & 1100 & 1500 & 2000 & 2500 & 3000 \\
\hline Nominal Wake Delta Altitude (ft) & -57.802044 & -79.685149 & -100.11776 & -118.95494 & -153.24361 & -189.78476 & -220.12288 & -245.36553 \\
\hline Weight Derivative (ft/lb.) & -0.0022021 & -0.0029756 & -0.0036645 & -0.004269 & -0.0052861 & -0.0062344 & -0.006893 & -0.0073299 \\
\hline Speed Derivative (ft/knot) & 0.5024616 & 0.6809904 & 0.8410286 & 0.9824426 & 1.2230681 & 1.4518397 & 1.6152063 & 1.7278353 \\
\hline Wingspan Derivative (ft/ft) & 1.6217225 & 2.1612403 & 2.6319428 & 3.035265 & 3.6834937 & 4.2350906 & 4.5578097 & 4.7054009 \\
\hline Wind Derivative (ft/knot) & 2.7355304 & 3.6730926 & 4.4913078 & 5.153862 & 6.2860624 & 7.2118068 & 7.7072908 & 7.870776 \\
\hline EDR Derivative $\left(\mathrm{ft} /\left(\mathrm{m}^{\wedge} 2 / \mathrm{s}^{\wedge} 2\right)\right)$ & 658.84091 & 1242.7157 & 1948.9792 & 2734.8145 & 4489.5111 & 6809.2591 & 9083.6321 & - \\
\hline
\end{tabular}


Table 45. Wake age approximate derivatives, IGE.

\begin{tabular}{|c|c|c|c|c|c|c|c|c|}
\hline Distance (ft) & 500 & 700 & 900 & 1100 & 1500 & 2000 & 2500 & 3000 \\
\hline Nominal Wake Age (s) & 12.3 & 18.55 & 25.1 & 32 & 46.35 & - & - & - \\
\hline Weight Derivative (s/lb.) & -0.000075 & $-8.929 E-05$ & $-9.286 \mathrm{E}-05$ & $-8.929 E-05$ & - & - & - & - \\
\hline Speed Derivative (s/knot) & 0.04 & 0.045 & 0.05 & -0.015 & -0.03 & - & - & - \\
\hline Wingspan Derivative (s/ft) & -0.0143678 & -0.0143678 & -0.0431034 & -0.0718391 & -0.158046 & 305.60345 & - & - \\
\hline Wind Derivative (s/knot) & -0.49 & -0.77 & -1.08 & -1.42 & -2.14 & 209.72 & - & - \\
\hline EDR Derivative $\left(\mathrm{s} /\left(\mathrm{m}^{\wedge} 2 / \mathrm{s}^{\wedge} 2\right)\right)$ & 10.10101 & 20.20202 & 40.40404 & 70.707071 & - & - & - & - \\
\hline
\end{tabular}

Table 46. Wake age approximate derivatives, OGE.

\begin{tabular}{|c|c|c|c|c|c|c|c|c|}
\hline Distance (ft) & 500 & 700 & 900 & 1100 & 1500 & 2000 & 2500 & 3000 \\
\hline Nominal Wake Age (s) & 18.15 & 26.1 & 34.05 & 41.95 & 57.75 & 77.55 & 97.25 & 117.05 \\
\hline Weight Derivative (s/lb.) & 0 & 0 & 0 & 0 & 0 & 0 & 0 & 0 \\
\hline Speed Derivative (s/knot) & 0 & 0 & 0 & 0 & 0 & 0 & 0 & 0 \\
\hline Wingspan Derivative (s/ft) & -0.0143678 & -0.0143678 & -0.0143678 & -0.0143678 & -0.0143678 & -0.0143678 & -0.0143678 & -0.0287356 \\
\hline Wind Derivative (s/knot) & -0.93 & -1.33 & -1.73 & -2.13 & -2.91 & -3.9 & -4.89 & -5.88 \\
\hline EDR Derivative $\left(s /\left(\mathrm{m}^{\wedge} 2 / \mathrm{s}^{\wedge} 2\right)\right)$ & 0 & 0 & 0 & 0 & 0 & 0 & 0 & 0 \\
\hline
\end{tabular}

Table 47. Circulation strength approximate derivatives, IGE.

\begin{tabular}{|c|c|c|c|c|c|c|c|c|}
\hline Distance (ft) & 500 & 700 & 900 & 1100 & 1500 & 2000 & 2500 & 3000 \\
\hline Nominal Wake Circulation (m^2/s) & 90.863936 & 79.085604 & "68.066453 & 56.458533 & 32.317402 & 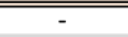 & - & - \\
\hline Weight Derivative $\left(\left(\mathrm{m}^{\wedge} 2 / \mathrm{s}\right) / \mathrm{lb}\right)$ & 0.0017077 & 0.0011506 & 0.0004537 & -0.0003039 & - & - & - & - \\
\hline Speed Derivative $\left(\left(\mathrm{m}^{\wedge} 2 / \mathrm{s}\right) / \mathrm{knot}\right)$ & -0.7767281 & -0.5783132 & -0.3359502 & 0.0371953 & 0.4394755 & - & - & - \\
\hline Wingspan Derivative $\left(\left(\mathrm{m}^{\wedge} 2 / \mathrm{s}\right) / \mathrm{ft}\right)$ & -0.1658399 & 0.1123822 & 0.6800336 & 1.3112043 & 2.6604474 & 291.57879 & - & - \\
\hline Wind Derivative $\left(\left(\mathrm{m}^{\wedge} 2 / \mathrm{s}\right) / \mathrm{knot}\right)$ & 0.9024738 & 1.1543598 & 1.6503446 & 2.2877682 & 3.6343118 & 205.3797 & - & - \\
\hline EDR Derivative $\left(\left(\mathrm{m}^{\wedge} 2 / \mathrm{s}\right) /\left(\mathrm{m}^{\wedge} 2 / \mathrm{s}^{\wedge} 2\right)\right)$ & -496.31828 & -1049.9806 & -1790.1479 & -2594.3928 & - & - & - & - \\
\hline
\end{tabular}

Table 48. Circulation strength approximate derivatives, OGE.

\begin{tabular}{|c|c|c|c|c|c|c|c|c|}
\hline Distance (ft) & 500 & 700 & 900 & 1100 & 1500 & 2000 & 2500 & 3000 \\
\hline Nominal Wake Circulation ( $\left.\mathrm{m}^{\wedge} 2 / \mathrm{s}\right)$ & 104.68951 & 97.738197 & 91.199689 & 85.088773 & 73.93363 & 61.752147 & 51.356551 & 42.398297 \\
\hline Weight Derivative $\left(\left(\mathrm{m}^{\wedge} 2 / \mathrm{s}\right) / \mathrm{lb}\right)$ & 0.0025251 & 0.0022368 & 0.0019749 & 0.0017386 & 0.0013296 & 0.000919 & 0.0006021 & 0.0003564 \\
\hline Speed Derivative $\left(\left(\mathrm{m}^{\wedge} 2 / \mathrm{s}\right) / \mathrm{knot}\right)$ & -0.7965235 & -0.7132003 & -0.6369659 & -0.5676001 & -0.4460459 & -0.3216258 & -0.2233318 & -0.1453872 \\
\hline Wingspan Derivative $\left(\left(\mathrm{m}^{\wedge} 2 / \mathrm{s}\right) / \mathrm{ft}\right)$ & -1.0523399 & -0.8257089 & -0.621227 & -0.4384606 & -0.1332411 & 0.1569207 & 0.367896 & 0.5233402 \\
\hline Wind Derivative $\left(\left(\mathrm{m}^{\wedge} 2 / \mathrm{s}\right) / \mathrm{knot}\right)$ & 0.8484236 & 1.1575076 & 1.4270058 & 1.665718 & 2.0445964 & 2.3965524 & 2.629953 & 2.7651224 \\
\hline EDR Derivative $\left(\left(\mathrm{m}^{\wedge} 2 / \mathrm{s}\right) /\left(\mathrm{m}^{\wedge} 2 / \mathrm{s}^{\wedge} 2\right)\right)$ & -2243.1162 & -2871.8664 & -3345.5224 & -3688.5068 & -4077.8049 & -4177.0048 & -4013.4979 & -3705.2932 \\
\hline
\end{tabular}

Table 49. Wake altitude change approximate derivatives, IGE.

\begin{tabular}{|c|c|c|c|c|c|c|c|c|}
\hline Distance (ft) & 500 & 700 & 900 & 1100 & 1500 & 2000 & 2500 & 3000 \\
\hline Nominal Wake Delta Altitude (ft) & 3.365097 & 4.877003 & 6.269969 & 7.522211 & 9.391527 & 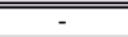 & - & - \\
\hline Weight Derivative (ft/lb.) & $4.718 \mathrm{E}-05$ & 7.036E-05 & $8.512 \mathrm{E}-05$ & 8.764E-05 & - & - & - & - \\
\hline Speed Derivative (ft/knot) & -0.00832 & -0.0194878 & -0.0256893 & -0.0935323 & -0.0943864 & - & - & - \\
\hline Wingspan Derivative (ft/ft) & -0.1188178 & -0.1625376 & -0.2002822 & -0.225625 & -0.2138394 & 289.96181 & - & - \\
\hline Wind Derivative (ft/knot) & -0.1095962 & -0.1583668 & -0.1991 & -0.2260058 & -0.2216152 & 201.78619 & - & - \\
\hline EDR Derivative (ft/(m^^2/s^2)) & -10.153333 & -21.647879 & -44.291515 & -85.866667 & - & - & - & - \\
\hline
\end{tabular}

Table 50. Wake altitude change approximate derivatives, OGE.

\begin{tabular}{|c|c|c|c|c|c|c|c|c|}
\hline Distance $(\mathrm{ft})$ & 500 & 700 & 900 & 1100 & 1500 & 2000 & 2500 & 3000 \\
\hline Nominal Wake Delta Altitude (ft) & -66.204108 & -91.413287 & -114.94244 & -136.75773 & -176.07106 & -218.07183 & -252.90649 & -281.92447 \\
\hline Weight Derivative (ft/lb.) & -0.0016951 & -0.0022877 & -0.0028119 & -0.0032711 & -0.0040274 & -0.0047197 & -0.0051851 & -0.0054793 \\
\hline Speed Derivative (ft/knot) & 0.5319443 & 0.7198567 & 0.887919 & 1.0369004 & 1.2869487 & 1.5236641 & 1.690714 & 1595 \\
\hline Wingspan Derivative (ft/ft) & 1.7038259 & 2.2711664 & 2.7643871 & 3.1877353 & 3.8571296 & 4.4205261 & 4.7394664 & 4.8911629 \\
\hline Wind Derivative (ft/knot) & 3.1113798 & 4.1920486 & 5.1344998 & 5.9526102 & 7.1979924 & 8.2590404 & 8.844008 & 9.0364392 \\
\hline EDR Derivative $\left(\mathrm{ft} /\left(\mathrm{m}^{\wedge} 2 / \mathrm{s}^{\wedge} 2\right)\right)$ & 716.0298 & 1356.6286 & 2134.01 & 3007.1002 & 4944.1638 & 7522.9043 & 10061.129 & 12461.158 \\
\hline
\end{tabular}


Table 51. Wake age approximate derivatives, IGE.

\begin{tabular}{|c|c|c|c|c|c|c|c|c|}
\hline Distance (ft) & 500 & 700 & 900 & 1100 & 1500 & 2000 & 2500 & 3000 \\
\hline Nominal Wake Age (s) & 10.05 & 15.45 & 21.2 & 27.25 & 40.05 & 57.35 & 75.85 & 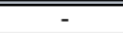 \\
\hline Weight Derivative (s/lb.) & $-3.261 E-05$ & $-4.348 \mathrm{E}-05$ & $-4.891 \mathrm{E}-05$ & $-5.435 E-05$ & $-5.978 E-05$ & $-5.435 \mathrm{E}-05$ & $-2.717 \mathrm{E}-05$ & - \\
\hline Speed Derivative (s/knot) & 0.045 & 0.06 & 0.07 & 0.005 & 0 & 0.075 & - & - \\
\hline Wingspan Derivative $(\mathrm{s} / \mathrm{ft})$ & 0 & -0.0089286 & -0.0178571 & -0.0357143 & -0.0803571 & -0.1517857 & -0.2589286 & 195.05357 \\
\hline Wind Derivative (s/knot) & -0.35 & -0.57 & -0.82 & -1.09 & -1.69 & -2.57 & -3.57 & 214.2 \\
\hline EDR Derivative $\left(\mathrm{s} /\left(\mathrm{m}^{\wedge} \mathbf{2} / \mathrm{s}^{\wedge} \mathbf{2}\right)\right)$ & 10.10101 & 15.151515 & 20.20202 & 35.353535 & 95.959596 & - & - & - \\
\hline
\end{tabular}

Table 52. Wake age approximate derivatives, OGE.

\begin{tabular}{|c|c|c|c|c|c|c|c|c|}
\hline Distance (ft) & 500 & 700 & 900 & 1100 & 1500 & 2000 & 2500 & 3000 \\
\hline Nominal Wake Age (s) & 17.5 & 25.45 & 33.35 & 41.25 & 57.1 & 76.9 & 96.6 & 116.35 \\
\hline Weight Derivative (s/lb.) & 0 & 0 & 0 & 0 & 0 & 0 & 0 & 0 \\
\hline Speed Derivative (s/knot) & 0 & 0 & 0 & 0 & 0 & 0 & 0 & 0 \\
\hline Wingspan Derivative (s/ft) & -0.0178571 & -0.0178571 & -0.0089286 & -0.0089286 & -0.0178571 & -0.0178571 & -0.0178571 & -0.0178571 \\
\hline Wind Derivative (s/knot) & -0.9 & -1.3 & -1.69 & -2.09 & -2.88 & -3.87 & -4.86 & -5.84 \\
\hline EDR Derivative $\left(s /\left(m^{\wedge} 2 / s^{\wedge} 2\right)\right)$ & 0 & 0 & 0 & 0 & 0 & 0 & 0 & 0 \\
\hline
\end{tabular}

Table 53. Circulation strength approximate derivatives, IGE.

\begin{tabular}{|c|c|c|c|c|c|c|c|c|}
\hline Distance (ft) & 500 & 700 & 900 & 1100 & 1500 & 2000 & 2500 & 3000 \\
\hline Nominal Wake Circulation (m^2/s) & 205.9765 & 184.05264 & 166.26885 & 150.4482 & 1117.37762 & 72.680655 & 24.883363 & - \\
\hline Weight Derivative $\left(\left(\mathrm{m}^{\wedge} 2 / \mathrm{s}\right) / \mathrm{lb}\right)$ & 0.0015417 & 0.0013098 & 0.0011022 & 0.0008633 & 0.0003073 & -0.0004825 & -0.001391 & - \\
\hline Speed Derivative $\left(\left(\mathrm{m}^{\wedge} 2 / \mathrm{s}\right) / \mathrm{knot}\right)$ & -1.9973207 & -1.6928975 & -1.4259186 & -0.644268 & -0.118179 & 0.6827416 & - & - \\
\hline Wingspan Derivative $\left(\left(\mathrm{m}^{\wedge} 2 / \mathrm{s}\right) / \mathrm{ft}\right)$ & -0.4295018 & -0.0948166 & 0.184578 & 0.5437354 & 1.6802936 & 3.2407323 & 4.9748407 & 180.63008 \\
\hline Wind Derivative $\left(\left(\mathrm{m}^{\wedge} 2 / \mathrm{s}\right) / \mathrm{knot}\right)$ & 1.2550026 & 1.6755646 & 2.0647646 & 2.5152232 & 4.220853 & 6.7437506 & 9.5882836 & 207.40134 \\
\hline EDR Derivative $\left(\left(\mathrm{m}^{\wedge} 2 / \mathrm{s}\right) /\left(\mathrm{m}^{\wedge} 2 / \mathrm{s}^{\wedge} 2\right)\right)$ & -658.15616 & -757.08566 & -1328.2838 & -2261.0451 & -4390.4013 & - & - & - \\
\hline
\end{tabular}

Table 54. Circulation strength approximate derivatives, OGE.

\begin{tabular}{|c|c|c|c|c|c|c|c|c|}
\hline Distance (ft) & 500 & 700 & 900 & 1100 & 1500 & 2000 & 2500 & 3000 \\
\hline Nominal Wake Circulation ( $\left.\mathrm{m}^{\wedge} 2 / \mathrm{s}\right)$ & 218.34664 & 207.02863 & 196.29338 & 186.04613 & 166.87179 & 145.30814 & 126.2205 & 109.19724 \\
\hline Weight Derivative $\left(\left(\mathrm{m}^{\wedge} 2 / \mathrm{s}\right) / \mathrm{lb}\right)$ & 0.0017079 & 0.0015721 & 0.0014456 & 0.0013273 & 0.0011123 & 0.0008813 & 0.0006876 & 0.0005243 \\
\hline Speed Derivative $\left(\left(\mathrm{m}^{\wedge} 2 / \mathrm{s}\right) /\right.$ knot $)$ & -1.7071483 & -1.5710638 & -1.4444486 & -1.32592 & -1.1106286 & -0.8794947 & -0.6856743 & -0.5223814 \\
\hline Wingspan Derivative $\left(\left(\mathrm{m}^{\wedge} 2 / \mathrm{s}\right) / \mathrm{ft}\right)$ & -1.4860491 & -1.2641161 & -1.0708734 & -0.8821987 & -0.5376607 & -0.1919584 & 0.0836513 & 0.3021641 \\
\hline Wind Derivative $\left(\left(\mathrm{m}^{\wedge} 2 / \mathrm{s}\right) / \mathrm{knot}\right)$ & 1.3209632 & 1.8430716 & 2.3005184 & 2.731891 & 3.4692846 & 4.2093704 & 4.7752256 & 5.180508 \\
\hline EDR Derivative $\left(\left(\mathrm{m}^{\wedge} 2 / \mathrm{s}\right) /\left(\mathrm{m}^{\wedge} 2 / \mathrm{s}^{\wedge} 2\right)\right)$ & -3409.813 & -4533.5126 & -5449.4418 & -6190.9578 & -7241.2626 & -7920.1612 & -8104.7673 & -7957.1183 \\
\hline
\end{tabular}

Table 55. Wake altitude change approximate derivatives, IGE.

\begin{tabular}{|c|c|c|c|c|c|c|c|c|}
\hline Distance (ft) & 500 & 700 & 900 & 1100 & 1500 & 2000 & 2500 & 3000 \\
\hline Nominal Wake Delta Altitude (ft) & 3.19447 & 4.866891 & 6.496909 & 8.051538 & 10.862557 & 13.597358 & 15.095361 & 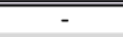 \\
\hline Weight Derivative (ft/lb.) & $1.393 \mathrm{E}-05$ & 2.184E-05 & $3.141 \mathrm{E}-05$ & $4.052 \mathrm{E}-05$ & 5.229E-05 & $5.052 \mathrm{E}-05$ & $2.444 \mathrm{E}-05$ & - \\
\hline Speed Derivative (ft/knot) & -0.0055422 & -0.0169685 & -0.0270396 & -0.0909965 & -0.1140256 & -0.0471237 & - & - \\
\hline Wingspan Derivative (ft/ft) & -0.070925 & -0.1035204 & -0.136915 & -0.1601964 & -0.1963593 & -0.192577 & -0.1192846 & 181.14005 \\
\hline Wind Derivative (ft/knot) & -0.1035092 & -0.1567788 & -0.2122156 & -0.2583406 & -0.3324366 & -0.3472182 & -0.2359104 & 202.84278 \\
\hline EDR Derivative $\left(\mathrm{ft} /\left(\mathrm{m}^{\wedge} 2 / \mathrm{s}^{\wedge} 2\right)\right)$ & -5.939899 & -9.6405051 & -18.742525 & -32.421818 & -91.657071 & - & - & - \\
\hline
\end{tabular}

Table 56. Wake altitude change approximate derivatives, OGE.

\begin{tabular}{|c|c|c|c|c|c|c|c|c|}
\hline Distance (ft) & 500 & 700 & 900 & 1100 & 1500 & 2000 & 2500 & 3000 \\
\hline Nominal Wake Delta Altitude (ft) & -80.71339 & -113.46127 & -144.3163 & -173.56637 & -227.70126 & -287.48979 & -339.2277 & -384.19807 \\
\hline Weight Derivative (ft/lb.) & -0.0006523 & -0.0009047 & -0.0011355 & -0.0013476 & -0.0017214 & -0.0021025 & -0.0024008 & -0.0026317 \\
\hline Speed Derivative (ft/knot) & 0.6556552 & 0.9079668 & 1.1386049 & 1.3504964 & 1.7238269 & 2.1042389 & 2.4018263 & 2.6320094 \\
\hline Wingspan Derivative (ft/ft) & 1.3440714 & 1.8226289 & 2.2215418 & 2.6111789 & 3.3037361 & 3.9408495 & 4.3962518 & 4.7047555 \\
\hline Wind Derivative (ft/knot) & 3.8616546 & 5.3263932 & 6.610587 & 7.8039136 & 9.7849418 & 11.6654 & 12.977689 & 13.77377 \\
\hline EDR Derivative $\left(\mathrm{ft} /\left(\mathrm{m}^{\wedge} 2 / \mathrm{s}^{\wedge} 2\right)\right)$ & 634.05596 & 1248.4321 & 2014.6192 & 2907.3198 & 4982.8686 & 7909.4899 & 10979.845 & 14060.926 \\
\hline
\end{tabular}


Table 57. Wake age approximate derivatives, IGE.

\begin{tabular}{|c|c|c|c|c|c|c|c|c|}
\hline Distance (ft) & 500 & 700 & 900 & 1100 & 1500 & 2000 & 2500 & 3000 \\
\hline Nominal Wake Age (s) & 9.95 & 15.4 & 21.2 & 27.3 & 40.3 & 57.9 & - & - \\
\hline Weight Derivative (s/lb.) & -0.0000175 & -0.000025 & $-3 E-05$ & $-3 E-05$ & $-3.25 \mathrm{E}-05$ & -0.000025 & - & - \\
\hline Speed Derivative (s/knot) & 0.035 & 0.045 & 0.055 & 0.055 & 0.06 & 0.05 & - & - \\
\hline Wingspan Derivative (s/ft) & 0 & -0.0080645 & -0.0241935 & -0.0322581 & -0.0806452 & -0.1532258 & 173.25 & - \\
\hline Wind Derivative (s/knot) & -0.4 & -0.64 & -0.91 & -1.19 & -1.72 & -2.76 & 211.35 & 214.21 \\
\hline EDR Derivative $\left(\mathrm{s} /\left(\mathrm{m}^{\wedge} \mathbf{2} / \mathrm{s}^{\wedge} \mathbf{2}\right)\right)$ & 5.0505051 & 10.10101 & 15.151515 & 30.30303 & 70.707071 & - & - & - \\
\hline
\end{tabular}

Table 58. Wake age approximate derivatives, OGE.

\begin{tabular}{|c|c|c|c|c|c|c|c|c|}
\hline Distance (ft) & 500 & 700 & 900 & 1100 & 1500 & 2000 & 2500 & 3000 \\
\hline Nominal Wake Age (s) & 17.4 & 25.35 & 33.1 & 41 & 57 & 76.8 & 96.35 & 116.1 \\
\hline Weight Derivative (s/lb.) & 0 & 0 & 0 & 0 & 0 & 0 & 0 & 0 \\
\hline Speed Derivative (s/knot) & 0.01 & 0.01 & -0.005 & -0.005 & 0.01 & 0.015 & -0.005 & -0.005 \\
\hline Wingspan Derivative (s/ft) & -0.016129 & -0.016129 & -0.016129 & -0.016129 & -0.016129 & -0.016129 & -0.016129 & -0.016129 \\
\hline Wind Derivative (s/knot) & -0.91 & -1.31 & -1.67 & -2.07 & -2.9 & -3.89 & -4.84 & -5.82 \\
\hline EDR Derivative $\left(\mathrm{s} /\left(\mathrm{m}^{\wedge} 2 / \mathrm{s}^{\wedge} 2\right)\right)$ & 0 & 0 & 0 & 0 & 0 & 0 & 0 & 0 \\
\hline
\end{tabular}

Table 59. Circulation strength approximate derivatives, IGE.

\begin{tabular}{|c|c|c|c|c|c|c|c|c|}
\hline Distance $(\mathrm{ft})$ & 500 & 700 & 900 & 1100 & 1500 & 2000 & 2500 & 3000 \\
\hline Nominal Wake Circulation (m^2/s) & 270.63754 & 240.36587 & 215.88632 & 193.07122 & 144.49863 & 78.738894 & 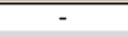 & 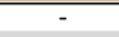 \\
\hline Weight Derivative $\left(\left(\mathrm{m}^{\wedge} 2 / \mathrm{s}\right) / \mathrm{lb}\right)$ & 0.0011714 & 0.0009781 & 0.000799 & 0.0005476 & $2.081 \mathrm{E}-05$ & -0.0007421 & - & - \\
\hline Speed Derivative $\left(\left(\mathrm{m}^{\wedge} 2 / \mathrm{s}\right) / \mathrm{knot}\right)$ & -2.0086337 & -1.6566507 & -1.3601647 & -0.9379886 & -0.0554827 & 1.2136393 & - & - \\
\hline Wingspan Derivative $\left(\left(\mathrm{m}^{\wedge} 2 / \mathrm{s}\right) / \mathrm{ft}\right)$ & -0.6006318 & -0.1755839 & 0.1977953 & 0.7544945 & 2.2845403 & 4.3777461 & 169.17217 & - \\
\hline Wind Derivative $\left(\left(\mathrm{m}^{\wedge} 2 / \mathrm{s}\right) / \mathrm{knot}\right)$ & 4.3643134 & 4.5753402 & 4.8081042 & 5.3479064 & 6.3605452 & 10.048034 & 214.69612 & 203.27739 \\
\hline EDR Derivative $\left(\left(\mathrm{m}^{\wedge} 2 / \mathrm{s}\right) /\left(\mathrm{m}^{\wedge} 2 / \mathrm{s}^{\wedge} 2\right)\right)$ & -644.86293 & -708.36293 & -1312.4081 & -2294.9435 & -4436.1472 & - & - & - \\
\hline
\end{tabular}

Table 60. Circulation strength approximate derivatives, OGE.

\begin{tabular}{|c|c|c|c|c|c|c|c|c|}
\hline Distance (ft) & 500 & 700 & 900 & 1100 & 1500 & 2000 & 2500 & 3000 \\
\hline Nominal Wake Circulation ( $\left.\mathrm{m}^{\wedge} 2 / \mathrm{s}\right)$ & 295.34257 & 279.65859 & 265.04164 & 250.86811 & 224.186 & 194.5251 & 168.52639 & 145.24328 \\
\hline Weight Derivative $\left(\left(\mathrm{m}^{\wedge} 2 / \mathrm{s}\right) / \mathrm{lb}\right)$ & 0.0014483 & 0.0013263 & 0.0012151 & 0.0011094 & 0.0009167 & 0.0007134 & 0.0005457 & 0.0004033 \\
\hline Speed Derivative $\left(\left(\mathrm{m}^{\wedge} 2 / \mathrm{s}\right) /\right.$ knot $)$ & -2.1880734 & -2.0061115 & -1.8131925 & -1.6564811 & -1.394323 & -1.0976279 & -0.8190859 & -0.6088645 \\
\hline Wingspan Derivative $\left(\left(\mathrm{m}^{\wedge} 2 / \mathrm{s}\right) / \mathrm{ft}\right)$ & -1.783365 & -1.4981868 & -1.2416892 & -1.0007226 & -0.5710531 & -0.1348306 & 0.2071398 & 0.4776542 \\
\hline Wind Derivative $\left(\left(\mathrm{m}^{\wedge} 2 / \mathrm{s}\right) / \mathrm{knot}\right)$ & 1.8432684 & 2.5656888 & 3.1476956 & 3.7422816 & 4.8139954 & 5.8163904 & 6.5255254 & 7.0645446 \\
\hline EDR Derivative $\left(\left(\mathrm{m}^{\wedge} 2 / \mathrm{s}\right) /\left(\mathrm{m}^{\wedge} 2 / \mathrm{s}^{\wedge} 2\right)\right)$ & -4300.0874 & -5733.8707 & -6885.2698 & -7841.0023 & -9213.2977 & -10099.953 & -10349.878 & -10178.115 \\
\hline
\end{tabular}

Table 61. Wake altitude change approximate derivatives, IGE.

\begin{tabular}{|c|c|c|c|c|c|c|c|c|}
\hline Distance (ft) & 500 & 700 & 900 & 1100 & 1500 & 2000 & 2500 & 3000 \\
\hline Nominal Wake Delta Altitude (ft) & 4.451785 & 6.819591 & 9.112008 & 11.287311 & 15.134865 & 18.613956 & - & - \\
\hline Weight Derivative (ft/lb.) & 1.273E-05 & $1.93 \mathrm{E}-05$ & $2.667 \mathrm{E}-05$ & $3.443 E-05$ & $4.118 \mathrm{E}-05$ & 3.037E-05 & - & - \\
\hline Speed Derivative (ft/knot) & -0.0214972 & -0.031003 & -0.0428967 & -0.0544615 & -0.0642531 & -0.0496845 & - & - \\
\hline Wingspan Derivative $(\mathrm{ft} / \mathrm{ft}$ ) & -0.0915516 & -0.1339906 & -0.1756089 & -0.2098005 & -0.250295 & -0.2209085 & 164.27454 & - \\
\hline Wind Derivative (ft/knot) & -0.2000496 & -0.2816774 & -0.3588416 & -0.427571 & -0.443182 & -0.5149514 & 203.49244 & 203.72118 \\
\hline EDR Derivative $\left(\mathrm{ft} /\left(\mathrm{m}^{\wedge} 2 / \mathrm{s}^{\wedge} \mathrm{2}\right)\right)$ & -7.270404 & -10.64404 & -18.429798 & -33.253636 & -101.00384 & - & - & - \\
\hline
\end{tabular}

Table 62. Wake altitude change approximate derivatives, OGE.

\begin{tabular}{|c|c|c|c|c|c|c|c|c|}
\hline Distance (ft) & 500 & 700 & 900 & 1100 & 1500 & 2000 & 2500 & 3000 \\
\hline Nominal Wake Delta Altitude (ft) & -98.042336 & -137.98166 & -174.86815 & -210.47884 & -276.85175 & -349.19652 & -411.10851 & -465.18384 \\
\hline Weight Derivative (ft/lb.) & -0.0004988 & -0.0006915 & -0.0008634 & -0.0010238 & -0.0013066 & -0.0015876 & -0.0018017 & -0.0019649 \\
\hline Speed Derivative (ft/knot) & 0.6899133 & 0.9811738 & 1.3158287 & 1.5552423 & 1.9137262 & 2.3240743 & 2.7193161 & 2.9646402 \\
\hline Wingspan Derivative (ft/ft) & 1.4694308 & 1.9912382 & 2.448981 & 2.8684995 & 3.5832095 & 4.2490256 & 4.7072502 & 5.0055213 \\
\hline Wind Derivative (ft/knot) & 4.7778714 & 6.5573238 & 7.9738632 & 9.4215594 & 11.976503 & 14.207982 & 15.611434 & 16.526851 \\
\hline EDR Derivative $\left(\mathrm{ft} /\left(\mathrm{m}^{\wedge} 2 / \mathrm{s}^{\wedge} 2\right)\right)$ & 716.64606 & 1416.8156 & 2273.5683 & 3292.4734 & 5693.5614 & 9057.2917 & 12564.115 & 16117.144 \\
\hline
\end{tabular}


Table 63. Wake age approximate derivatives, IGE.

\begin{tabular}{|c|c|c|c|c|c|c|c|c|}
\hline Distance (ft) & 500 & 700 & 900 & 1100 & 1500 & 2000 & 2500 & 3000 \\
\hline Nominal Wake Age (s) & 10.05 & 15.45 & 21.1 & 27.05 & 39.45 & 55.95 & 73.25 & 91.4 \\
\hline Weight Derivative (s/lb.) & $-1.391 \mathrm{E}-05$ & $-1.826 \mathrm{E}-05$ & $-2.174 \mathrm{E}-05$ & $-2.522 \mathrm{E}-05$ & $-2.87 E-05$ & $-3.043 E-05$ & $-2.696 \mathrm{E}-05$ & $-1.826 \mathrm{E}-05$ \\
\hline Speed Derivative (s/knot) & 0.04 & 0.055 & 0.07 & 0.08 & 0.095 & 0.105 & 0.1 & 0.09 \\
\hline Wingspan Derivative (s/ft) & 0.0064103 & 0 & -0.0064103 & -0.0128205 & -0.0320513 & -0.0641026 & -0.1089744 & -0.1666667 \\
\hline Wind Derivative (s/knot) & -0.4 & -0.63 & -0.88 & -1.16 & -1.73 & -2.55 & -3.42 & -4.38 \\
\hline EDR Derivative $\left(\mathrm{s} /\left(\mathrm{m}^{\wedge} 2 / \mathrm{s}^{\wedge} 2\right)\right)$ & 10.10101 & 20.20202 & 30.30303 & 35.353535 & 80.808081 & 171.71717 & - & - \\
\hline
\end{tabular}

Table 64. Wake age approximate derivatives, OGE.

\begin{tabular}{|c|c|c|c|c|c|c|c|c|}
\hline Distance (ft) & 500 & 700 & 900 & 1100 & 1500 & 2000 & 2500 & 3000 \\
\hline Nominal Wake Age (s) & 16.85 & 24.75 & 32.7 & 40.6 & 56.4 & 76.2 & 95.95 & 115.7 \\
\hline Weight Derivative (s/lb.) & 0 & 0 & 0 & 0 & 0 & 0 & 0 & 0 \\
\hline Speed Derivative (s/knot) & 0 & 0 & 0 & 0 & 0 & 0 & 0 & 0 \\
\hline Wingspan Derivative (s/ft) & -0.0192308 & -0.0128205 & -0.0128205 & -0.0192308 & -0.0128205 & -0.0128205 & -0.0192308 & -0.0192308 \\
\hline Wind Derivative (s/knot) & -0.87 & -1.26 & -1.66 & -2.06 & -2.84 & -3.83 & -4.83 & -5.81 \\
\hline EDR Derivative $\left(s /\left(m^{\wedge} 2 / s^{\wedge} 2\right)\right)$ & 0 & 0 & 0 & 0 & 0 & 0 & 0 & 0 \\
\hline
\end{tabular}

Table 65. Circulation strength approximate derivatives, IGE.

\begin{tabular}{|c|c|c|c|c|c|c|c|c|}
\hline Distance $(\mathrm{ft})$ & 500 & 700 & 900 & 1100 & 1500 & 2000 & 2500 & 3000 \\
\hline Nominal Wake Circulation (m^2/s) & 297.7145 & 270.57554 & 249.44644 & 231.32677 & 200.73654 & 161.92875 & 121.23939 & 78.550844 \\
\hline Weight Derivative $\left(\left(\mathrm{m}^{\wedge} 2 / \mathrm{s}\right) / \mathrm{lb}\right)$ & 0.0010318 & 0.0008924 & 0.0007752 & 0.0006752 & 0.0004404 & 8.864E-05 & -0.0002992 & -0.0007244 \\
\hline Speed Derivative $\left(\left(\mathrm{m}^{\wedge} 2 / \mathrm{s}\right) / \mathrm{knot}\right)$ & -2.5694244 & -2.2499835 & -1.979867 & -1.7314572 & -1.2107886 & -0.4053921 & 0.4833001 & 1.4292456 \\
\hline Wingspan Derivative $\left(\left(\mathrm{m}^{\wedge} 2 / \mathrm{s}\right) / \mathrm{ft}\right)$ & -0.7099867 & -0.4838476 & -0.2515577 & -0.0459846 & 0.3898913 & 1.3325797 & 2.3437806 & 3.4252023 \\
\hline Wind Derivative $\left(\left(\mathrm{m}^{\wedge} 2 / \mathrm{s}\right) / \mathrm{knot}\right)$ & 4.2607122 & 4.206293 & 4.3403396 & 4.5321162 & 4.910839 & 6.428977 & 8.0757836 & 9.9219204 \\
\hline EDR Derivative $\left(\left(\mathrm{m}^{\wedge} 2 / \mathrm{s}\right) /\left(\mathrm{m}^{\wedge} 2 / \mathrm{s}^{\wedge} 2\right)\right)$ & -1360.6161 & -1385.9549 & -1706.5383 & -2437.4334 & -4832.6797 & -8340.0787 & - & - \\
\hline
\end{tabular}

Table 66. Circulation strength approximate derivatives, OGE.

\begin{tabular}{|c|c|c|c|c|c|c|c|c|}
\hline Distance (ft) & 500 & 700 & 900 & 1100 & 1500 & 2000 & 2500 & 3000 \\
\hline Nominal Wake Circulation ( $\left.\mathrm{m}^{\wedge} 2 / \mathrm{s}\right)$ & 304.10603 & 291.6667 & 279.58946 & 268.01271 & 246.07071 & 220.71285 & 197.60352 & 176.49329 \\
\hline Weight Derivative $\left(\left(\mathrm{m}^{\wedge} 2 / \mathrm{s}\right) / \mathrm{lb}\right)$ & 0.0011965 & 0.0011222 & 0.0010512 & 0.0009842 & 0.0008602 & 0.0007219 & 0.0006011 & 0.0004954 \\
\hline Speed Derivative $\left(\left(\mathrm{m}^{\wedge} 2 / \mathrm{s}\right) / \mathrm{knot}\right)$ & -2.2456392 & -2.1128109 & -1.9855292 & -1.8651214 & -1.6414331 & -1.3907895 & -1.1703363 & -0.9762177 \\
\hline Wingspan Derivative $\left(\left(\mathrm{m}^{\wedge} 2 / \mathrm{s}\right) / \mathrm{ft}\right)$ & -1.6065873 & -1.4511722 & -1.2949945 & -1.1404792 & -0.8816442 & -0.5902491 & -0.3358197 & -0.1263867 \\
\hline Wind Derivative $\left(\left(\mathrm{m}^{\wedge} 2 / \mathrm{s}\right) / \mathrm{knot}\right)$ & 1.392999 & 1.9773966 & 2.5243184 & 3.0358388 & 3.929859 & 4.8979488 & 5.7099266 & 6.3468096 \\
\hline EDR Derivative $\left(\left(\mathrm{m}^{\wedge} 2 / \mathrm{s}\right) /\left(\mathrm{m}^{\wedge} 2 / \mathrm{s}^{\wedge} 2\right)\right)$ & -3796.2328 & -5182.4706 & -6381.6428 & -7398.4357 & -8979.6258 & -10264.802 & -10954.881 & -11208.341 \\
\hline
\end{tabular}

Table 67. Wake altitude change approximate derivatives, IGE.

\begin{tabular}{|c|c|c|c|c|c|c|c|c|}
\hline Distance (ft) & 500 & 700 & 900 & 1100 & 1500 & 2000 & 2500 & 3000 \\
\hline Nominal Wake Delta Altitude (ft) & 3.537998 & 5.491754 & 7.392554 & 9.286421 & 12.817212 & 16.834293 & 20.14274 & 22.589497 \\
\hline Weight Derivative (ft/lb.) & 7.575E-06 & 1.277E-05 & $1.812 \mathrm{E}-05$ & $2.242 \mathrm{E}-05$ & 3.123E-05 & 3.623E-05 & $3.497 \mathrm{E}-05$ & 2.337E-05 \\
\hline Speed Derivative (ft/knot) & -0.0054432 & -0.0130996 & -0.0200948 & -0.0271178 & -0.0465923 & -0.0546785 & -0.0491488 & -0.0255048 \\
\hline Wingspan Derivative (ft/ft) & -0.0562978 & -0.0862459 & -0.1163422 & -0.1428291 & -0.191025 & -0.2291329 & -0.2424377 & -0.216285 \\
\hline Wind Derivative (ft/knot) & -0.1844056 & -0.251123 & -0.3134172 & -0.3900528 & -0.5017798 & -0.6237024 & -0.682133 & -0.6578312 \\
\hline EDR Derivative $\left(\mathrm{ft} /\left(\mathrm{m}^{\wedge} 2 / \mathrm{s}^{\wedge} 2\right)\right)$ & -8.6078788 & -13.789394 & -21.177475 & -36.184444 & -87.202323 & -220.08808 & - & - \\
\hline
\end{tabular}

Table 68. Wake altitude change approximate derivatives, OGE.

\begin{tabular}{|c|c|c|c|c|c|c|c|c|}
\hline Distance (ft) & 500 & 700 & 900 & 1100 & 1500 & 2000 & 2500 & 3000 \\
\hline Nominal Wake Delta Altitude (ft) & -76.981623 & -109.86027 & -141.5857 & -171.80619 & -228.52627 & -293.04693 & -350.72167 & -402.2967 \\
\hline Weight Derivative (ft/lb.) & -0.0003104 & -0.0004384 & -0.0005591 & -0.0006714 & -0.0008747 & -0.0010932 & -0.0012754 & -0.0014264 \\
\hline Speed Derivative (ft/knot) & 0.58616 & 0.8266517 & 1.0542311 & 1.2667032 & 1.6533713 & 2.0721084 & 2.4248804 & 2.7204943 \\
\hline Wingspan Derivative (ft/ft) & 0.965959 & 1.3027756 & 1.641521 & 1.9763765 & 2.5132088 & 3.0997656 & 3.5901541 & 3.9647318 \\
\hline Wind Derivative (ft/knot) & 3.735371 & 5.217615 & 6.6264134 & 7.92702 & 10.146133 & 12.453061 & 14.277707 & 15.58351 \\
\hline EDR Derivative $\left(\mathrm{ft} /\left(\mathrm{m}^{\wedge} 2 / \mathrm{s}^{\wedge} 2\right)\right)$ & 483.40343 & 980.90485 & 1624.9373 & 2387.0383 & 4205.257 & 6883.1236 & 9822.7663 & 12889.465 \\
\hline
\end{tabular}


Table 69. Wake age approximate derivatives, IGE.

\begin{tabular}{|c|c|c|c|c|c|c|c|c|}
\hline Distance (ft) & 500 & 700 & 900 & 1100 & 1500 & 2000 & 2500 & 3000 \\
\hline Nominal Wake Age (s) & 9.3 & 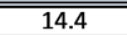 & 19.75 & 25.35 & 37.1 & 52.6 & 68.85 & 85.75 \\
\hline Weight Derivative (s/lb.) & $-6.579 E-06$ & $-8.882 E-06$ & $-1.118 \mathrm{E}-05$ & $-1.316 \mathrm{E}-05$ & $-1.645 \mathrm{E}-05$ & $-1.908 \mathrm{E}-05$ & $-1.974 \mathrm{E}-05$ & $-1.908 \mathrm{E}-05$ \\
\hline Speed Derivative (s/knot) & 0.02 & 0.025 & 0.03 & 0.035 & 0.045 & 0.055 & 0.055 & 0.05 \\
\hline Wingspan Derivative (s/ft) & 0.0043103 & 0.0043103 & 0.0043103 & 0 & -0.0086207 & -0.0258621 & -0.0517241 & -0.0775862 \\
\hline Wind Derivative (s/knot) & -0.32 & -0.52 & -0.73 & -0.97 & -1.48 & -2.18 & -2.96 & -3.79 \\
\hline EDR Derivative $\left(\mathrm{s} /\left(\mathrm{m}^{\wedge} \mathbf{2} / \mathrm{s}^{\wedge} \mathbf{2}\right)\right)$ & 10.10101 & 20.20202 & 30.30303 & 40.40404 & 70.707071 & 141.41414 & 262.62626 & 444.44444 \\
\hline
\end{tabular}

Table 70. Wake age approximate derivatives, OGE.

\begin{tabular}{|c|c|c|c|c|c|c|c|c|}
\hline Distance (ft) & 500 & 700 & 900 & 1100 & 1500 & 2000 & 2500 & 3000 \\
\hline Nominal Wake Age (s) & 15.95 & 23.9 & 31.8 & 39.7 & 55.55 & 75.35 & 95.05 & 114.8 \\
\hline Weight Derivative (s/lb.) & 0 & 0 & 0 & 0 & 0 & 0 & 0 & 0 \\
\hline Speed Derivative (s/knot) & 0 & 0 & 0 & 0 & 0.005 & 0.005 & 0 & 0 \\
\hline Wingspan Derivative (s/ft) & -0.0172414 & -0.0172414 & -0.012931 & -0.012931 & -0.0172414 & -0.0172414 & -0.0172414 & -0.0172414 \\
\hline Wind Derivative (s/knot) & -0.82 & -1.22 & -1.61 & -2.01 & -2.81 & -3.8 & -4.78 & -5.76 \\
\hline EDR Derivative $\left(s /\left(m^{\wedge} 2 / s^{\wedge} 2\right)\right)$ & 0 & 0 & 0 & 0 & 0 & 0 & 0 & 0 \\
\hline
\end{tabular}

Table 71. Circulation strength approximate derivatives, IGE.

\begin{tabular}{|c|c|c|c|c|c|c|c|c|}
\hline Distance (ft) & 500 & 700 & 900 & 1100 & 1500 & 2000 & 2500 & 3000 \\
\hline Nominal Wake Circulation ( $\left.\mathrm{m}^{\wedge} 2 / \mathrm{s}\right)$ & 4441.56377 & 400.21442 & 373.21838 & 350.83594 & 313.86436 & 276.07147 & 238.60161 & 199.63294 \\
\hline Weight Derivative $\left(\left(\mathrm{m}^{\wedge} 2 / \mathrm{s}\right) / \mathrm{lb}\right)$ & 0.0007336 & 0.0006734 & 0.0006081 & 0.0005491 & 0.0004489 & 0.0003076 & 0.0001375 & $-4.468 \mathrm{E}-05$ \\
\hline Speed Derivative $\left(\left(\mathrm{m}^{\wedge} 2 / \mathrm{s}\right) / \mathrm{knot}^{\prime}\right)$ & -2.0560563 & -1.9674267 & -1.7590619 & -1.5719035 & -1.2628387 & -0.8743581 & -0.3678456 & 0.1719968 \\
\hline Wingspan Derivative $\left(\left(\mathrm{m}^{\wedge} 2 / \mathrm{s}\right) / \mathrm{ft}\right)$ & -0.9232088 & -0.7592787 & -0.6224472 & -0.4490259 & -0.1447271 & 0.2165433 & 0.8729339 & 1.563239 \\
\hline Wind Derivative $\left(\left(\mathrm{m}^{\wedge} 2 / \mathrm{s}\right) / \mathrm{knot}\right)$ & 2.323667 & 2.8662686 & 3.0169214 & 3.3693784 & 4.0173826 & 4.8128562 & 6.5744258 & 8.5787908 \\
\hline EDR Derivative $\left(\left(m^{\wedge} 2 / s\right) /\left(m^{\wedge} 2 / s^{\wedge} 2\right)\right)$ & -2391.0095 & -2374.0282 & -2417.5147 & -2848.8593 & -4805.7337 & -8639.7448 & -13096.782 & -17992.817 \\
\hline
\end{tabular}

Table 72. Circulation strength approximate derivatives, OGE.

\begin{tabular}{|c|c|c|c|c|c|c|c|c|}
\hline Distance (ft) & 500 & 700 & 900 & 1100 & 1500 & 2000 & 2500 & 3000 \\
\hline Nominal Wake Circulation ( $\left.\mathrm{m}^{\wedge} 2 / \mathrm{s}\right)$ & 418.02215 & 403.87334 & 390.13623 & 376.79008 & 351.15156 & 321.15145 & 293.39643 & 267.52641 \\
\hline Weight Derivative $\left(\left(\mathrm{m}^{\wedge} 2 / \mathrm{s}\right) / \mathrm{lb}\right)$ & 0.0008106 & 0.0007705 & 0.0007327 & 0.0006965 & 0.000628 & 0.0005499 & 0.0004797 & 0.0004162 \\
\hline Speed Derivative $\left(\left(\mathrm{m}^{\wedge} 2 / \mathrm{s}\right) / \mathrm{knot}\right)$ & -2.7735621 & -2.6456079 & -2.5247287 & -2.408354 & -2.1962375 & -1.9425644 & -1.7058091 & -1.4974087 \\
\hline Wingspan Derivative $\left(\left(\mathrm{m}^{\wedge} 2 / \mathrm{s}\right) / \mathrm{ft}\right)$ & -1.6992684 & -1.5774996 & -1.4619368 & -1.3449178 & -1.1274648 & -0.8957477 & -0.6911858 & -0.5098011 \\
\hline Wind Derivative $\left(\left(\mathrm{m}^{\wedge} 2 / \mathrm{s}\right) / \mathrm{knot}\right)$ & 1.468551 & 2.1649322 & 2.8008178 & 3.4096924 & 4.5307532 & 5.7494462 & 6.7877832 & 7.6743256 \\
\hline EDR Derivative $\left(\left(\mathrm{m}^{\wedge} 2 / \mathrm{s}\right) /\left(\mathrm{m}^{\wedge} 2 / \mathrm{s}^{\wedge} 2\right)\right)$ & -4197.676 & -5910.0644 & -7409.8498 & -8732.548 & -10911.781 & -12878.625 & -14169.733 & -14933.108 \\
\hline
\end{tabular}

Table 73. Wake altitude change approximate derivatives, IGE.

\begin{tabular}{|c|c|c|c|c|c|c|c|c|}
\hline Distance (ft) & 500 & 700 & 900 & 1100 & 1500 & 2000 & 2500 & 3000 \\
\hline Nominal Wake Delta Altitude (ft) & 3.071881 & 4.984805 & 6.941888 & 8.791306 & 12.552003 & 16.903474 & 21.000132 & 24.588565 \\
\hline Weight Derivative (ft/lb.) & 3.305E-06 & $5.77 \mathrm{E}-06$ & 7.833E-06 & 1.035E-05 & $1.444 \mathrm{E}-05$ & 1.979E-05 & 2.297E-05 & $2.426 \mathrm{E}-05$ \\
\hline Speed Derivative (ft/knot) & -0.0122764 & -0.0245898 & -0.0310579 & -0.04216 & -0.0490407 & -0.0717054 & -0.0816758 & -0.0873841 \\
\hline Wingspan Derivative (ft/ft) & -0.0393713 & -0.0581036 & -0.0829296 & -0.1005303 & -0.1432352 & -0.1851846 & -0.2224281 & -0.2385566 \\
\hline Wind Derivative (ft/knot) & -0.121325 & -0.1875406 & -0.2610336 & -0.3178766 & -0.466669 & -0.5968406 & -0.7361918 & -0.8043522 \\
\hline EDR Derivative $\left(\mathrm{ft} /\left(\mathrm{m}^{\wedge} 2 / \mathrm{s}^{\wedge} \mathrm{2}\right)\right)$ & -9.0588889 & -11.417879 & -22.370404 & -30.487374 & -67.533939 & -154.30899 & -309.46828 & -550.18343 \\
\hline
\end{tabular}

Table 74. Wake altitude change approximate derivatives, OGE.

\begin{tabular}{|c|c|c|c|c|c|c|c|c|}
\hline Distance (ft) & 500 & 700 & 900 & 1100 & 1500 & 2000 & 2500 & 3000 \\
\hline Nominal Wake Delta Altitude (ft) & -72.836985 & -106.29015 & -138.40453 & -169.42366 & -228.48002 & -296.60198 & -358.55823 & -415.24894 \\
\hline Weight Derivative (ft/lb.) & -0.0001435 & -0.0002078 & -0.0002686 & -0.0003264 & -0.0004338 & -0.0005531 & -0.0006568 & -0.0007473 \\
\hline Speed Derivative (ft/knot) & 0.4896857 & 0.7103019 & 0.9194059 & 1.1189188 & 1.4725838 & 1.8917971 & 2.2760623 & 2.5996416 \\
\hline Wingspan Derivative (ft/ft) & 0.6875587 & 0.9629597 & 1.2065903 & 1.4523146 & 1.9196575 & 2.4170046 & 2.8443839 & 3.2116034 \\
\hline Wind Derivative (ft/knot) & 3.5524064 & 5.1243176 & 6.5581828 & 7.940987 & 10.438705 & 13.060896 & 15.190961 & 16.902222 \\
\hline EDR Derivative $\left(\mathrm{ft} /\left(\mathrm{m}^{\wedge} 2 / \mathrm{s}^{\wedge} 2\right)\right)$ & 367.35838 & 780.23657 & 1320.3227 & 1974.4507 & 3576.7694 & 6001.4351 & 8739.4991 & 11690.499 \\
\hline
\end{tabular}


Table 75. Wake age approximate derivatives, IGE.

\begin{tabular}{|c|c|c|c|c|c|c|c|c|}
\hline Distance (ft) & 500 & 700 & 900 & 1100 & 1500 & 2000 & 2500 & 3000 \\
\hline Nominal Wake Age (s) & 7.55 & 11.9 & 16.5 & 21.4 & 31.75 & 45.6 & 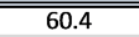 & $\overline{76}$ \\
\hline Weight Derivative (s/lb.) & $-4.444 \mathrm{E}-06$ & $-6.667 E-06$ & $-7.778 \mathrm{E}-06$ & $-1 \mathrm{E}-05$ & $-1.222 \mathrm{E}-05$ & $-1.333 \mathrm{E}-05$ & $-1.556 \mathrm{E}-05$ & $-1.667 \mathrm{E}-05$ \\
\hline Speed Derivative (s/knot) & 0.045 & 0.065 & 0.08 & 0.1 & 0.06 & 0.155 & 0.075 & 0.08 \\
\hline Wingspan Derivative (s/ft) & 0.0038226 & 0.0038226 & 0.0038226 & 0 & -0.0076453 & -0.0191131 & -0.0382263 & -0.0649847 \\
\hline Wind Derivative (s/knot) & -0.23 & -0.38 & -0.54 & -0.73 & -1.15 & -1.73 & -2.4 & -3.14 \\
\hline EDR Derivative $\left(\mathrm{s} /\left(\mathrm{m}^{\wedge} 2 / \mathrm{s}^{\wedge} 2\right)\right)$ & 5.0505051 & 15.151515 & 25.252525 & 35.353535 & 55.555556 & 106.06061 & 196.9697 & 333.33333 \\
\hline
\end{tabular}

Table 76. Wake age approximate derivatives, OGE.

\begin{tabular}{|c|c|c|c|c|c|c|c|c|}
\hline Distance (ft) & 500 & 700 & 900 & 1100 & 1500 & 2000 & 2500 & 3000 \\
\hline Nominal Wake Age (s) & 15.2 & 23.15 & 31.05 & 38.95 & "54.8 & 74.6 & 94.3 & 114.05 \\
\hline Weight Derivative (s/lb.) & 0 & 0 & 0 & 0 & 0 & 0 & 0 & 0 \\
\hline Speed Derivative (s/knot) & 0 & 0 & 0 & 0 & 0 & 0 & 0 & 0 \\
\hline Wingspan Derivative (s/ft) & -0.0152905 & -0.0191131 & -0.0152905 & -0.0152905 & -0.0152905 & -0.0152905 & -0.0152905 & -0.0152905 \\
\hline Wind Derivative (s/knot) & -0.79 & -1.19 & -1.58 & -1.97 & -2.77 & -3.76 & -4.74 & -5.72 \\
\hline EDR Derivative $\left(s /\left(\mathrm{m}^{\wedge} 2 / \mathrm{s}^{\wedge} 2\right)\right)$ & 0 & 0 & 0 & 0 & 0 & 0 & 0 & 0 \\
\hline
\end{tabular}

Table 77. Circulation strength approximate derivatives, IGE.

\begin{tabular}{|c|c|c|c|c|c|c|c|c|}
\hline Distance (ft) & 500 & 700 & 900 & 1100 & 1500 & 2000 & 2500 & 3000 \\
\hline Nominal Wake Circulation ( $\left.\mathrm{m}^{\wedge} 2 / \mathrm{s}\right)$ & 682.21338 & 621.91928 & 580.62869 & 547.16766 & 4992.5794 & 437.32393 & 386.85668 & 333.76346 \\
\hline Weight Derivative $\left(\left(\mathrm{m}^{\wedge} 2 / \mathrm{s}\right) / \mathrm{lb}\right)$ & 0.0007368 & 0.0006149 & 0.0005562 & 0.0005107 & 0.000422 & 0.000327 & 0.0002121 & $8.408 \mathrm{E}-05$ \\
\hline Speed Derivative $\left(\left(\mathrm{m}^{\wedge} 2 / \mathrm{s}\right) / \mathrm{knot}\right)$ & -7.3071324 & -6.2871292 & -5.7411102 & -5.3039911 & -2.8864866 & -3.6320178 & -1.5668919 & -0.758446 \\
\hline Wingspan Derivative $\left(\left(\mathrm{m}^{\wedge} 2 / \mathrm{s}\right) / \mathrm{ft}\right)$ & -2.2247885 & -0.8469081 & -0.7997877 & -0.6082226 & -0.2450807 & 0.1343589 & 0.727231 & 1.5217096 \\
\hline Wind Derivative $\left(\left(\mathrm{m}^{\wedge} 2 / \mathrm{s}\right) / \mathrm{knot}\right)$ & 0.2245258 & 4.5254378 & 4.1708202 & 4.5504194 & 5.430523 & 6.3679552 & 8.0324174 & 10.618874 \\
\hline EDR Derivative $\left(\left(\mathrm{m}^{\wedge} 2 / \mathrm{s}\right) /\left(\mathrm{m}^{\wedge} 2 / \mathrm{s}^{\wedge} 2\right)\right)$ & -2389.5827 & -3069.0203 & -3101.5726 & -3136.4425 & -4324.7735 & -7859.7939 & -12736.121 & -18141.333 \\
\hline
\end{tabular}

Table 78. Circulation strength approximate derivatives, OGE.

\begin{tabular}{|c|c|c|c|c|c|c|c|c|}
\hline Distance (ft) & 500 & 700 & 900 & 1100 & 1500 & 2000 & 2500 & 3000 \\
\hline Nominal Wake Circulation ( $\left.\mathrm{m}^{\wedge} 2 / \mathrm{s}\right)$ & 625.08224 & 605.05821 & 585.68953 & 566.83964 & 530.32531 & 487.40509 & 447.52502 & 410.19067 \\
\hline Weight Derivative $\left(\left(\mathrm{m}^{\wedge} 2 / \mathrm{s}\right) / \mathrm{lb}\right)$ & 0.0007411 & 0.0007092 & 0.0006776 & 0.0006452 & 0.0005882 & 0.0005231 & 0.0004639 & 0.0004098 \\
\hline Speed Derivative $\left(\left(\mathrm{m}^{\wedge} 2 / \mathrm{s}\right) /\right.$ knot $)$ & -4.6274664 & -4.4267138 & -4.2279462 & -4.0292562 & -3.6721539 & -3.2635465 & -2.8922398 & -2.5524259 \\
\hline Wingspan Derivative $\left(\left(\mathrm{m}^{\wedge} 2 / \mathrm{s}\right) / \mathrm{ft}\right)$ & -2.0877262 & -1.9361967 & -1.8087996 & -1.678547 & -1.4180177 & -1.1211615 & -0.8638959 & -0.6442757 \\
\hline Wind Derivative $\left(\left(\mathrm{m}^{\wedge} 2 / \mathrm{s}\right) / \mathrm{knot}\right)$ & 1.9838818 & 2.9883486 & 3.8747168 & 4.7173706 & 6.3640106 & 8.1370526 & 9.663793 & 10.983307 \\
\hline EDR Derivative $\left(\left(\mathrm{m}^{\wedge} 2 / \mathrm{s}\right) /\left(\mathrm{m}^{\wedge} 2 / \mathrm{s}^{\wedge} 2\right)\right)$ & -5321.04 & -7647.8052 & -9720.9381 & -11572.434 & -14665.744 & -17558.817 & -19557.501 & -20848.875 \\
\hline
\end{tabular}

Table 79. Wake altitude change approximate derivatives, IGE.

\begin{tabular}{|c|c|c|c|c|c|c|c|c|}
\hline Distance (ft) & 500 & 700 & 900 & 1100 & 1500 & 2000 & 2500 & 3000 \\
\hline Nominal Wake Delta Altitude (ft) & 2.623052 & 4.427858 & 6.272777 & 8.117116 & 11.788349 & 16.176789 & 20.446009 & 24.342274 \\
\hline Weight Derivative (ft/lb.) & $1.41 \mathrm{E}-06$ & 2.477E-06 & $3.742 \mathrm{E}-06$ & 4.576E-06 & 7.234E-06 & $1.029 \mathrm{E}-05$ & $1.225 \mathrm{E}-05$ & $1.447 \mathrm{E}-05$ \\
\hline Speed Derivative (ft/knot) & 0.0098175 & -0.0019363 & -0.013356 & -0.0211931 & -0.0709369 & -0.0701445 & -0.1211376 & -0.1421503 \\
\hline Wingspan Derivative (ft/ft) & -0.0301375 & -0.0420139 & -0.0602386 & -0.0765361 & -0.110507 & -0.1434917 & -0.1828075 & -0.2037385 \\
\hline Wind Derivative (ft/knot) & -0.105186 & -0.1524198 & -0.2153058 & -0.2694422 & -0.3968884 & -0.5303628 & -0.6731972 & -0.7776538 \\
\hline EDR Derivative $\left(\mathrm{ft} /\left(\mathrm{m}^{\wedge} \mathbf{2} / \mathrm{s}^{\wedge} 2\right)\right)$ & -4.0912121 & -5.1980808 & -16.003434 & -17.698586 & -39.122121 & -81.333535 & -173.43949 & -317.73657 \\
\hline
\end{tabular}

Table 80. Wake altitude change approximate derivatives, OGE.

\begin{tabular}{|c|c|c|c|c|c|c|c|c|}
\hline Distance (ft) & 500 & 700 & 900 & 1100 & 1500 & 2000 & 2500 & 3000 \\
\hline Nominal Wake Delta Altitude (ft) & -84.310899 & -125.07184 & -164.27976 & -202.22852 & -274.69228 & -358.64496 & -435.37855 & -505.95371 \\
\hline Weight Derivative (ft/lb.) & -0.0001011 & -0.0001491 & -0.0001948 & -0.0002384 & -0.0003198 & -0.0004114 & -0.0004924 & -0.0005642 \\
\hline Speed Derivative (ft/knot) & 0.6350591 & 0.9350507 & 1.2201192 & 1.4919741 & 2.0003518 & 2.5722565 & 3.0772799 & 3.525078 \\
\hline Wingspan Derivative (ft/ft) & 0.661867 & 0.9551491 & 1.1980388 & 1.4455503 & 1.9039683 & 2.4086456 & 2.8424144 & 3.2173264 \\
\hline Wind Derivative (ft/knot) & 4.143325 & 6.070018 & 7.8352574 & 9.4953478 & 12.603978 & 15.901644 & 18.618703 & 20.840829 \\
\hline EDR Derivative $\left(\mathrm{ft} /\left(\mathrm{m}^{\wedge} 2 / \mathrm{s}^{\wedge} 2\right)\right)$ & 360.30071 & 791.34586 & 1364.4324 & 2066.7563 & 3808.7434 & 6481.7652 & 9540.2579 & 12875.303 \\
\hline
\end{tabular}

\section{Acknowledgments}

This simulation study was conducted for the Aeronautics Systems Analysis Branch at NASA Langley Research Center, under the Airspace Systems Program. Jeremy Smith was the technical monitor for this work. The contents of this paper reflect the views of the authors and have not been endorsed in any way by the Federal Aviation Administration.

The authors wish to thank Neil O'Connor and Fred Proctor of NASA Langley for sharing their wealth of knowledge in wake modeling and their invaluable comments. In addition, the authors thank Ed Johnson of the FAA for providing helpful comments on an early draft of the manuscript. 


\section{References}

${ }^{1}$ Viken, J., et. al., "NAS Demand Predictions, Transportation Systems Analysis Model (TSAM) Compared with Other Forecasts," $6^{\text {th }}$ AIAA Aviation Technology, Integration, and Operations Conference, AIAA-2006-7761, Wichita, Kansas, 25-27 September, 2006.

${ }^{2}$ Miller, M.E., Trott, G.A., "Effects of Future Traffic on the National Airspace System," AIAA Modeling and Simulation Technologies Conference and Exhibit, AIAA-2004-5438, Providence, Rhode Island, 16-19 August, 2004.

${ }^{3}$ USDOT/FAA, Order 7110.65U, Air Traffic Control, Section 5 - Radar Separation, 9 February 2012.

${ }^{4}$ Joint Planning and Development Office (JPDO), Integrated Work Plan (IWP FY14 R1), http://jpe.jpdo.gov/ee/request/home, accessed 31 July 2012.

${ }^{5}$ USDOT/FAA, Order 7210.3X, Facility Operation and Administration, Paragraph 10-4-8 - Precision Runway MonitorSimultaneous Offset Instrument Approaches, 9 February 2012.

${ }^{6}$ Closely Spaced Parallel Operation Working Group, November 2-4, 2008, meeting minutes, www.faa.gov, accessed February 09, 2010.

${ }^{7}$ Closely Spaced Parallel Operations, focus area descriptions, accessed July 17, 2012, http://www.faa.gov/about/office_org/headquarters_offices/avs/offices/afs/afs400/afs450/cspo/focus_areas/index.cfm?print=go.

${ }^{8}$ Bone, R.S., Olmos, B.O., Mundra, A., "Paired Approach: A Closely Spaced Parallel Runway Approach Concept," MITRE paper, The MITRE Corporation's Center for Advanced Aviation System Development, February 2001.

${ }^{9}$ Stone, R., "Paired Approach Concept," Proceedings of the NASA Workshop on Flight Deck Centered Parallel Runway Approaches in IMC, NASA Langley Research Center, Hampton, VA, October 29,1996.

${ }^{10}$ Hammer, J., "Case Study of Paired Approach, Procedure to Closely Spaced Parallel Runway," Air Traffic Control Quarterly, Volume 8, Number 3, pp. 223 - 252, Air Traffic Control Association Institute, Arlington, VA, 2000.

${ }^{11}$ Al-Bulushi, A., Chau, N., Eftekari, R., Graziano, R., Tarakemeh, A. "Closely Spaced Parallel Approaches in Terminal Airspace," 2006 IEEE Systems and Information Engineering Design Symposium, Charlottesville, VA, April 28, 2006.

${ }^{12}$ Arkind, K., "Maximum Capacity Terminal Area Operation in 2022," 3rd Annual ATIO Conference, AIAA-2003-6791, 1719 November 2003.

${ }^{13}$ The USDOT/FAA and NASA LaRC, Technical Direction 2, Interagency Agreement IA1-973, signed August 12, 2009.

${ }^{14}$ Guerreiro, N.M., Neitzke, K.W., Johnson, S.C., Stough, H.P., McKissick, B.T., Syed, H.I., "Characterizing a Wake-free Safe Zone for the Simplified Aircraft-based Paired Approach Concept," Abstract submitted to the 2010 AIAA Atmospheric \& Space Environments Conference, Invited Paper, Toronto, Ontario, Canada, August 2-5, 2010.

${ }^{15}$ Robins, R.R., Delisi, D.P., "NWRA AVOSS Wake Vortex Prediction Algorithm Version 3.1.1," NASA/CR-2002-211746, June 2002.

${ }^{16}$ Pruis, M.J., Delisi, D.P., “Assessment of Fast-Time Wake Vortex Prediction Models using Pulsed and Continuous Wave Lidar Observations at Several Different Airports," $3^{\text {rd }}$ AIAA Atmospheric Space Environments Conference, Honolulu, Hawaii, June 27-30, 2011.

${ }^{17}$ www.atsi.aero

${ }^{18}$ The International Civil Aviation Organization, Wake Vortex Aspects of A380 aircraft, reference document TEC/OPS/SEP (T11/72) - 06-0320.SLG, October 9, 2006. 